CENTRO UNIVERSITÁRIO FEI

ANA PAULA DE QUEIROZ

AVALIAÇÃO DO DESEMPENHO DE DIFERENTES ALCANOLAMINAS NA REMOÇÃO DE GASES ÁCIDOS DO BIOGÁS POR ABSORÇÃO QUíMICA

São Bernardo do Campo 
ANA PAULA DE QUEIROZ

\title{
AVALIAÇÃO DO DESEMPENHO DE DIFERENTES ALCANOLAMINAS NA REMOÇÃO DE GASES ÁCIDOS DO BIOGÁS POR ABSORÇÃO QUÍMICA
}

\begin{abstract}
Dissertação apresentada ao Centro Universitário FEI, como parte dos requisitos necessários para obtenção do título de Mestre em Engenharia Química. Orientada pela Prof. ${ }^{a}$ Dra. Maristhela Passoni de Araújo Marin e coorientada pelo Prof. Dr. Newton Libanio Ferreira.
\end{abstract}

São Bernardo do Campo 
Queiroz, Ana Paula de.

Avaliação do desempenho de diferentes alcanolaminas na remoção de gases ácidos do biogás por absorção química / Ana Paula de Queiroz. São Bernardo do Campo, 2016.

$111 \mathrm{f}$ : : il.

Dissertação - Centro Universitário FEI.

Orientadora: Prof. ${ }^{a}$ Dra. Maristhela Passoni de Araújo Marin.

Coorientador: Prof. Dr. Newton Libanio Ferreira.

1. Biogás . 2. Absorção química. 3. Alcanolaminas. 4. Recheios estruturados. 5. Abordagem de não-equilíbrio. I. Passoni de Araújo Marin, Maristhela, orient. II. Título.

Elaborada pelo sistema de geração automática de ficha catalográfica da FEI com os dados fornecidos pelo(a) autor(a). 
Aluno: Ana Paula de Queiroz

Título do Trabalho: Avaliação do desempenho de diferentes alcanolaminas na remoção de gases ácidos do biogás por absorção química.

Área de Concentração: Engenharia Química

Orientador: Prof. a Dr.a Maristhela Passoni de Araújo Marin

Data da realização da defesa: 23/09/2016

Avaliação da Banca Examinadora:

São Bernardo do Campo, 23 / 09 / 2016.

\section{MEMBROS DA BANCA EXAMINADORA}

Prof. ${ }^{a}$ Dr.a Maristhela Passoni de Araújo Marin

Prof. Dr. Luis Fernando Novazzi

Prof. Dr. Roberto Nasser Júnior
Ass. :

Ass. :

Ass. :

\footnotetext{
A Banca Julgadora acima-assinada atribuiu ao aluno o seguinte resultado:

APROVADO $\bigotimes$

REPROVADO
}

\section{VERSÃO FINAL DA DISSERTAC̄ÃO}

APROVO A VERSÃO FINAL DA DISSERTAÇÃO EM QUE FORAM INCLUÍDAS AS RECOMENDAÇÕES DA BANCA EXAMINADORA
Aprovação do Coordenador do Programa de Pós-graduação

Prof. Dr. Ricardo Belchior Torres 
A quem queira utilizar. 


\section{AGRADECIMENTOS}

A Deus, pela agradável impressão de sentido.

À minha família, pelo apoio em diversos momentos.

À Professora Maristhela e ao Professor Newton, pela orientação, discussões proveitosas e estímulo.

Aos Professores do Centro Universitário FEI, pelas discussões proveitosas e estímulo.

Aos demais funcionários do Centro Universitário FEI, pela solicitude.

Aos Amigos, pelo afeto, apoio, auxílio, alegria e ânimo atemporais! 
"Food for thought!"

Sherlock Holmes (2009) 


\section{RESUMO}

O biogás é uma mistura gasosa composta majoritariamente por metano e dióxido de carbono e se destaca entre os biocombustíveis por apresentar contribuições não apenas em relação à redução da emissão de gases do efeito estufa, mas também em termos de gerenciamento de resíduos orgânicos, uma vez que pode ser produzido tanto a partir de recursos renováveis como dos resíduos mencionados. A aplicação que confere a este biocombustível maior versatilidade em termos de utilização é a produção do biometano, que é realizada por meio da remoção dos gases ácidos, dióxido de carbono $\left(\mathrm{CO}_{2}\right)$ e sulfeto de hidrogênio $\left(\mathrm{H}_{2} \mathrm{~S}\right)$, e de outros componentes indesejados presentes no biogás. Neste trabalho foi estudado e proposto um processo para a remoção destes gases ácidos empregando a técnica de absorção química com soluções aquosas de alcanolaminas dentre as quais foram selecionadas a monoetanolamina (MEA), a dietanolamina (DEA) e a metildietanolamina (MDEA). Para tanto, foram configuradas colunas de absorção e de dessorção aplicando a abordagem de não-equilíbrio, que considera as cinéticas das reações e as não idealidades destes sistemas eletrolíticos, disponível no software Aspen Plus ${ }^{\circledR}$. No processo proposto o $\mathrm{H}_{2} \mathrm{~S}$ foi removido preferencialmente com a solução de MDEA enquanto o $\mathrm{CO}_{2}$ era absorvido com soluções de MEA ou de DEA. Nestes estudos as concentrações de $\mathrm{CO}_{2}$ e de $\mathrm{H}_{2} \mathrm{~S}$ no biometano foram limitadas de acordo com as especificações da Resolução ${ }^{0}$ 8/2015 da ANP. As colunas configuradas para o sistema com MEA apresentaram as menores alturas de recheio, uma vez que esta alcanolamina absorve os gases ácidos mais rápido do que as demais. Os resultados obtidos para a demanda energética percentual relacionada à energia disponível no biogás foi de 12,9\% para a remoção do $\mathrm{H}_{2} \mathrm{~S}$ com MDEA e de 20,6\% e 15,3\% para a remoção do $\mathrm{CO}_{2}$ para os casos com MEA e DEA, respectivamente.

Palavras-chave: Biogás. Absorção química. Alcanolaminas. Recheios estruturados. Abordagem de não-equilíbrio. 


\begin{abstract}
Biogas is a gas mixture composed mainly of methane and carbon dioxide and stands out among biofuels because of its contributions not only related to reducing the emission of greenhouse gases, but also in terms of management of organic waste, since it can be produced both from renewable resources and the waste mentioned. The application that confers this biofuel greater versatility in terms of usability is the production of biomethane, which is accomplished by removing the acid gases: carbon dioxide $\left(\mathrm{CO}_{2}\right)$ and hydrogen sulfide $\left(\mathrm{H}_{2} \mathrm{~S}\right)$, as well as other undesirable components present in biogas. In this work it was studied and proposed a process for the removal of such acid gases by employing the technique of chemical absorption with aqueous solutions of alkanolamines, among which were selected monoethanolamine (MEA), diethanolamine (DEA), and methyldiethanolamine (MDEA). Therefore, absorption and desorption columns were modelled applying the non-equilibrium approach available in Aspen Plus ${ }^{\circledR}$ software, which considers kinetic reactions and nonidealities of the electrolytic systems considered. In the proposed process $\mathrm{H}_{2} \mathrm{~S}$ was removed preferably by MDEA solution while $\mathrm{CO}_{2}$ was absorbed by MEA or DEA solutions. In these studies the concentrations of $\mathrm{CO}_{2}$ and $\mathrm{H}_{2} \mathrm{~S}$ present in biomethane were limited according to the specifications set by ANP Resolution $n^{\circ}$ 8/2015. The columns designed for MEA system had the lowest structured packing heights, since this alkanolamine absorbs acid gases faster than the other considered. The results obtained for the percentage energy demand related to the energy available in biogas were $12.9 \%$ for the removal of $\mathrm{H}_{2} \mathrm{~S}$ with MDEA and $20.6 \%$ and $15.3 \%$ for the removal of $\mathrm{CO}_{2}$ for the cases with MEA and DEA, respectively.
\end{abstract}

Keywords: Biogas. Chemical absorption. Alkanolamines. Structured packings. Nonequilibrium approach. 


\section{LISTA DE ILUSTRAÇÕES}

Figura 1 - Esquema da decomposição anaeróbia.............................................................. 21

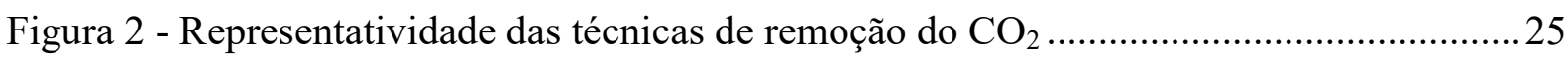

Figura 3 - Possibilidades de aplicações energéticas do biogás..............................................29

Figura 4 - Fórmulas estruturais das alcanolaminas de maior interesse comercial....................32

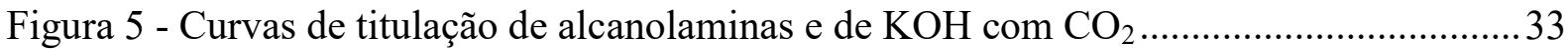

Figura 6 - Esquema simplificado do sistema de absorção/dessorção de gases ácidos ............. 35

Figura 7 - Representação geométrica da corrugação de recheios estruturados .........................37

Figura 8 - Representação da complexidade dos modelos de absorção química ........................ 39

Figura 9 - Esquema do sistema de absorção química seletiva................................................47

Figura 10 - Esquema geral dos sistemas dos Casos de estudo 1, 2 e 3 ..................................61

Figura 11 - Comparação entre os resultados experimentais e simulados dos casos E1 e E2 ...65

Figura 12 - Porcentagem de absorção de $\mathrm{CO}_{2}$ em função da altura da coluna...........................67

Figura 13 - Porcentagem de absorção de $\mathrm{H}_{2} \mathrm{~S}$ em função da altura da coluna ..........................68

Figura 14 - Relação $\mathrm{H}_{2} \mathrm{~S} / \mathrm{CH}_{4}$ em função da altura da coluna .................................................69

Figura 15 - Relação $\mathrm{H}_{2} \mathrm{~S} / \mathrm{CH}_{4}$ em função da altura da coluna para o Caso 1 ........................... 70

Figura 16 - Influência da temperatura do solvente na absorção dos gases ácidos: Caso 1 ......71

Figura 17 - Influência da composição do solvente na absorção dos gases ácidos: Caso 1 ......72

Figura 18 - Porcentagem de dessorção de $\mathrm{H}_{2} \mathrm{~S}$ em função da altura da coluna: Caso 1........... 73

Figura 19 - Porcentagem de absorção de $\mathrm{CO}_{2}$ em função da altura da coluna: Caso 2 ............ 74

Figura 20 - Influência da temperatura do solvente na absorção do $\mathrm{CO}_{2}$ : Caso 2 ..................... 75

Figura 21 - Influência da composição do solvente na absorção do $\mathrm{CO}_{2}$ : Caso 2 …................. 76

Figura 22 - Porcentagem de dessorção de $\mathrm{CO}_{2}$ em função da altura da coluna: Caso 2 .......... 76

Figura 23 - Porcentagem de absorção de $\mathrm{CO}_{2}$ em função da altura da coluna: Caso 3 ............ 78

Figura 24 - Influência da temperatura do solvente na absorção do $\mathrm{CO}_{2}$ : Caso 3 ..................... 79

Figura 25 - Influência da composição do solvente na absorção do $\mathrm{CO}_{2}$ : Caso 3 ...................... 80

Figura 26 - Porcentagem de dessorção de $\mathrm{CO}_{2}$ em função da altura da coluna: Caso 3 ...........81

Figura 1A - Estágio/seção j considerado para a modelagem de não-equilíbrio ........................97 


\section{LISTA DE TABELAS}

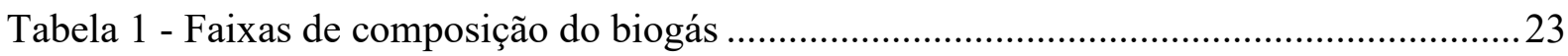

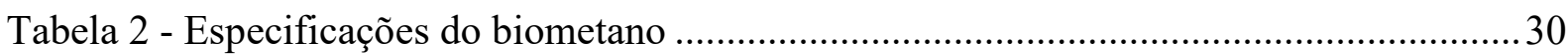

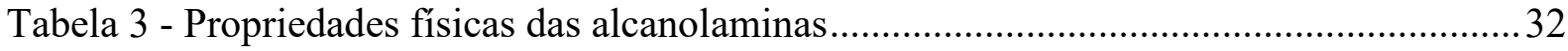

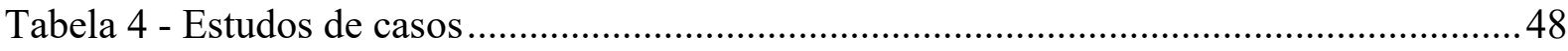

Tabela 5 - Faixas de aplicação das soluções de alcanolaminas ................................................. 50

Tabela 6 - Reações de equilíbrio empregadas nos modelos de absorção ................................ 51

Tabela 7- Reações cinéticas empregadas nos modelos de absorção .......................................52

Tabela 8 - Especificações da corrente de biogás para as simulações ......................................53

Tabela 9 - Especificações das correntes de solvente para as simulações .................................53

Tabela 10 - Pontos de discretização do filme de líquido.......................................................55

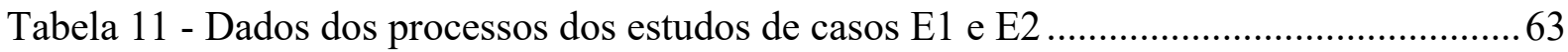

Tabela 12 - Porcentagem de absorção e energia específica dos casos E1 e E2 ........................ 64

Tabela 13 - Diâmetro da coluna e altura de seção das colunas de absorção simultânea ...........66

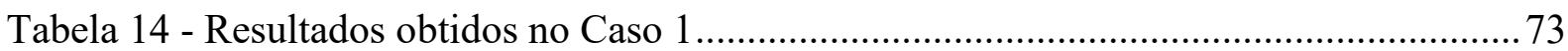

Tabela 15 - Especificações da corrente de biogás com teor reduzido de $\mathrm{H}_{2} \mathrm{~S}$......................... 74

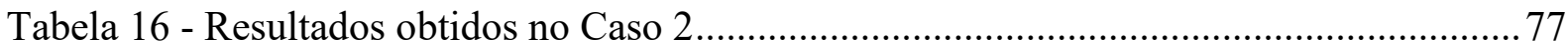

Tabela 17 - Especificações da corrente de biometano obtida no Caso 2 ................................ 78

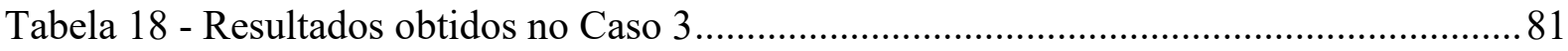

Tabela 19 - Especificações da corrente de biometano obtida no Caso 3 ................................. 82 


\section{LISTA DE SÍMBOLOS}

$\% A b s \quad$ Porcentagem de absorção (\%)

$\%$ Pes Porcentagem de dessorção (\%)

$A_{t} \quad$ Área da seção transversal da coluna $\left[\mathrm{m}^{2}\right]$

$a_{e} \quad$ Área superficial efetiva por volume da coluna $\left[\mathrm{m}^{2} \mathrm{~m}^{-3}\right]$

$a_{I} \quad$ Área interfacial para transferência de massa $\left[\mathrm{m}^{2}\right]$

$a_{p} \quad$ Área específica do recheio $\left[\mathrm{m}^{2} \cdot \mathrm{m}^{-3}\right]$

$c \quad$ Concentração molar $\left[\mathrm{kmol}^{-3}\right]$

$D \quad$ Difusividade $\left[\mathrm{m}^{2} \cdot \mathrm{s}^{-1}\right]$

$\bar{D} \quad$ Difusividade média $\left[\mathrm{m}^{2} \cdot \mathrm{s}^{-1}\right]$

$d_{h} \quad$ Diâmetro hidráulico [m]

$E \quad$ Energia de ativação $\left[\mathrm{J}^{\mathrm{kmol}}{ }^{-1}\right]$

$F \quad$ Vazão molar de alimentação $\left[\mathrm{kmol}^{-1}{ }^{-1}\right]$

$g \quad$ Constante gravitacional $\left[\mathrm{m}^{-2} \mathrm{~s}^{-2}\right]$

$g_{\text {eff }} \quad$ Gravidade efetiva $\left[\mathrm{m} \cdot \mathrm{s}^{-2}\right]$

$H \quad$ Entalpia $\left[\mathrm{J}^{\mathrm{kmol}}{ }^{-1}\right]$

$\bar{H} \quad$ Entalpia parcial $\left[\mathrm{J}^{\mathrm{kmol}}{ }^{-1}\right]$

$h \quad$ Coeficiente de transferência de calor $\left[\mathrm{J} \cdot \mathrm{m}^{-2} \cdot \mathrm{K}^{-1} \cdot \mathrm{s}^{-1}\right]$

$h_{c} \quad$ Altura total de recheio da coluna [m]

$h_{L} \quad$ Holdup volumétrico líquido $\left[\mathrm{m}^{3}\right]$

$h_{p} \quad$ Altura de uma seção de recheio [m]

$h_{t} \quad$ Holdup fracionário [-]

$k \quad$ Coeficiente de transferência de massa $\left[\mathrm{m}^{-1}{ }^{-1}\right]$

$\bar{k} \quad$ Coeficiente de transferência de massa médio $\left[\mathrm{m}^{-1}{ }^{-1}\right]$

$k_{R} \quad$ Fator pré-exponencial $\left[\mathrm{s}^{-1}\right]$ para reações de ordem $1,\left[\mathrm{~m}^{3} \cdot \mathrm{s}^{-1} \mathrm{kmol}^{-1}\right]$

$K_{e q} \quad$ Constante de equilíbrio de uma reação

$K_{i} \quad$ Constante de equilíbrio - mede a tendência de vaporização de uma substância i - [-]

$L \quad$ Vazão molar de líquido $\left[\mathrm{kmol}^{-1}{ }^{-1}\right]$

$N \quad$ Taxa de transferência de massa $\left[\mathrm{kmol}^{-1} \mathrm{~s}^{-1}\right]$

$n \quad$ Número de moles [kmol]

$m \quad$ Massa $[\mathrm{kg}]$ ou $[\mathrm{t}]$

$P \quad$ Pressão [Pa] 
$Q \quad$ Calor que entra em um estágio $\left[\mathrm{J} \cdot \mathrm{s}^{-1}\right]$

$Q_{\%} \quad$ Demanda energética percentual (\%)

$Q_{e s p, \mathrm{CO}_{2}}$ Energia específica requerida para a dessorção do $\mathrm{CO}_{2}\left[{\left.\mathrm{GJ} \cdot \mathrm{t}^{-1}\right]}^{-1}\right.$

$Q_{e s p, H_{2} S}$ Energia específica requerida para a dessorção do $\mathrm{H}_{2} \mathrm{~S}$ [ $\mathrm{GJ} \mathrm{kg}^{-1}$ ]

$q \quad$ Taxa de transferência de calor $\left[\mathrm{J} \cdot \mathrm{s}^{-1}\right]$

$\boldsymbol{R} \quad$ Matriz do inverso dos coeficientes de transferência de massa [ $\left.\mathrm{s}^{\mathrm{kmol}}{ }^{-1}\right]$

$R \quad$ Constante universal dos gases $\left[8314 \mathrm{~J}^{\mathrm{kmol}}{ }^{-1} \cdot \mathrm{K}^{-1}\right.$ ]

$r \quad$ Taxa de reação $\left[\mathrm{kmol}^{-1} \mathrm{~s}^{-1}\right]$

$r_{R} \quad$ Velocidade de reação $\left[\mathrm{kmol}^{-3} \cdot \mathrm{s}^{-1}\right]$

$S \quad$ Altura inclinada da corrugação [m]

$T \quad$ Temperatura [K]

$u_{s} \quad$ Velocidade superficial $\left[\mathrm{m}^{-1}{ }^{-1}\right]$

$V \quad$ Vazão molar de vapor $\left[\mathrm{kmol} \cdot \mathrm{s}^{-1}\right]$

$x \quad$ Fração molar no líquido [-]

$x$, $\quad$ Fração mássica no líquido [-]

X Loading [-]

$y \quad$ Fração molar no vapor [-]

$z \quad$ Número de carga elétrica [-]

Adimensionais

$\mathrm{Fr} \quad$ Número de Froude [-]

Re Número de Reynolds [-]

Sc Número de Schmidt [-]

We Numero de Weber [-]

Símbolos gregos

$\alpha \quad$ Coeficiente estequiométrico [-]

$\boldsymbol{\Gamma} \quad$ Matriz dos coeficientes termodinâmicos [-]

$\delta_{i, k} \quad$ Delta de Kronecker [-]

$\frac{\Delta P}{\Delta Z} \quad$ Perda de carga por unidade de altura de recheio $\left[\mathrm{Pa} \cdot \mathrm{m}^{-1}\right]$

$\frac{\Delta P}{\Delta Z_{f}} \quad$ Perda de carga por unidade de altura de recheio no ponto de inundação $\left[\mathrm{Pa}^{\cdot} \mathrm{m}^{-1}\right]$

$\varepsilon \quad$ Fração de vazio do recheio [-]

$\gamma \quad$ Ângulo de contato entre a superfície sólida e o filme líquido [rad]

$\mu \quad$ Viscosidade dinâmica [Pa.s] 


$\begin{array}{ll}\bar{\rho} & \text { Densidade molar }\left[\mathrm{kmol}^{-3}\right] \\ \rho & \text { Densidade mássica }\left[\mathrm{kgm}^{-3}\right] \\ \sigma & \text { Tensão superficial do líquido }\left[\mathrm{Nm}^{-1}\right] \\ \varphi & \text { Coeficiente de fugacidade [-] } \\ \psi & \text { Parâmetro médio de Chilton-Colburn [-] } \\ \theta & \text { Ângulo de inclinação da corrugação [rad] } \\ & \text { Subscritos e sobrescritos } \\ \mathrm{F} & \text { Alimentação } \\ \mathrm{f} & \text { Filme } \\ \mathrm{i} & \text { Componente } \\ \mathrm{I} & \text { Interface } \\ \mathrm{j} & \text { Estágio } \\ \mathrm{k} & \text { Componente } \\ \mathrm{L} & \text { Liquido } \\ \mathrm{m} & \text { Componente } \\ \mathrm{n} & \text { Último componente } \\ \mathrm{t} & \text { Total } \\ \mathrm{G} & \text { Gás } \\ \end{array}$




\section{SUMÁRIO}

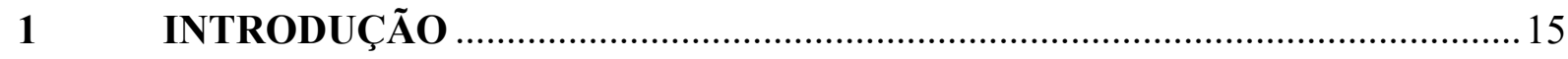

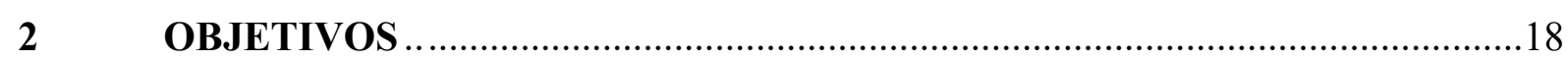

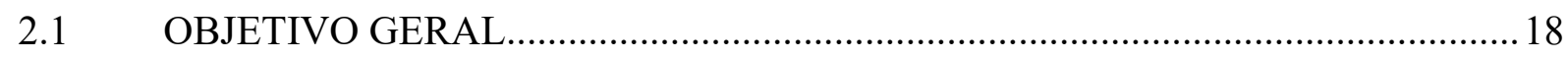

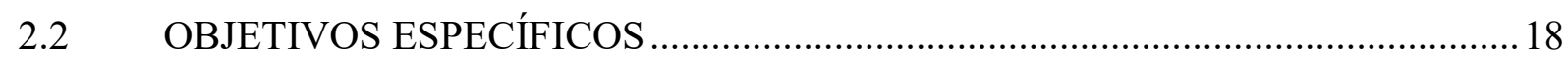

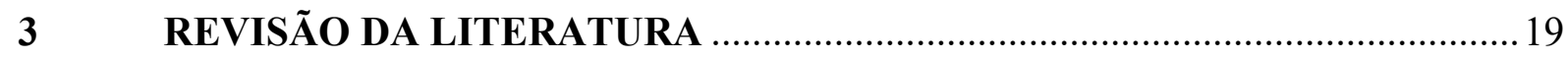

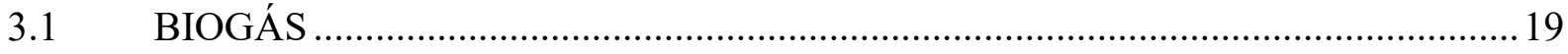

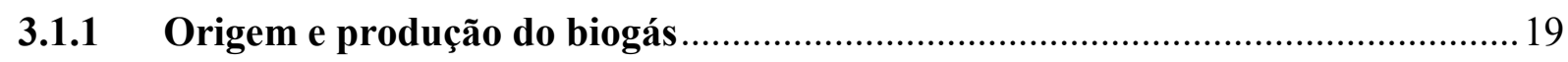

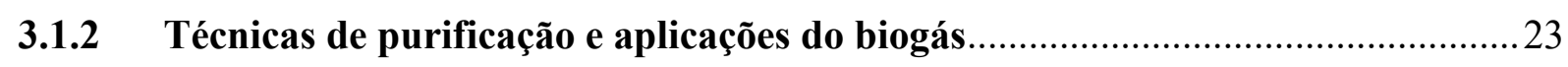

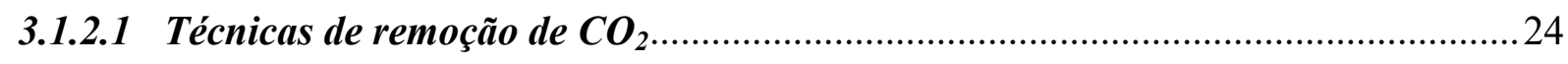

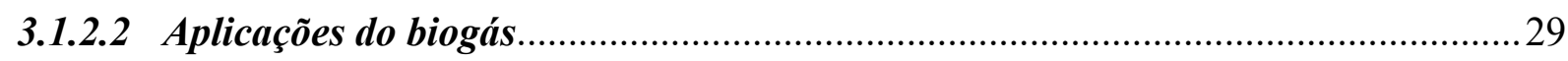

3.2 REMOÇÃO DE GASES ÁCIDOS POR ABSORÇÃO QUÍMICA COM

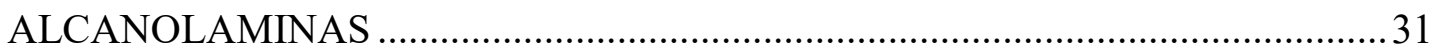

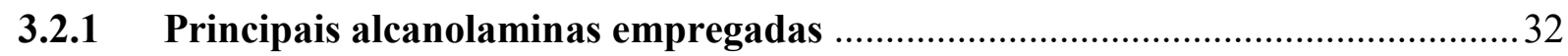

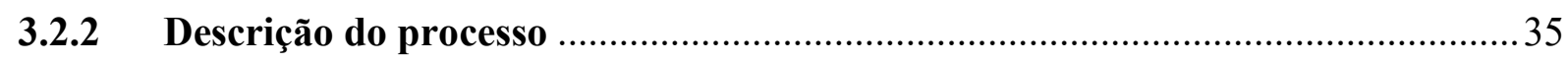

3.2.2.1 Recheios estruturados utilizados em colunas de absorção e dessorção .................. 36

3.2.3 Modelagem de sistemas de absorção química ...................................................... 38

3.3 REAÇÕES ENTRE GASES ÁCIDOS E SOLUÇÕES DE ALCANOLAMINAS ... 42

3.3.1 Reações entre $\mathrm{H}_{2} \mathrm{~S}$ e soluções aquosas de alcanolaminas .................................... 42

3.3.2 Reações entre $\mathrm{CO}_{2}$ e soluções aquosas de alcanolaminas ................................... 43

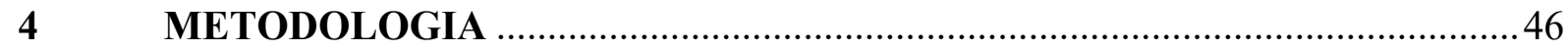

4.1 DEFINIÇÃO DO PROCESSO DE ABSORÇÃO SELETIVA ...................................46

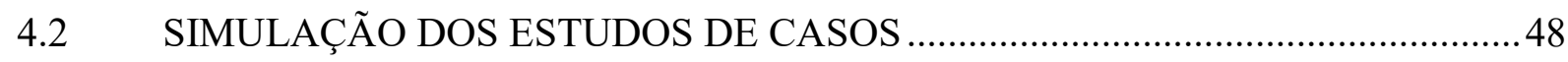

4.2.1 Modelagem de não-equilíbrio utilizada para a simulação da absorção química 48

4.2.2 Modelos de absorção de gases ácidos com alcanolaminas para simulação da

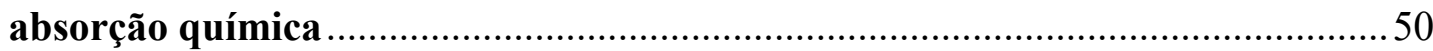

4.2.3 Procedimentos aplicados à simulação do processo de absorção química.............52

4.2.3.1 Simulação da absorção simultânea dos gases ácidos ............................................52

4.2.3.2 Simulação da absorção seletiva dos gases ácidos ................................................57

4.2.3.3 Simulação dos estudos de casos experimentais obtidos na literatura ..................... 61

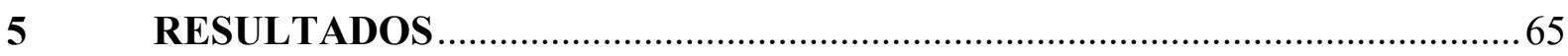

5.1 RESULTADOS DAS SIMULAÇÕES DOS ESTUDOS DE CASOS EXPERIMENTAIS 
5.2 RESULTADOS DAS SIMULAÇÕES DE ABSORÇÃO SIMULTÂNEA ..............66

5.3 RESULTADOS DA SIMULAÇÃO DE ABSORÇÃO SELETIVA .......................... 70

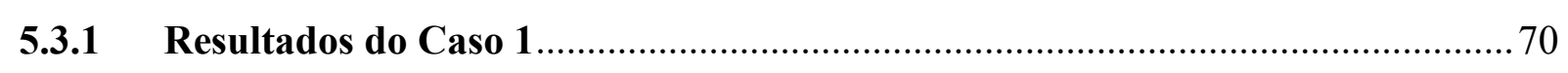

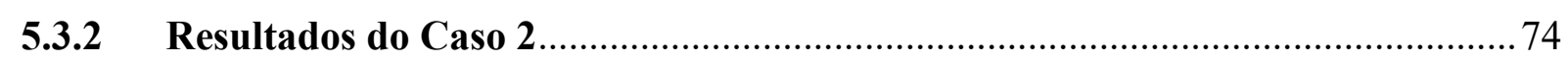

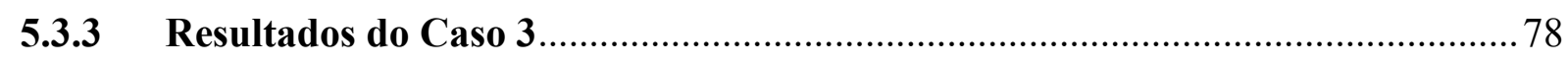

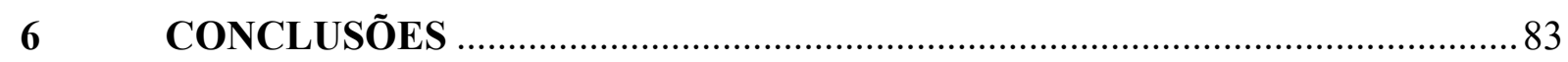

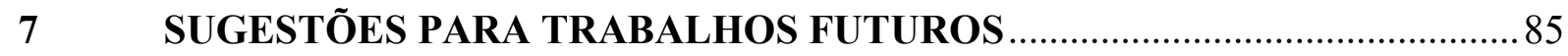

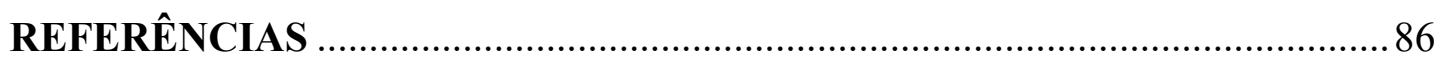

APÊNDICE A - Detalhamento do cálculo das vazões molares das soluções de

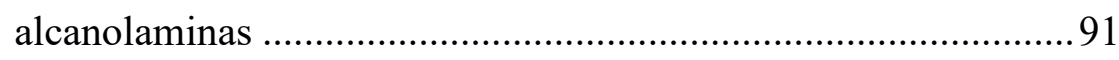

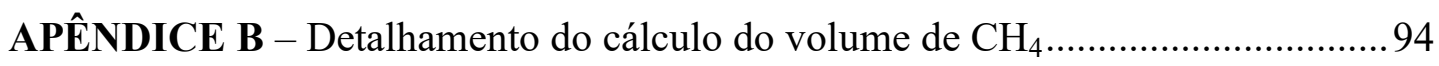

ANEXO A - Detalhamento das equações utilizadas para a modelagem da absorção

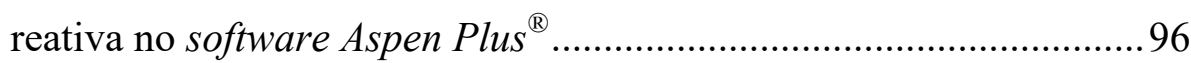

ANEXO B - Detalhamento da correlação Bravo et al. (1992)................................. 102

ANEXO C - Detalhamento das equações de taxas de massa.................................... 105

ANEXO D - Detalhamento da correlação HanleyStruc (2010) ............................... 107

ANEXO E - Detalhamento do método de Chilton e Colburn.................................. 110 


\section{INTRODUÇÃO}

Os biocombustíveis são, atualmente, importantes aliados na redução da emissão dos gases do efeito estufa - sendo os principais o dióxido de carbono $\left(\mathrm{CO}_{2}\right)$, o metano $\left(\mathrm{CH}_{4}\right)$ e o óxido nitroso $\left(\mathrm{N}_{2} \mathrm{O}\right)$-, que tem sido o principal tema de convenções ambientais e tratados, tais como a Rio-92 e o Protocolo de Quioto, os quais discutem e propõem medidas para promover uma estabilização dos níveis de concentração destes gases na atmosfera visando evitar alterações prejudiciais ao sistema climático do planeta (EPE, 2007).

A principal contribuição desses combustíveis, que geralmente provêm de matériasprimas renováveis, reside na substituição daqueles de origem fóssil (EPE, 2007). No caso do biogás, que constitui uma mistura gasosa composta majoritariamente por $\mathrm{CH}_{4}$ e $\mathrm{CO}_{2}$, esta contribuição pode se estender a uma gestão adequada de resíduos e efluentes gerados em processos produtivos. Desta forma, podem ser utilizados como matérias-primas para a produção do biogás materiais orgânicos tais como esgotos urbanos e efluentes industriais com alta carga orgânica, cuja disposição inadequada gera uma relevante fonte de contaminação do solo e corpos hídricos além de proliferação de vetores e doenças, geração de maus odores e emissão de gases do efeito estufa. No entanto, a submissão destes materiais à produção de biogás, realizada por meio da digestão anaeróbia, promove um retorno destes resíduos e efluentes à cadeia produtiva evitando os problemas mencionados (FEAM; FIEMG; GIZ, 2015).

Devido à presença majoritária de $\mathrm{CH}_{4}$, cuja fração volumétrica pode variar entre $50 \%$ e 85\% (FNR, 2010; THRÄN et al., 2014), o biogás caracteriza-se como um gás energético cuja utilização pode ser destinada à geração de energia térmica ou elétrica, ou para a produção de biometano, que constitui o biogás com teor elevado de $\mathrm{CH}_{4}$. Este gás pode ser então empregado como combustível veicular ou injetado na rede de gás natural, onde sua utilização é mais versátil, considerando-se que pode ser destinado à produção de energia térmica e elétrica em diferentes locais, além de poder ser estocado para ser utilizado quando houver picos de demanda (FEAM; FIEMG; GIZ, 2015).

Desta forma, o biogás tem sido visto como um biocombustível estratégico para o país, cujo reconhecimento estimulou a implementação de projetos como o PROBIOGÁS, que constitui um projeto de parceria entre o Governo Brasileiro e o Governo Alemão com o objetivo de contribuir para a ampliação do uso energético e eficiente do biogás (FEAM; FIEMG; GIZ, 2015), e de decretos e leis estaduais, como o Decreto $n^{\circ} 58.659$, de 4 de dezembro de 2012 que institui o Programa Paulista de Biogás (SÃO PAULO, 2012) e a Lei 
$\mathrm{n}^{\circ}$ 6361, de 18 de dezembro de 2012 que dispõe sobre a Política Estadual de Gás Natural Renovável - GNR (RIO DE JANEIRO, 2012), que também incentiva a produção de biometano, cujas especificações são regulamentadas pela Resolução da Agência Nacional do Petróleo, Gás Natural e Biocombustíveis (ANP) nº 8/2015 (BRASIL, 2015).

A produção do biometano depende da remoção de alguns componentes indesejados presentes no biogás. Entre os principais são citados o $\mathrm{CO}_{2}$ e o sulfeto de hidrogênio $\left(\mathrm{H}_{2} \mathrm{~S}\right)$, ambos gases ácidos que podem provocar corrosão e desgaste de equipamentos, além de riscos à saúde, no caso do $\mathrm{H}_{2} \mathrm{~S}$ que possui elevada toxicidade. Na literatura são descritas diversas técnicas de purificação do biogás voltadas à remoção do $\mathrm{CO}_{2}$, dentre as quais se destacam: a absorção física com água, ou lavagem com água a alta pressão; a absorção química, ou lavagem química; a adsorção com modulação de pressão, ou pressure swing adsorption (PSA); o processo de separação por membrana, a absorção física com solvente orgânico e a separação criogênica (PETERSSON; WELLINGER, 2009; FNR, 2010; THRÄN et al., 2014). Thrän et al. (2014) reportam a existência de aproximadamente 280 plantas de purificação de biogás operantes em países membros da International Energy Agency (IEA) com capacidade global de produção de cerca de $100.000 \mathrm{Nm}^{3} / \mathrm{h}$ e aponta o crescimento em número destas unidades, bem como da participação da técnica de absorção química com aminas nestes processos, desde 2009.

A técnica de absorção ou lavagem química aplicada à purificação do biogás se baseia na transferência dos componentes ácidos deste gás para o solvente básico empregado, onde são ambos quimicamente convertidos. Dentre os solventes empregados se destacam as soluções aquosas de aminas, tais como a monoetanolamina (MEA), a dietanolamina (DEA) e a metildietanolamina (MDEA). Nesta técnica tanto o $\mathrm{CO}_{2}$ como o $\mathrm{H}_{2} \mathrm{~S}$ podem ser removidos e é possível atingir um teor de $\mathrm{CH}_{4}$ no gás tratado superior a $99 \%$ com perda de menos de $0,1 \%$ deste componente no gás residual. A principal desvantagem deste processo está relacionada à regeneração do solvente, que é realizada pelo fornecimento de calor ao solvente rico em gases ácidos e demanda elevada quantidade de energia térmica (PETERSSON; WELLINGER, 2009; FNR, 2010).

A absorção química é conduzida em colunas de absorção e a regeneração do solvente em colunas de dessorção. Estas operações geralmente são realizadas em colunas recheadas, que oferecem extensas áreas superficiais para a transferência de massa (SCHLAUER; KRIEBEL, 2011), sobretudo quando empregados recheios estruturados (KOHL; NIELSEN, 1997). Para a modelagem destas operações existem diversas abordagens que podem ser empregadas, desde as mais simples, que consideram estágios e reações de equilíbrio, às mais 
sofisticadas, baseadas em taxas de transferência de massa e de calor, também referenciadas como abordagens de não-equilíbrio, que podem considerar as cinéticas das reações e as não idealidades de sistemas eletrolíticos. Naturalmente, as técnicas mais sofisticadas são preferíveis, uma vez que podem descrever tais sistemas de forma mais precisa (KENIG; SCHNEIDER; GÓRAK, 2001).

Diante desse cenário, este trabalho visa estudar e propor um processo para avaliar o desempenho de soluções aquosas de MEA, DEA e MDEA na absorção química dos gases ácidos presentes em uma corrente de biogás em relação às demandas de solvente e de energia, bem como em relação às dimensões das colunas configuradas para cada sistema. Nestes estudos as concentrações de $\mathrm{CO}_{2}$ e de $\mathrm{H}_{2} \mathrm{~S}$ no biometano são limitadas de acordo com as especificações da ANP e para a modelagem do processo é adotada a abordagem de nãoequilíbrio disponível no software Aspen Plus ${ }^{\circledR}$. 


\section{OBJETIVOS}

Nesta seção são apresentados os objetivos geral e específicos definidos para orientar este trabalho.

\subsection{OBJETIVO GERAL}

Neste projeto tem-se como objetivo geral estudar e propor um processo para avaliar o desempenho de soluções de alcanolaminas empregadas na separação dos gases ácidos, $\mathrm{CO}_{2} \mathrm{e}$ $\mathrm{H}_{2} \mathrm{~S}$, do biogás por absorção química, aplicando a abordagem de não-equilíbrio, e modelá-lo utilizando o software Aspen Plus ${ }^{\circledR}$.

\subsection{OBJETIVOS ESPECÍFICOS}

Os objetivos específicos definidos para este trabalho são:

a) selecionar soluções de alcanolaminas para simular a absorção química dos gases ácidos do biogás: $\mathrm{CO}_{2}$ e $\mathrm{H}_{2} \mathrm{~S}$, os tipos de colunas empregados nesta operação e as abordagens de reação dos sistemas estudados, a partir de informações obtidas na literatura;

b) propor um processo para a absorção química dos gases ácidos com as alcanolaminas, que se beneficie tanto das características destes solventes como dos equipamentos empregados, e simular este processo utilizando a abordagem de nãoequilíbrio para casos de estudos definidos de acordo com a solução de alcanolamina empregada;

c) avaliar e comparar os resultados obtidos nos casos de estudo em relação às demandas de solvente e de energia, bem como em relação às dimensões das colunas configuradas para cada sistema. 


\section{REVISÃO DA LITERATURA}

Nesta seção é apresentada uma revisão dos principais assuntos relacionados ao estudo proposto. Inicialmente são apresentadas revisões sobre o biogás que contemplam desde sua origem e produção, visando caracterizar este material e apresentar condições em que é produzido, às técnicas de purificação para a remoção de gases ácidos, sendo focadas neste trabalho as técnicas para remoção do $\mathrm{CO}_{2}$; como também as aplicações em que o biogás pode ser empregado. A seguir, uma revisão mais detalhada da remoção de gases ácidos com soluções alcanolaminas é apresentada, abordando algumas características das principais alcanolaminas empregadas, como também o processo convencional descrito na literatura e as abordagens utilizadas para modelar estes sistemas de absorção química. Finalmente, as principais abordagens para o estudo das reações entre os gases ácidos e as alcanolaminas são apresentadas, visando orientar a seleção da mais adequada, dentre a de equilíbrio e a cinética, para a simulação dos sistemas estudados.

\subsection{BIOGÁS}

Os assuntos abordados neste item objetivam apresentar, primeiramente, uma breve revisão sobre a origem do biogás e seu processo de formação, bem como indicar algumas das técnicas empregadas para sua produção, que já são aplicadas em usinas operantes, e faixas de composição obtidas para os componentes deste produto. A seguir pretende-se mostrar algumas técnicas utilizadas para a purificação do biogás visando a remoção de gases ácidos, mas focadas principalmente na remoção do $\mathrm{CO}_{2}$. Neste item também serão citadas aplicações do biogás em função da pureza e de algumas exigências que devem ser atendidas para cada finalidade.

\subsubsection{Origem e produção do biogás}

O biogás é uma mistura gasosa composta majoritariamente por $\mathrm{CH}_{4}$ e $\mathrm{CO}_{2}$ que tem origem no processo biológico de decomposição da matéria orgânica em meio anaeróbio, ou seja, na ausência de oxigênio. Este processo é comum na natureza podendo ocorrer em pântanos, fundos de lagos e outros meios que forneçam condições propícias, e produz, além do biogás, energia térmica e nova biomassa (FNR, 2010). 
O processo de formação do biogás ocorre em quatro estágios de degradação da matéria orgânica: a hidrólise, a acidogênese, a acetogênese e a metanogênese. Durante a hidrólise os compostos orgânicos complexos, tais como carboidratos, proteínas e lipídios, são decompostos em substâncias menos complexas como aminoácidos, açúcares e ácidos graxos. Neste processo atuam bactérias hidrolíticas que liberam enzimas para que a decomposição do material ocorra por meio de reações bioquímicas. No segundo estágio, as bactérias acidogênicas promovem a decomposição das substâncias formadas durante a hidrólise em $\mathrm{CO}_{2}$, hidrogênio e ácidos graxos de cadeia curta, tais como os ácidos: acético, propiônico e butírico, além de pequenas quantidades de ácido lático e álcoois. Segue-se então a acetogênese, em que as bactérias acetogênicas promovem a conversão de ácidos e álcoois formados na acidogênese em $\mathrm{CO}_{2}$, hidrogênio e ácido acético. A última etapa é promovida por arqueas metanogênicas que podem ser hidrogenotróficas, as quais produzem $\mathrm{CH}_{4}$ a partir do hidrogênio e do $\mathrm{CO}_{2}$, ou acetoclásticas, que produzem $\mathrm{CH}_{4}$ a partir da redução do ácido acético (FNR, 2010).

Um esquema simplificado da decomposição anaeróbia que resulta na produção de biogás é apresentado na Figura 1 (FNR, 2010). Este processo também é comumente referido na literatura como metanização ou fermentação (FNR, 2010; NYNS, 2011; FEAM; FIEMG; GIZ, 2015).

As faixas de pH ótimas são de 5,2 a 6,3 para os estágios de hidrólise e acidogênese, embora possam ocorrer em valores de $\mathrm{pH}$ ligeiramente maiores, e de 6,5 a 8 para os estágios de acetogênese e metanogênese. A maioria dos microrganismos metanogênicos apresentam picos de crescimento em temperaturas entre 37 e $42{ }^{\circ} \mathrm{C}$, dentro da faixa mesofílica de temperatura, embora algumas culturas se desenvolvam bem na faixa termofílica, entre 50 e 60 ${ }^{\circ} \mathrm{C}$ (FNR, 2010).

Segundo Nyns (2011) o processo biológico que leva à formação de biogás foi descoberto por Volta em 1776, mas foi explorado tecnologicamente mais de cem anos depois para a redução do conteúdo de matéria orgânica presente em lodo de esgoto e águas residuárias na França, Reino Unido, Estados Unidos e Alemanha.

Além da matéria orgânica citada, outros resíduos orgânicos podem ser empregados como matéria-prima para a produção de biogás, provenientes de fontes urbanas, industriais ou agrícolas. Da primeira fonte citada são exemplos, além do lodo de esgoto e águas residuárias, os resíduos sólidos orgânicos de origem doméstica. A segunda fonte inclui principalmente resíduos da indústria alimentícia provenientes de cervejarias; destilarias; processamento de frutas, vegetais e óleos; entre outros. Os resíduos agrícolas de maior interesse são os dejetos 
de animais (NYNS, 2011). Outras fontes são as culturas energéticas ou biomassas dedicadas, tais como milho, beterraba e gramíneas (FNR, 2010).

Figura 1 - Esquema da decomposição anaeróbia

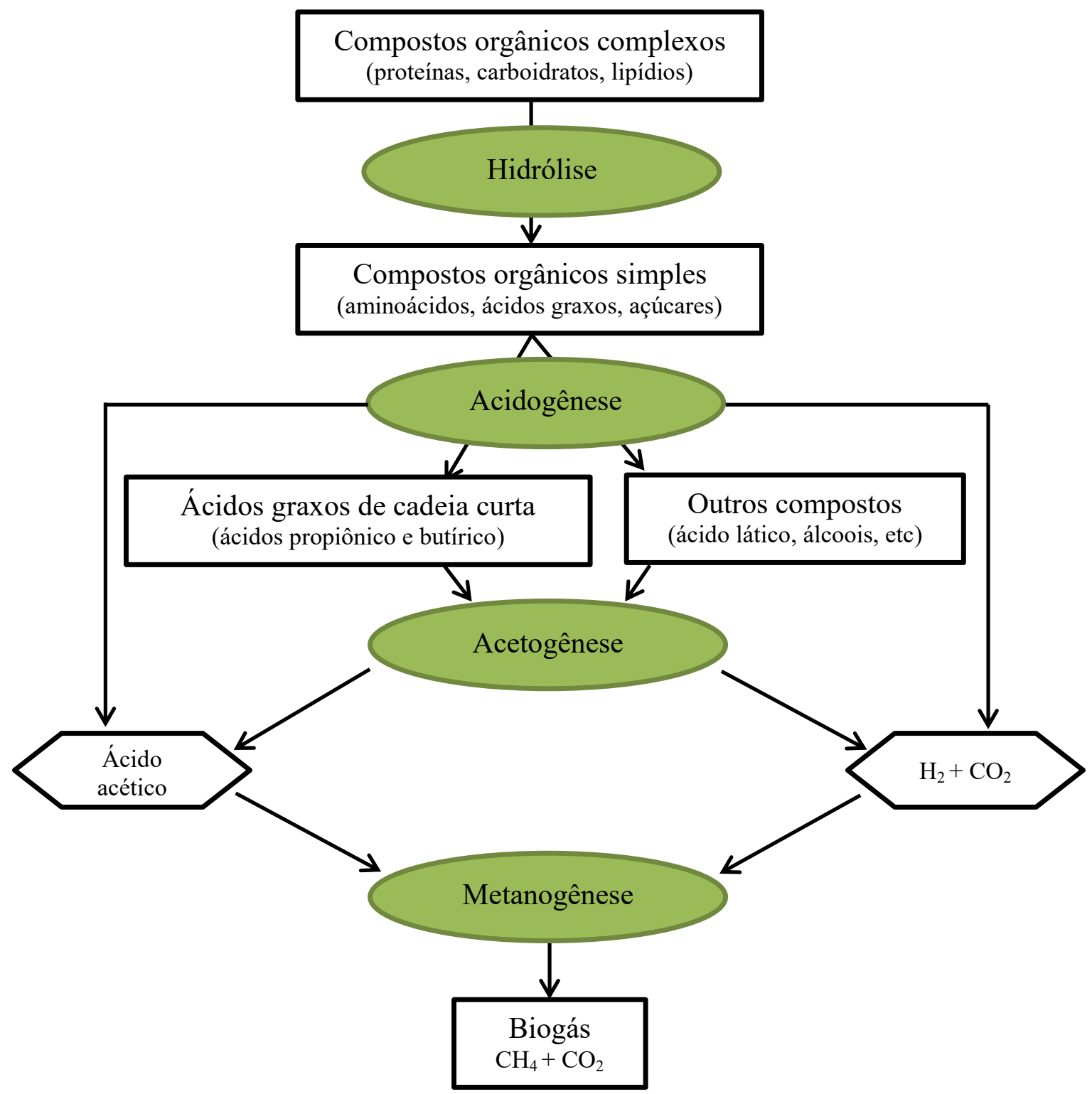

Fonte: Autor "adaptado de" FNR, 2010

Atualmente o processo de metanização conta com diversas tecnologias disponíveis para sua realização, cuja viabilidade de aplicação depende de alguns fatores tais como: composição e características físico-químicas dos substratos disponíveis, como composição, $\mathrm{pH}$, teor de sólidos totais e viscosidade; presença de substâncias inibidoras do processo de metanização, a exemplo: antibióticos, metais pesados e detergentes; e disponibilidade de substrato, que depende do volume de produção e da sazonalidade produtiva. Dentre as tecnologias usuais para a digestão de resíduos orgânicos, destacam-se os Reatores Contínuos 
de Mistura Completa CSTR (CSTR ou Continuous Stirred Tank Reactor), as lagoas otimizadas e os Reatores Anaeróbios de Manta de Lodo e Fluxo Ascendente (UASB ou Upflow Anaerobic Sludge Blanket Reactor). Estes sistemas podem ser configurados de diversas formas, conforme as condições impostas pelos fatores citados para a análise da viabilidade da técnica. Dentre eles o mais difundido é o CSTR, que já foi empregado em mais de 10.000 plantas de produção de biogás em âmbito global e possui versões avançadas que permitem a produção estável de biogás, enquanto os reatores UASB foram aplicados entre 800 e 1200 plantas e as lagoas otimizadas em menos de 100 plantas (FEAM; FIEMG; GIZ, 2015). Uma apresentação mais detalhada das configurações possíveis destes sistemas foge do escopo deste trabalho, e para a obtenção destas informações podem ser consultados os guias compilados pela FNR (2010) e pela FEAM, FIEMG e GIZ (2015) sobre a produção de biogás.

Além da aplicação dos biodigestores, Nyns (2011) aponta os aterros sanitários como um exemplo interessante de condução da degradação da matéria orgânica em batelada, onde grandes quantidades de resíduos sólidos urbanos são dispostas e o biogás é produzido pela fermentação natural destes materiais durante longos períodos de tempo. Desta forma, tanto a composição como a quantidade de biogás produzida é variável no tempo. De acordo com O'Leary e Tchobanoglous (2002), sob condições normais de operação do aterro (tais como a distribuição dos componentes orgânicos, nutrientes, umidade e grau inicial de compactação) a taxa de decomposição da mistura de resíduos orgânicos, medida pela produção de gás, atinge um pico dentro dos primeiros dois anos de operação do aterro e diminui gradualmente por períodos de até 25 anos ou mais.

A composição do biogás varia amplamente conforme as matérias-primas, condições operacionais e técnicas selecionadas para sua produção. Além dos componentes majoritários, $\mathrm{CH}_{4}$ e $\mathrm{CO}_{2}$, o biogás se apresenta saturado de vapor de água e conta com a presença de outros gases em pequenas quantidades. Na Tabela 1 é apresentada uma compilação de composições volumétricas típicas dos componentes do biogás obtido por digestão anaeróbia, indicadas em algumas das referências já citadas.

$\mathrm{O}$ componente de interesse energético do biogás é o $\mathrm{CH}_{4}$, que apresenta poder calorífico inferior (PCI) de $50 \mathrm{MJ} / \mathrm{kg}$. Uma vez que o biogás contém outros componentes que não possuem valor energético, seu poder calorífico é reduzido conforme a quantidade destes componentes aumenta; com $60 \%$ em volume de metano, o biogás apresenta um poder calorífico inferior de $30 \mathrm{MJ} / \mathrm{kg}$ (NYNS, 2011). Assim como o metano, o biogás também pode formar misturas explosivas com o ar, dentro de faixas que variam com a composição da 
mistura gasosa; para o metano, esta faixa varia de $4,4 \%$ a $16,5 \%$ em volume misturado com o ar (FNR, 2010).

Tabela 1 - Faixas de composição do biogás

\begin{tabular}{l|c|c|c|c}
\hline \multicolumn{1}{c|}{ Componente } & Unidade & FNR & SGC & Thrän et al. \\
\hline Metano $\left(\mathrm{CH}_{4}\right)$ & $\%$ vol & $50-75$ & $60-70$ & $50-85$ \\
\hline Dióxido de carbono $\left(\mathrm{CO}_{2}\right)$ & $\%$ vol & $25-45$ & $30-40$ & $15-50$ \\
\hline Água $\left(\mathrm{H}_{2} \mathrm{O}\right)$ & $\%$ vol & $2-7\left(20-40^{\circ} \mathrm{C}\right)$ & NI & NI \\
\hline Sulfeto de hidrogênio $\left(\mathrm{H}_{2} \mathrm{~S}\right)$ & $\mathrm{ppm}$ & $20-2.000$ & $0-4.000$ & $<4.000$ \\
\hline Nitrogênio $\left(\mathrm{N}_{2}\right)$ & $\% \mathrm{vol}$ & $<2$ & 0,2 & $0-1$ \\
\hline Oxigênio $\left(\mathrm{O}_{2}\right)$ & $\% \mathrm{vol}$ & $<2$ & 0 & $0,01-1$ \\
\hline Hidrogênio $\left(\mathrm{H}_{2}\right)$ & $\%$ vol & $<1$ & 0 & traços \\
\hline Argônio $(\mathrm{Ar})$ & $\%$ vol & NI & NI & 0,001 \\
\hline Amônia $\left(\mathrm{NH}_{3}\right)$ & $\mathrm{ppm}$ & NI & 100 & traços \\
\hline
\end{tabular}

Fontes: FNR, 2010; Nyns, 2011; SGC, 2012; Thrän et al., 2014

Legenda: * - composições apresentadas provavelmente em base seca, NI - não indicado

Em se tratando de segurança de processo, tanto o perigo potencial relacionado à formação de atmosferas explosivas como o relacionado à presença de gases corrosivos, como é o caso do $\mathrm{CO}_{2}$ e do $\mathrm{H}_{2} \mathrm{~S}$, e tóxicos, como o $\mathrm{H}_{2} \mathrm{~S}$, devem ser levados em conta no projeto de uma planta de produção de biogás. Recomenda-se a elaboração de uma análise preliminar de riscos, como o Estudo de Perigos e Operabilidade (HAZOP: Hazard and Operability Study), durante os estágios finais de projeto da planta, que deve levar em conta os perigos potenciais mencionados além de outros, tais como vasos pressurizados, espaços confinados, entre outros. Por meio desta análise é possível propor meios e medidas de segurança a serem implantados nas plantas, tais como: a implantação de flares para eliminar gases inflamáveis e corrosivos quando em excesso ou em situações de emergência, a identificação de zonas de atmosfera inflamável para a utilização de meios e medidas de segurança compatíveis com o perigo potencial apresentado em cada uma, a operação da planta em pressões positivas - acima da pressão atmosférica - para evitar a entrada de ar em pontos de amostragem, junções de flanges, entre outros (ADBA, 2013). Uma análise detalhada dos riscos e perigos potenciais de uma planta de biogás foge do escopo deste trabalho, mais informações podem ser obtidas nos guias compilados pela FNR (2010) e pela ADBA (2013).

\subsubsection{Técnicas de purificação e aplicações do biogás}

O emprego das diferentes técnicas de purificação disponíveis para aumentar a qualidade do biogás, ou técnicas de upgrading, depende da aplicação final que se pretende dar 
a este produto. Alguns tratamentos tornam possível a substituição do gás natural, o qual possui teor de $\mathrm{CH}_{4}$ mais elevado do que o biogás, pelo biometano, como é chamado o biogás purificado que passa a apresentar elevado teor de $\mathrm{CH}_{4}$. Entretanto, como a aplicação destas técnicas gera custos adicionais, torna-se importante contar com um processo otimizado em termos de reduzido consumo energético, alta eficiência que garanta um teor de $\mathrm{CH}_{4}$ elevado no biogás purificado e minimização da emissão de $\mathrm{CH}_{4}$ em correntes de rejeitos (PETERSSON; WELLINGER, 2009).

Os principais componentes indesejados presentes no biogás são a água $\left(\mathrm{H}_{2} \mathrm{O}\right), \mathrm{o}_{2} \mathrm{~S}$ e o $\mathrm{CO}_{2}$. A remoção destes visa evitar: a corrosão; o desgaste e os danos aos equipamentos de tratamentos posteriores ou de utilização do biogás; satisfazer padrões de segurança, no caso da remoção do $\mathrm{H}_{2} \mathrm{~S}$ que é altamente tóxico (FNR, 2010); além de aumentar a quantidade de energia disponível no gás por volume deste, no caso do $\mathrm{CO}_{2}$. Uma vez que o componente de interesse energético é o $\mathrm{CH}_{4}$, quanto menor a quantidade de $\mathrm{CO}_{2}$ presente no gás, maior será o teor de $\mathrm{CH}_{4}$ no produto final (PETERSSON; WELLINGER, 2009).

Algumas das técnicas de purificação disponíveis são capazes de remover mais do que um dos componentes indesejados (PETERSSON; WELLINGER, 2009; FNR, 2010; NYNS, 2011; THRÄN et al., 2014). Muitas das técnicas utilizadas para remover estes componentes, individualmente ou em conjunto, do biogás já eram aplicadas para a remoção destes do gás natural, sendo as mais intensivamente estudadas e divulgadas as de remoção de $\mathrm{CO}_{2}$, que ocasionalmente também removem o $\mathrm{H}_{2} \mathrm{~S}$ e a água (PETERSSON; WELLINGER, 2009; FNR, 2010; HAMMER, 2011; NYNS, 2011; THRÄN et al., 2014).

As principais técnicas empregadas para a remoção de $\mathrm{CO}_{2}$ do biogás são citadas no item 3.1.2.1; as técnicas empregadas para a remoção exclusiva da água e do $\mathrm{H}_{2} \mathrm{~S}$ não são abordadas. A seguir são apresentadas algumas das possíveis aplicações para o biogás, de acordo com o tratamento realizado, e exigências às quais este produto deve se adequar para tais finalidades no item 3.1.2.2.

\subsubsection{Técnicas de remoção de $\mathrm{CO}_{2}$}

Diversas técnicas podem ser aplicadas para a remoção do $\mathrm{CO}_{2}$ presente no biogás e algumas já são amplamente empregadas. Dentre estas, destacam-se a absorção física com água, ou lavagem com água a alta pressão; a absorção química, ou lavagem química; a adsorção com modulação de pressão, ou pressure swing adsorption (PSA); o processo de separação por membrana, a absorção física com solvente orgânico e a separação criogênica 
(PETERSSON; WELLINGER, 2009; FNR, 2010; THRÄN et al., 2014). Na Figura 2 é apresentada a representatividade de cada uma destas técnicas utilizadas em usinas de biogás de acordo com informações coletadas pela International Energy Agency (IEA) por meio de seu programa de energia do biogás, Task 37 (THRÄN et al., 2014).

Figura 2 - Representatividade das técnicas de remoção do $\mathrm{CO}_{2}$

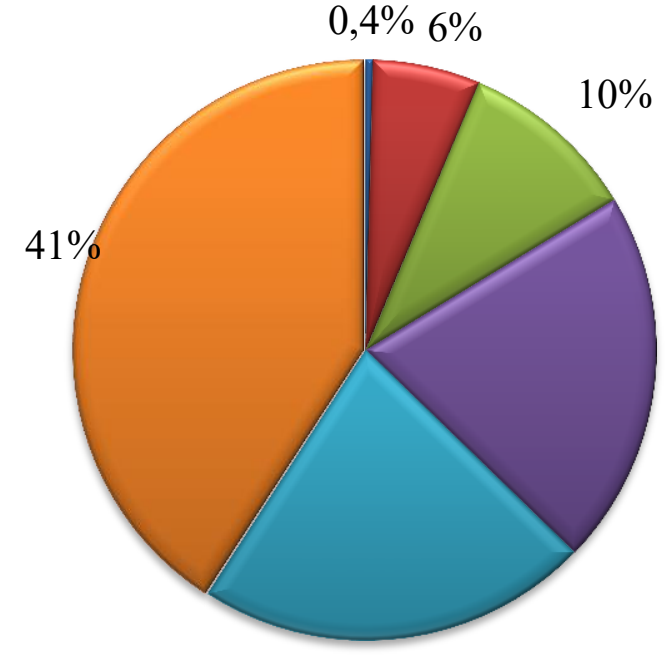

$22 \%$
- Separação criogênica

- Absorção física com solventes orgânicos

$\square$ Processo de membrana $21 \%$

घ Adsorção com modulação de pressão

๑ Absorção química Absorção física com água

Fonte: Autor "adaptado de" Thrän et al., 2014

$\mathrm{O}$ processo de absorção física com água foi a técnica de remoção de $\mathrm{CO}_{2}$ mais empregada de acordo com os dados apresentados na Figura 2. Segundo Thrän et al. (2014) isto se deve ao fato de que esta foi a técnica mais utilizada quando foram construídas as primeiras plantas de purificação de biogás na década de 1980, seguida pelo emprego da adsorção com modulação de pressão. A absorção química começou a ganhar maior participação a partir de 2009 (THRÄN et al., 2014), quando sua aplicação em plantas com capacidade de tratamento de biogás acima de $1.000 \mathrm{Nm}^{3} / \mathrm{h}$ também começou a crescer (PETERSSON; WELLINGER, 2009). O desenvolvimento do processo de separação por membrana indica que esta técnica também poderá obter maior representatividade em termos de aplicação em plantas de purificação do biogás no futuro (THRÄN et al., 2014).

As técnicas apontadas são explicadas a seguir de acordo com seus princípios teóricos básicos e valores práticos reportados na literatura, tanto para a condução destas como para os resultados obtidos por meio de sua aplicação.

Os processos de absorção ou lavagens físicas baseiam-se na transferência de um ou mais componentes de uma corrente gasosa para uma de solvente líquido (HILLER, 2011). Estes processos são conduzidos em torres ou colunas de absorção e tiram proveito das 
diferentes solubilidades dos componentes do biogás no solvente empregado, sendo os mais utilizados para a remoção dos gases ácidos a água, o Selexol ${ }^{\circledR}$ e o Genosorb ${ }^{\circledR}$ (PETERSSON; WELLINGER, 2009; FNR, 2010); estes últimos, solventes comerciais de polietileno glicol de dietil éter, no caso do Selexol ${ }^{\circledR}$, e de misturas de polietileno glicol de dialquil éteres, no caso do Genosorb $^{\circledR}$ (HILLER, 2011; CLARIANT, 2013). Nestes processos é possível separar tanto o $\mathrm{CO}_{2}$ como o $\mathrm{H}_{2} \mathrm{~S}$, e ainda a água quando empregados os solventes físicos, embora a prática tenha mostrado que a remoção prévia do $\mathrm{H}_{2} \mathrm{~S}$ e da água seja mais economicamente atrativa na lavagem com solventes orgânicos (FNR, 2010). A pressão de operação aplicada nestas técnicas situa-se entre 4 e 7 bar (PETERSSON; WELLINGER, 2009), mas no caso da absorção com água, pressões de cerca de 9 bar também são empregadas (FNR, 2010). Após a absorção são obtidas a corrente de biogás purificado, com teor de $\mathrm{CH}_{4}$ que pode ser superior a 98\% para os sistemas de lavagem com água e a 96\% para os sistemas com solventes físicos, dependendo das configurações adotadas em cada caso, e a corrente de solvente rico em gases ácidos, a partir da qual o solvente é regenerado em colunas de dessorção por redução da pressão quando utilizada água e por redução da pressão a temperaturas em torno de $50{ }^{\circ} \mathrm{C}$ quando utilizados solventes orgânicos (FNR, 2010). A principal desvantagem destas técnicas é a perda de $\mathrm{CH}_{4}$ na corrente de gás dessorvido, que pode ser menor do que 1 a $2 \%$ no caso da absorção com água (PETERSSON; WELLINGER, 2009; FNR, 2010) e entre 1 a 2\% (FNR, 2010), podendo chegar a 4\% (PETERSSON; WELLINGER, 2009), no caso da absorção com solventes orgânicos.

Assim como os processos descritos, a absorção ou lavagem química também se baseia na transferência de um ou mais componentes de uma corrente gasosa para uma de solvente líquido e é conduzida em coluna de absorção. No entanto, este processo não se beneficia somente da solubilidade dos gases no solvente, mas principalmente da conversão química dos componentes que se deseja remover quando combinados com o solvente empregado (HILLER, 2011). Os principais solventes empregados são as soluções de alcanolaminas, dentre as quais são apontadas principalmente a monoetanolamina (MEA), a dietanolamina (DEA) e a metil-dietanolamina (MDEA) (PETERSSON; WELLINGER, 2009; FNR, 2010). Nesta técnica, tanto o $\mathrm{CO}_{2}$ como o $\mathrm{H}_{2} \mathrm{~S}$ podem ser removidos, embora seja indicado que a viabilidade da remoção de ambos os gases é condicionada ao tipo de amina empregada, sendo indicadas principalmente as aminas terciárias como a MDEA (FNR, 2010). Neste processo não são empregadas pressões elevadas e é possível atingir um teor de $\mathrm{CH}_{4}$ no gás tratado superior a $99 \%$ com perdas de menos de $0,1 \%$ deste componente no gás residual (PETERSSON; WELLINGER, 2009; FNR, 2010). A principal desvantagem deste processo 
está relacionada à regeneração do solvente, que é realizada pelo fornecimento de calor ao solvente rico em gases ácidos e demanda elevada quantidade de energia térmica (PETERSSON; WELLINGER, 2009; FNR, 2010).

A adsorção com modulação de pressão é uma técnica baseada na transferência de determinados componentes de uma corrente gasosa para a superfície de um material poroso devido à diferença de tamanho, massa molar, polaridade ou capacidade de interação dos componentes do gás com o material adsorvente (MCCABE; SMITH; HARRIOTT, 1993). Esta técnica é realizada por meio da passagem do gás a ser tratado por leitos de material adsorvente a pressões elevadas, seguida pela despressurização para a dessorção dos gases retidos e posterior condicionamento do leito que é novamente pressurizado (HILLER, 2011). $\mathrm{Na}$ literatura é reportado o uso de carvão ativado e peneiras moleculares de zeólitas ou de carbono como materiais adsorventes; a aplicação destes materiais depende da remoção prévia da água e do $\mathrm{H}_{2} \mathrm{~S}$ (FNR, 2010). A pressão de operação empregada situa-se entre 4 e 7 bar como na absorção física (PETERSSON; WELLINGER, 2009), embora sejam reportados valores de aproximadamente 6 a 10 bar (FNR, 2010). Dependendo da configuração do equipamento, pode-se atingir um teor de $\mathrm{CH}_{4}$ no biogás tratado superior a 97\% (FNR, 2010). Assim como na absorção física, esta técnica tem como principal desvantagem a perda de $\mathrm{CH}_{4}$ na corrente de gás dessorvido, que pode ser em torno de 1 a 5\% (FNR, 2010), embora também tenham sido reportadas perdas entre 6 a 10 \% (PETERSSON; WELLINGER, 2009).

O processo de separação por membrana baseia-se nas diferentes taxas com as quais cada componente da corrente gasosa é absorvido em uma membrana não porosa para então se difundir através desta com uma determinada variação de pressão; as taxas de difusão são afetadas por fatores como o tipo de material da membrana, o tamanho das moléculas dos componentes gasosos, a diferença de pressão através da membrana e a espessura desta (HILLER, 2011). Neste processo são empregadas membranas por meio das quais o $\mathrm{CO}_{2}$ é permeado em maior grau do que os outros componentes (PETERSSON; WELLINGER, 2009; THRÄN et al., 2014). Segundo Thrän et al. (2014) pressão de operação situa-se entre 5 a 20 bar. Esta técnica ainda se encontra em desenvolvimento para a purificação do biogás e seu desempenho varia amplamente conforme a configuração estabelecida, considerando o número de estágios empregados e de reciclos, além das condições operacionais (THRÄN et al., 2014). Segundo Petersson e Wellinger (2009) alguns projetos que operavam a pressões mais elevadas, até 30 bar, sofriam de perdas de $\mathrm{CH}_{4}$ de até $25 \%$, mas desde então novos projetos têm sido operados com pressões em torno de 8 bar com perdas consideravelmente menores. Este tipo de processo de separação, aplicado à remoção dos gases ácidos do biogás, ainda se 
encontra em desenvolvimento e pode vir a ser aplicado de formas diversas no futuro, como nos processos descritos por Nasser Junior (2009) em que é relatado o uso de membranas como contactores em colunas de absorção. Uma abordagem mais detalhada das tecnologias aplicáveis à separação por membranas foge do escopo deste trabalho; na sequência é apresentada a última técnica de separação mencionada neste item.

A separação criogênica é uma técnica baseada na separação dos componentes de uma mistura gasosa por meio da condensação ou sublimação de um ou mais de seus componentes mediante resfriamento a temperaturas muito baixas e/ ou aplicação de pressões elevadas. À pressão atmosférica, por exemplo, o $\mathrm{CO}_{2}$ sublima a $-78,5{ }^{\circ} \mathrm{C}$, enquanto o $\mathrm{CH}_{4}$ se liquefaz a -161,52 ${ }^{\circ} \mathrm{C}$ (PETERSSON; WELlingER, 2009). Segundo Petersson e Wellinger (2009) existem processos de separação criogênica dos componentes indesejados do biogás que são realizados gradualmente, pela remoção da água, do $\mathrm{H}_{2} \mathrm{~S}$ e de outros componentes por compressão a pressão de 17 a 26 bar com posterior resfriamento a $-25{ }^{\circ} \mathrm{C}$, seguida pela remoção gradual do $\mathrm{CO}_{2}$ a temperaturas cada vez menores; ou ainda após tratamentos preliminares de remoção de água e de $\mathrm{H}_{2} \mathrm{~S}$ para que seja realizada a posterior compressão e resfriamento do gás visando a remoção do $\mathrm{CO}_{2}$ e o pré-resfriamento do $\mathrm{CH}_{4}$, que é então liquefeito em um módulo de pós-purificação. Por ser uma tecnologia recente em termos de aplicação, é reportada a existência de apenas duas plantas piloto que aplicam esta tecnologia: uma delas no Canadá, que produz $\mathrm{CH}_{4}$ líquido com uma pureza de $96 \%$, e de apenas uma comercial nos Estados Unidos que opera desde 2006 (PETERSSON; WELLINGER, 2009). A FNR (2010) aponta que é possível obter um teor de $\mathrm{CH}_{4}$ superior a 99\% com perdas de menos de $0,1 \%$, embora o consumo energético seja elevado.

As informações e os dados reportados na literatura sobre as técnicas abordadas visam orientar a seleção de um processo de purificação com base, principalmente, na qualidade desejada para o biogás tratado, nas perdas de $\mathrm{CH}_{4}$ e na quantidade de energia requerida; eventualmente também apresentam informações econômicas sobre a aplicação dos processos abordados de acordo com o desenvolvimento alcançado com estas técnicas até então para a purificação do biogás (PETERSSON; WELLINGER, 2009; FNR, 2010; THRÄN et al., 2014). No entanto, como estas informações dependem diretamente das condições operacionais, que variam significativamente, e dos recursos utilizados e sua disponibilidade, os quais podem apresentar alternativas ainda não exploradas, um consenso sobre a melhor técnica a ser aplicada não pode ser definido de forma generalizada, o que por sua vez abre possibilidades para explorar ainda mais as técnicas já conhecidas. 


\subsubsection{Aplicações do biogás}

O biogás com baixa quantidade de energia tem sua principal aplicação na produção de energia elétrica e térmica em sistemas de cogeração ou Combined Heat and Power (CHP), enquanto o biometano, que constitui o biogás com alta quantidade de energia ou alto teor de $\mathrm{CH}_{4}$, pode ser injetado em redes de distribuição de gás natural ou utilizado como combustível veicular (FNR, 2010; FEAM; FIEMG; GIZ, 2015). Na Figura 3 são ilustradas possíveis aplicações para o biogás.

Figura 3 - Possibilidades de aplicações energéticas do biogás

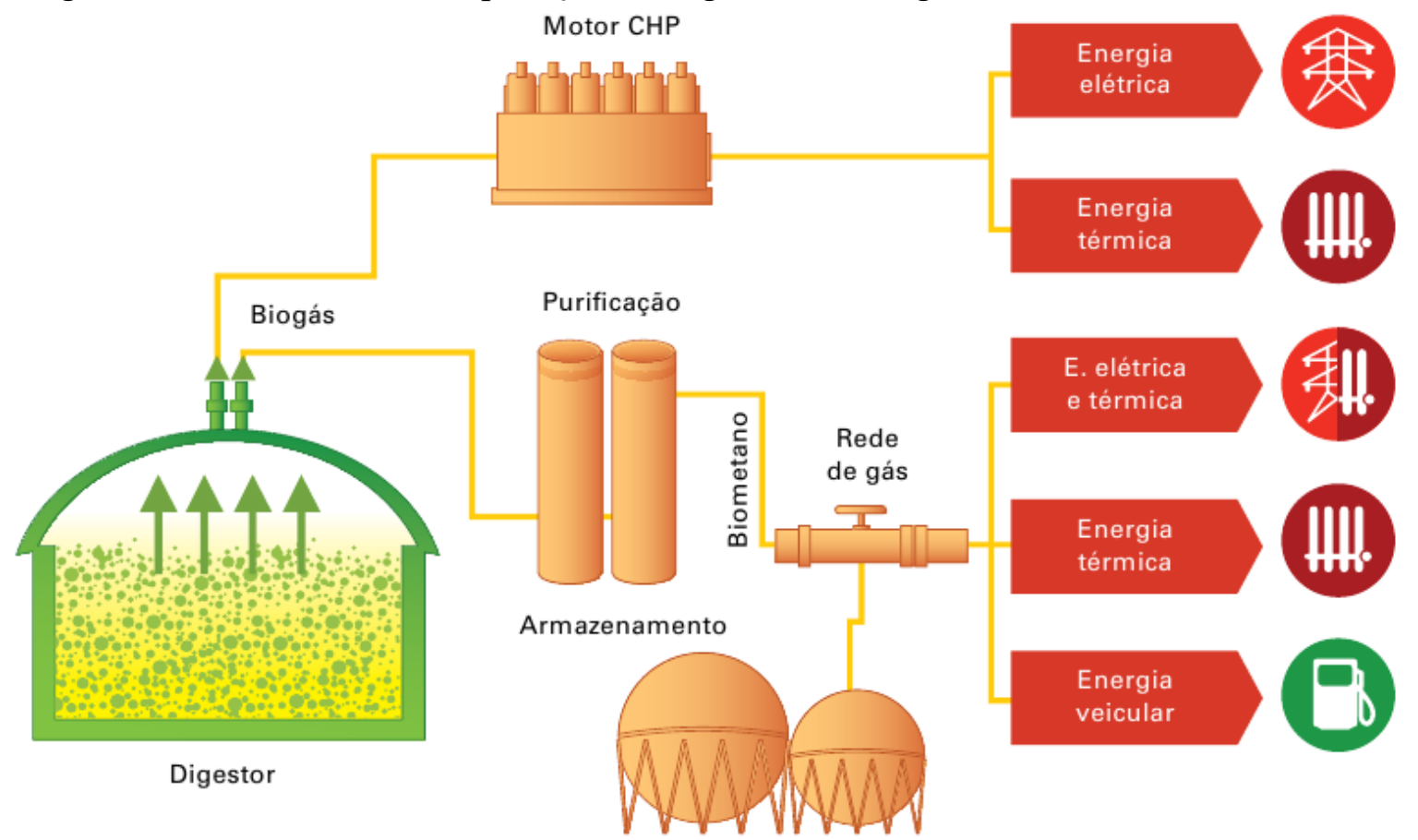

Fonte: Autor, “adaptado de” FNR, 2015 apud FEAM; FIEMG; GIZ, 2015

A utilização do biogás para a produção de energia térmica e elétrica requer que este produto apresente baixa quantidade de $\mathrm{H}_{2} \mathrm{~S}$ para evitar a corrosão e os consequentes danos aos equipamentos. No entanto, o tratamento de purificação para a remoção do $\mathrm{CO}_{2}$ não é necessário, uma vez que nestas usinas motores são acoplados a um gerador de energia elétrica, dentre os quais se destacam: os motores de combustão interna (ciclo Otto), que requerem um teor de $\mathrm{CH}_{4}$ mínimo de $45 \%$ no biogás; motores bicombustíveis (ciclo Diesel operando com biogás e óleo de ignição), que pode trabalhar com biogás com teor de $\mathrm{CH}_{4}$ mais reduzido (FNR, 2010; FEAM; FIEMG; GIZ, 2015); e as microturbinas, que podem utilizar biogás com teor de $\mathrm{CH}_{4}$ a partir de $35 \%$ (FNR, 2010). Nestes sistemas, a energia elétrica é gerada pela microturbina ou motor acoplado ao gerador e a energia térmica pelo emprego de 
trocadores de calor para a recuperação da energia contida no gás de combustão (FNR, 2010). Detalhes adicionais sobre a operação destas usinas e sobre eficiências obtidas podem ser consultados nos guias compilados pela FNR (2010) e pela FEAM, FIEMG e GIZ (2015) sobre a produção de biogás.

O emprego do biometano como substituto do gás natural, seja para a injeção na rede de distribuição deste ou para aplicação como combustível veicular, requer que o biogás seja purificado por meio da remoção de todos os componentes indesejados (água, $\mathrm{H}_{2} \mathrm{~S}$ e $\mathrm{CO}_{2}$ ). $\mathrm{O}$ grau de pureza exigido depende da regulamentação vigente em cada país (PETERSSON; WELLINGER, 2009). No Brasil este padrão foi estabelecido pela Resolução da Agência Nacional do Petróleo, Gás Natural e Biocombustíveis (ANP) nº 8/2015, cujas especificações são apresentadas na Tabela 2, nas condições de referência de temperatura de 293,15 K e pressão de 101,325 kPa.

Tabela 2 - Especificações do biometano

\begin{tabular}{l|c|c|c}
\hline \multirow{2}{*}{ Característica } & \multirow{2}{*}{ Unidade } & \multicolumn{2}{c}{ Limite } \\
\cline { 3 - 4 } & & $\begin{array}{c}\text { Região Norte - } \\
\text { Urucu }\end{array}$ & $\begin{array}{c}\text { Demais } \\
\text { Regióes }\end{array}$ \\
\hline Metano & $\% \mathrm{~mol}$ & 90,0 a 94,0 & 96,5 mín. \\
\hline Oxigênio, máx. & $\% \mathrm{~mol}$ & 0,8 & 0,5 \\
\hline $\mathrm{CO}_{2}$, máx. & $\% \mathrm{~mol}$ & 3,0 & 3,0 \\
\hline $\mathrm{CO}_{2}+\mathrm{O}_{2}+\mathrm{N}_{2}$, máx. & $\% \mathrm{~mol}$ & 10,0 & 3,5 \\
\hline Enxofre Total, máx. & $\mathrm{mg} / \mathrm{m} 3$ & 70 & 70 \\
\hline Gás sulfídrico $\left(\mathrm{H}_{2} \mathrm{~S}\right)$, máx. & $\mathrm{mg} / \mathrm{m} 3$ & 10 & 10 \\
\hline Ponto de orvalho de água a $1 \mathrm{~atm}$, máx. & ${ }^{\circ} \mathrm{C}$ & -45 & -45 \\
\hline
\end{tabular}

Fonte: Brasil, 2015

Além das especificações apresentadas, também é necessário que o biometano seja pressurizado até cerca de 200 bar para que seja utilizado como combustível veicular, ou que tenha a sua pressão condicionada de acordo com a da rede de distribuição do gás natural, se for aplicado desta forma (FNR, 2010). Nesta aplicação, os intervalos de pressão adotados para cada classe: de alta, média e baixa pressão; variam de acordo com a distribuidora do gás, mas de maneira geral variam entre dezenas de milibar a dezenas de bar (COMGÁS, 2015; SCGÁS, 2013); além disso, quando necessário o aumento do valor calorífico do biogás realiza-se também a adição de gases como o propano e o butano (FEAM; FIEMG; GIZ, 2015).

Dentre as aplicações indicadas, a que permite a maior versatilidade no emprego do biometano é a sua injeção na rede de gás natural, de onde pode ser destinado à produção de 
energia térmica e elétrica em diferentes locais, além de poder ser estocado para ser utilizado quando houver picos de demanda (FEAM; FIEMG; GIZ, 2015). Por esta razão, o número de plantas de purificação vem crescendo juntamente com o número de usinas que injetam o biometano nas redes de distribuição de biogás (FNR, 2010; THRÄN et al., 2014).

Segundo Thrän et al. (2014) a avaliação dos custos relacionados à produção de biometano deve ser dividida em função dos componentes de custo: de produção do biogás, de purificação do biogás e de distribuição. Os custos de produção de biogás estão intrinsicamente ligados à matéria-prima, que pode requerer pré-tratamentos diversificados e/ou apresentar disponibilidade sazonal. De acordo com estudos de casos reportados no programa de energia do biogás, Task 37, a produção do biogás contribui com o maior custo para a obtenção do biometano, seguido pelo custo de purificação e pelo custo de distribuição. Atualmente, estima-se que a viabilidade econômica do biometano em relação ao gás natural é pouco atrativa e que a competitividade daquele depende de programas de incentivo. Dados validados dos custos mencionados não foram reportados na literatura, tendo em vista que a produção do biometano ainda está em desenvolvimento e não conta com dados de plantas comerciais, como apontado por Thrän et al. (2014). Uma vez que a análise econômica da produção de biogás e de sua purificação para a obtenção do biometano não constitui o foco deste trabalho, recomenda-se a publicação de Thrän et al. (2014) para a obtenção de mais informações relacionadas a este assunto.

\subsection{REMOÇÃO DE GASES ÁCIDOS POR ABSORÇÃO QUÍMICA COM ALCANOLAMINAS}

Neste item é apresentada, inicialmente, uma breve revisão bibliográfica sobre as características, propriedades e faixas de aplicação das principais alcanolaminas empregadas em processos de absorção química de gases ácidos. A seguir, um esquema simplificado deste processo é apresentado e descrito, ao qual se segue com a descrição dos recheios selecionados para as colunas de absorção e dessorção a partir de sugestões da literatura. Finalmente, as principais abordagens relativas à modelagem de tais processos são apresentadas e os modelos considerados mais precisos para a modelagem destes sistemas são indicados. 


\subsubsection{Principais alcanolaminas empregadas}

Segundo Kohl e Nielsen (1997), as principais alcanolaminas empregadas para a remoção de $\mathrm{CO}_{2}$ e $\mathrm{H}_{2} \mathrm{~S}$ de correntes gasosas, do ponto de vista comercial, são: a monoetanolamina (MEA), a dietanolamina (DEA) e a metildietanolamina (MDEA); cujas fórmulas estruturais são apresentadas na Figura 4. Estas aminas são caracterizadas pela presença de pelo menos um grupo amino e uma hidroxila, sendo o primeiro responsável pelo caráter básico que promove a absorção química dos gases ácidos e o segundo pela redução da pressão de vapor e aumento da solubilidade em água.

Figura 4 - Fórmulas estruturais das alcanolaminas de maior interesse comercial<smiles>CC(C)(C)NC(C)(C)O</smiles><smiles>CC(C)(O)C1(C(O)O)NC1(C)O</smiles><smiles>CN1C(C)(O)C(C)(O)C1(O)I</smiles>

Monoetanolamina (MEA) Dietanolamina (DEA)

Metildietanolamina (MDEA)

Fonte: Autor "adaptado de" Kohl e Nielsen, 1997

Algumas propriedades físicas destas alcanolaminas são apresentadas na Tabela 3.

Tabela 3 - Propriedades físicas das alcanolaminas

\begin{tabular}{l|c|c|c|c}
\hline \multicolumn{1}{c|}{ Propriedade } & Unidade & MEA & DEA & MDEA \\
\hline Massa molar $^{[1]}$ & $\mathrm{g} / \mathrm{mol}$ & 61,08 & 105,14 & 119,17 \\
\hline Densidade $\left(20{ }^{\circ} \mathrm{C}\right)^{[1]}$ & $\mathrm{g} / \mathrm{cm}^{3}$ & 1,0160 & $1,0912\left(30^{\circ} \mathrm{C}\right)$ & $1,038-1,041$ \\
\hline Ponto de fusão & ${ }^{[1]}$ & 10,53 & 28,0 & -21 \\
\hline Ponto de ebulição & ${ }^{[1]} \mathrm{C}$ & 170,3 & 268,5 & 247 \\
\hline Pressão de vapor $\left(20^{\circ} \mathrm{C}\right)^{[2]}$ & $\mathrm{mmHg}$ & 0,36 & 0,01 & 0,01 \\
\hline Calor de vaporização $(101,3 \mathrm{kPa})^{[1]}$ & $\mathrm{kJ} / \mathrm{kg}$ & 848,1 & 638,4 & 418,7 \\
\hline Tensão superficial $\left(20^{\circ} \mathrm{C}\right)^{[1]}$ & $\mathrm{mN} / \mathrm{m}$ & 49 & 47,7 & $40,9\left(20,3^{\circ} \mathrm{C}\right)$ \\
\hline Solubilidade em água $\left(20^{\circ} \mathrm{C}\right)^{[2]}$ & $\%$ mássica & 100 & 96,4 & 100 \\
\hline
\end{tabular}

Fonte: Autor “adaptado de” Frauenkron, 2011 [1] e Kohl; Nielsen, 1997 [2]

As aminas podem ser classificadas como primárias, secundárias ou terciárias, dependendo do número de átomos de hidrogênio ligados diretamente ao átomo de nitrogênio. Aminas que possuem dois hidrogênios ligados diretamente ao átomo de nitrogênio são classificadas como primárias, como é o caso da MEA, e geralmente possuem caráter mais alcalino do que as demais, como pode ser observado na Figura 5, que mostra a variação do pH 
de soluções de alcanolaminas e de uma solução de hidróxido de potássio $(\mathrm{KOH})$, para efeito de comparação, de mesma concentração normal, quando tituladas com $\mathrm{CO}_{2}$. A DEA possui apenas um átomo de hidrogênio ligado diretamente ao átomo de nitrogênio e é classificada como secundária. A MDEA é uma amina terciária, uma vez que não apresenta nenhum átomo de hidrogênio ligado diretamente ao átomo de nitrogênio, mas apenas grupos substituindo estes átomos.

Figura 5 - Curvas de titulação de alcanolaminas e de $\mathrm{KOH}$ com $\mathrm{CO}_{2}$

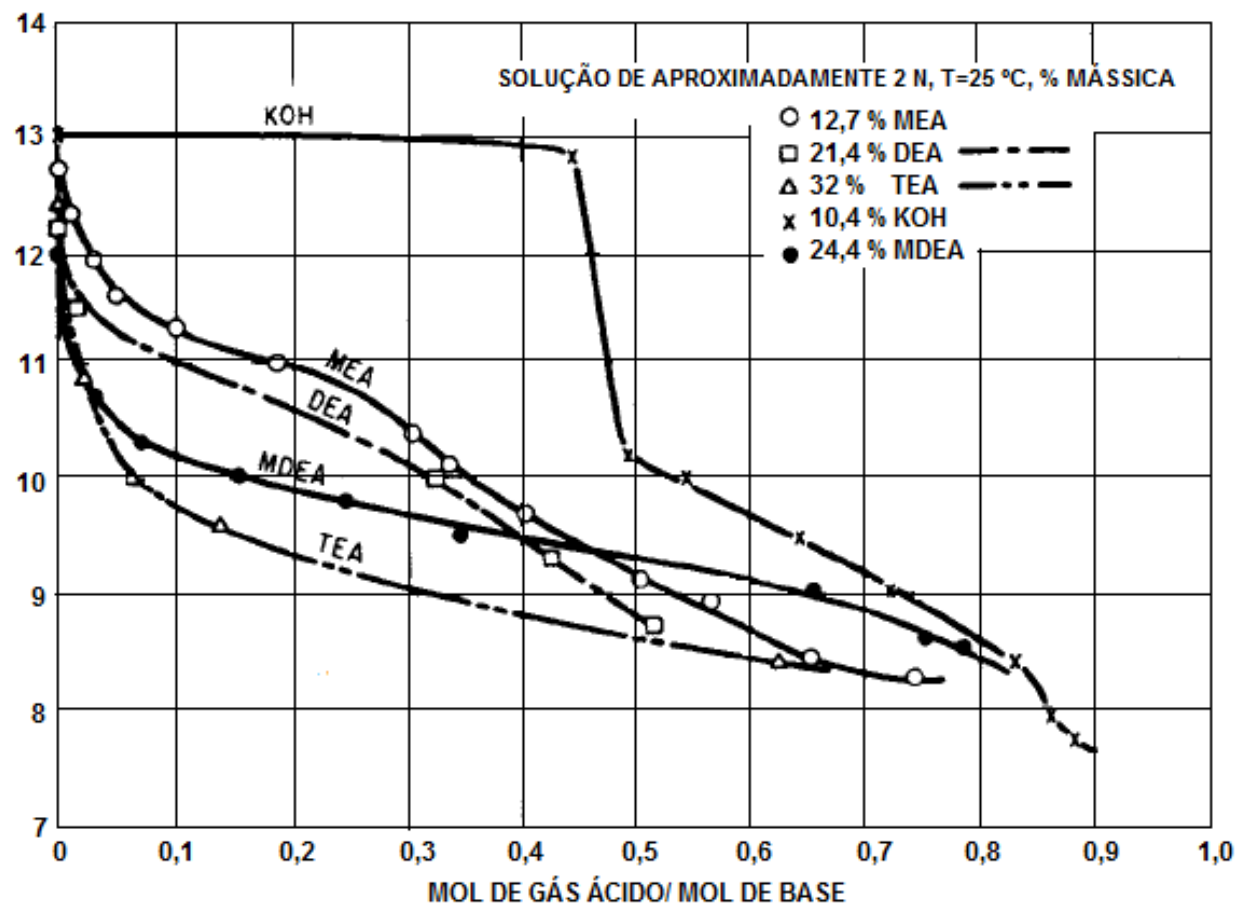

Fonte: Autor "adaptado de" Kohl e Nielsen, 1997

Legenda: TEA - trietanolamina

Tanto o número de grupos ligados diretamente ao nitrogênio, diferentes do átomo de hidrogênio, como o seu tamanho afetam a velocidade de reação das soluções destas aminas com o $\mathrm{CO}_{2}$, a qual diminui conforme os grupos aumentam em número e em tamanho, pois tal aumento resulta em um impedimento estérico. Desta forma, esta diminuição da velocidade de reação das soluções é mais pronunciada para aminas terciárias e aminas estericamente impedidas, que por sua vez são mais seletivas ao $\mathrm{H}_{2} \mathrm{~S}$, tendo em vista a menor velocidade de reação de suas soluções com o $\mathrm{CO}_{2}$ (KOHL; NIELSEN, 1997).

As principais reações que ocorrem quando soluções de aminas primárias e secundárias são utilizadas para absorver o $\mathrm{CO}_{2}$ e o $\mathrm{H}_{2} \mathrm{~S}$ são descritas nas equações de (1)-(5). Quando empregadas aminas terciárias, apenas a reação apresentada na equação (5), de formação do carbamato ( $\left.\mathrm{RR}^{\text {'NCOO}}{ }^{-}\right)$, não ocorre, corroborando com a observação apresentada sobre a 
velocidade de reação das aminas com $\mathrm{CO}_{2}$ (KOHL; NIELSEN, 1997). Uma discussão mais detalhada sobre as principais reações entre os gases ácidos e as soluções de alcanolaminas é apresentada no item 3.3.

$\mathrm{H}_{2} \mathrm{O} \leftrightarrow \mathrm{H}^{+}+\mathrm{OH}^{-}$

$\mathrm{H}_{2} \mathrm{~S} \leftrightarrow \mathrm{H}^{+}+H S^{-}$

$\mathrm{CO}_{2}+\mathrm{H}_{2} \mathrm{O} \leftrightarrow \mathrm{HCO}_{3}^{-}+\mathrm{H}^{+}$

$R R^{\prime} R^{\prime \prime} N+H^{+} \leftrightarrow R R^{\prime} R^{\prime \prime} N H^{+}$

$\mathrm{RR}^{\prime} \mathrm{NH}+\mathrm{CO}_{2} \leftrightarrow \mathrm{RR}^{\prime} \mathrm{NCOO}^{-}+\mathrm{H}^{+}$

onde RR'R' N é a alcanolamina, sendo os radicais R, R' e R' grupos alquil ou alcanol, ou hidrogênio, no caso das alcanolaminas primárias e secundárias.

Em termos de aplicação, as concentrações das soluções de alcanolaminas costumam ser limitadas em relação à corrosividade da solução rica em gases ácidos, à viscosidade, entre outras propriedades. Alguns processos utilizam soluções de MEA com concentração mássica de amina de até $30 \%$ para a remoção de $\mathrm{CO}_{2}$, fazendo uso de inibidores de corrosão. As soluções de DEA empregadas para grandes capacidades de absorção apresentam concentrações variando de 25 a 30\% em massa. A MDEA é utilizada com concentrações mássicas variando de 30 a 50\% (HILLER et al., 2011), bem como em mistura com aminas primárias e secundárias, entre outras, para aumentar a taxa de absorção do $\mathrm{CO}_{2}$ (KOHL; NIELSEN, 1997). Além do uso de inibidores de corrosão, o uso de agentes inibidores de espuma é realizado quando alguns contaminantes da solução estão presentes no sistema, tais como: hidrocarbonetos condensados, ácidos carboxílicos, alguns agentes de superfície ativa usados como inibidores de corrosão, entre outros; uma vez que as soluções de alcanolaminas não contaminadas não formam espumas estáveis (KOHL; NIELSEN, 1997).

A carga, ou loading, das soluções de alcanolaminas é definida como a relação entre o número de moles de gases ácidos, ou de seus principais produtos formados quando reagidos com as soluções, e o número de moles de alcanolamina em solução, ou também de seus principais produtos formados. Para a MEA, Kohl e Nielsen (1997) apresentam loading de 0,5 mol de $\mathrm{CO}_{2}$ por mol de amina, enquanto para a DEA reportam que este pode ser superior a 
0,7 mol de $\mathrm{CO}_{2}$ por mol de amina, visto que a estabilidade do carbamato formado é maior para aminas primárias, o que dificulta sua hidrólise a bicarbonato e diminui a disponibilidade de amina livre em solução. Para a MDEA, Hiller et al. (2011) reportam loading de até 0,8 mol de $\mathrm{CO}_{2}$ por mol de amina.

\subsubsection{Descrição do processo}

A absorção química de gases consiste na transferência de um ou mais componentes de uma fase gasosa para uma fase líquida, onde os componentes gasosos não são apenas dissolvidos, mas predominantemente convertidos quando combinados com os componentes da fase líquida (SCHLAUER; KRIEBEL, 2011), o que resulta em uma transferência de massa intensificada pela reação química (AUSTGEN, 1989).

A operação inversa referenciada como dessorção ou stripping, em que os componentes absorvidos são removidos do solvente, é promovida principalmente pela evaporação de parte deste, visando gerar vapor de stripping no qual os componentes gasosos a serem removidos são recuperados (SCHLAUER; KRIEBEL, 2011), e reverter as reações entre os gases absorvidos e o solvente (AUSTGEN, 1989).

$\mathrm{O}$ processo de purificação de gases contendo $\mathrm{H}_{2} \mathrm{~S}$ e $\mathrm{CO}_{2}$ por meio da absorção química com soluções de alcanolaminas é representado de forma simplificada na Figura 6.

Figura 6 - Esquema simplificado do sistema de absorção/dessorção de gases ácidos

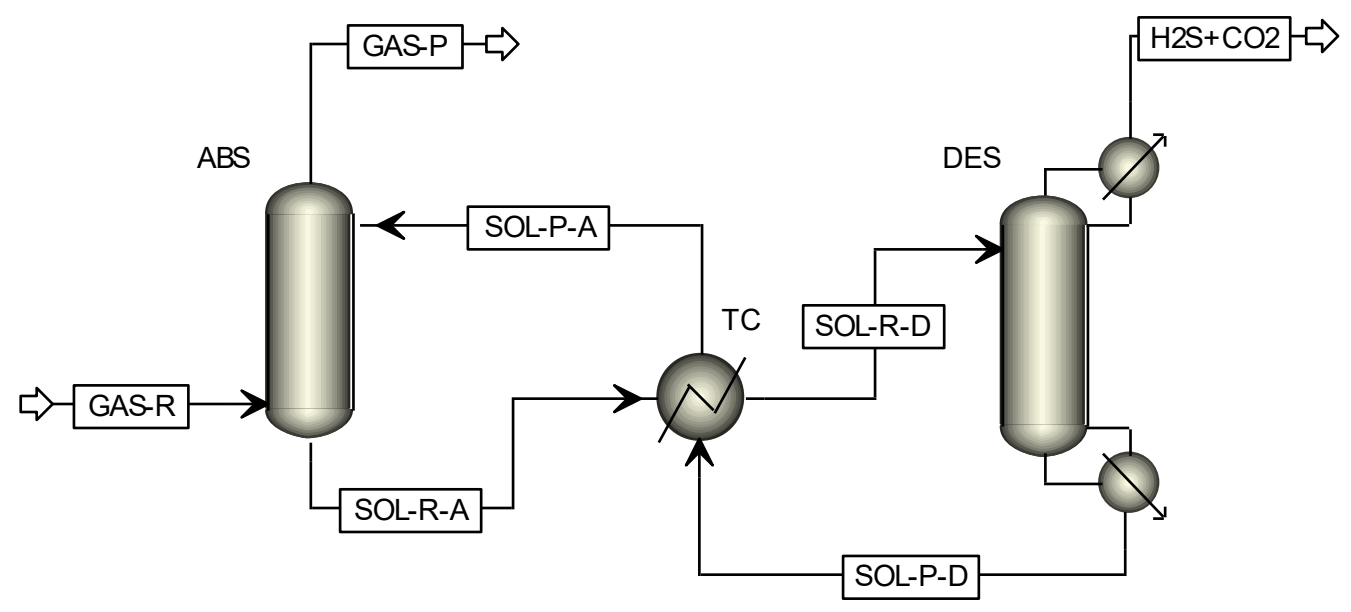

Fonte: Autor "adaptado de" Austgen, 1989 
Neste processo, o gás rico nos componentes ácidos (GAS-R) é introduzido no fundo da coluna de absorção (ABS) e flui até o topo desta em contato contracorrente com a solução de alcanolamina (SOL-P-A), introduzida no topo da coluna, que absorve seletivamente os gases ácidos. O gás purificado (GAS-P) é obtido no topo da coluna de absorção e a solução rica em gases ácidos (SOL-R-A) é retirada no fundo desta. A seguir, esta solução rica é bombeada para trocadores de calor (TC), onde é aquecida (SOL-R-D), e então segue para o topo da coluna de dessorção (DES), onde entra em contracorrente com o vapor produzido no refervedor, que carrega os gases ácidos da solução. São obtidos no topo da coluna de dessorção os gases ácidos $(\mathrm{H} 2 \mathrm{~S}+\mathrm{CO} 2)$ e no fundo a solução de alcanolamina pobre nestes componentes (SOL-P-D). Esta solução de alcanolamina pobre é enviada a trocadores de calor (TC) onde é resfriada, a princípio, com a solução que sai da coluna de absorção (SOL-R-A), e retorna à esta como uma solução com menor loading (SOL-P-A), fechando o ciclo de regeneração do solvente e promovendo um melhor aproveitamento da energia fornecida ao processo.

As colunas de absorção e de dessorção podem apresentar diversas configurações e conter internos como pratos, recheios randômicos ou estruturados. Segundo Schlauer e Kriebel (2011), a absorção química geralmente é realizada em colunas recheadas, que oferecem extensas áreas superficiais para a transferência de massa com perdas de carga pequenas. Dentre os internos utilizados, Kohl e Nielsen (1997) apontam que os recheios estruturados se apresentam como alternativas dignas de consideração para casos que requerem elevada eficiência em transferência de massa e reduzida perda de carga. Algumas particularidades destes internos são abordadas no item 3.2.2.1.

\subsubsection{Recheios estruturados utilizados em colunas de absorção e dessorção}

Os primeiros recheios estruturados foram lançados por volta da década de 1940. No entanto, a aplicação deste tipo de recheio na indústria foi iniciada com os recheios estruturados de segunda geração, de tela metálica ou wire-mesh, Goodloe ${ }^{\circledR}$, Hyperfil $^{\circledR}$ e Sulzer ${ }^{\circledR}$, que surgiram na década de 1950 . No início da década de 1970 sua aplicação havia se tornado substancial em destilações a vácuo, principalmente devido à baixa perda de carga. Ainda atualmente, seu uso costuma ser restringido a aplicações a vácuo, pois embora apresentem alta eficiência, são mais sensíveis a sólidos e possuem custo mais elevado do que os recheios lançados posteriormente (KISTER et al., 2008). 
A terceira geração de recheios estruturados foi introduzida pela Sulzer ${ }^{\circledR}$, no final da década de 1970, com os recheios estruturados corrugados. Estes recheios se destacam por manter altas eficiências e baixas perdas de carga com menor sensibilidade a sólidos e menor custo. Os elementos do recheio são feitos de chapas metálicas finas corrugadas, em vez de telas metálicas como ocorre com os recheios de segunda geração, arranjadas paralelamente, enquanto os elementos são posicionados com um ângulo de rotação por volta de $90^{\circ} \mathrm{em}$ relação ao outro. A superfície destes recheios pode conter furos, que agem como canais entre a superfície superior e inferior de cada chapa, como também tratamentos superficiais dependendo da aplicação, sendo a superfície lisa indicada para sistemas que apresentam sólidos e a rugosa para os demais, visando auxiliar a distribuição e promover a turbulência do líquido para melhorar a transferência de massa. A representação da geometria da corrugação é apresentada na Figura 7 (KISTER et al., 2008).

Figura 7 - Representação geométrica da corrugação de recheios estruturados

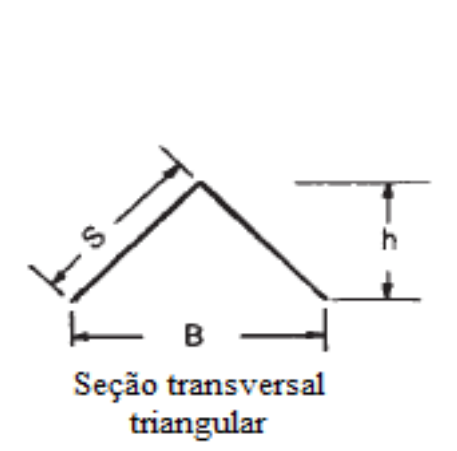

(a)

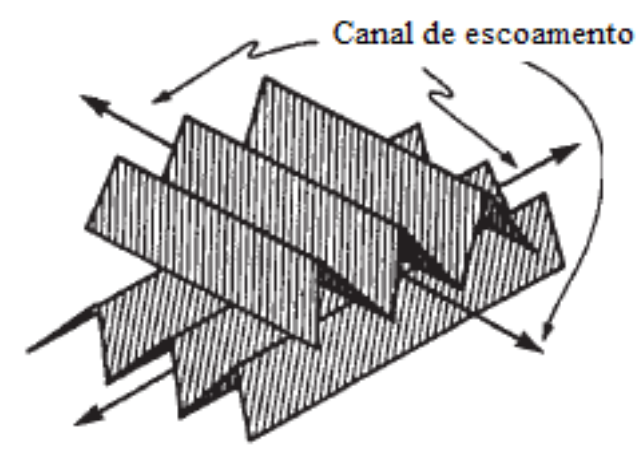

(b)

Fonte: Autor "adaptado de" Fair; Bravo, 1990 apud Kister et al., 2008

Legenda: (a) seção transversal do canal de escoamento. (b) arranjo do canal de escoamento na coluna.

Quanto menores as dimensões $(\mathrm{B}, \mathrm{h}, \mathrm{S})$ da corrugação, menores são as aberturas e a distância entre chapas adjacentes, resultando em um maior número de chapas e, portanto, numa maior área superficial por unidade de volume, o que confere maior eficiência à transferência de massa, embora também maior resistência ao fluxo do gás, o que diminui a capacidade do recheio. O ângulo de inclinação mais comum das placas corrugadas, em cada elemento, é de $45^{\circ}$ em relação à vertical, tipicamente indicado pela letra "Y" na nomenclatura dada aos recheios, que se mostra suficientemente largo para uma boa drenagem do líquido, evitando o acúmulo deste, como também suficientemente pequeno para que o gás não evite a superfície metálica (bypass), o que os torna mais eficientes por melhorar o contato gáslíquido. Exemplos deste tipo são os recheios Sulzer Mellapak $250 \mathrm{Y}^{T M}, 500 \mathrm{Y}^{T M}$ e $750 \mathrm{Y}^{T M}$, 
cuja nomenclatura indica, por meio do número, a superfície disponível por unidade de volume em $\mathrm{m}^{2} / \mathrm{m}^{3}$ e, por meio da letra, o ângulo de orientação com a vertical; estes recheios são perfurados e sua superfície é sulcada (KISTER et al., 2008).

A capacidade máxima dos recheios estruturados depende do tipo deste e é definida de acordo com critérios estabelecidos pelo fabricante. Para os recheios da Sulzer ${ }^{\circledR}$, por exemplo, é definida como o ponto operacional em que a perda de carga de $1200 \mathrm{~Pa} / \mathrm{m}$ é obtida; condição na qual a operação estável ainda é possível, pois a condição de inundação ainda não é atingida, embora a eficiência da separação seja reduzida (GÓRAK; OLUJIC, 2014), de forma que este fabricante recomenda que os projetos não excedam frações de 0,5 a 0,8 da capacidade máxima de seus recheios (ASPEN TECHNOLOGY, 2013a).

\subsubsection{Modelagem de sistemas de absorção química}

Existem diversas abordagens que podem ser adotadas para a modelagem de sistemas de absorção química, que variam de acordo com sua complexidade, mas que costumam ter em comum a consideração de segmentos ou estágios relacionados entre si por meio de balanços de massa e de energia (KENIG; SCHNEIDER; GÓRAK, 2001).

Kenig, Schneider e Górak (2001) apresentam um esquema representando as abordagens que têm sido adotadas na literatura, o qual é reproduzido na Figura 8, onde é indicado o aumento da complexidade dos modelos em relação à transferência de massa e às reações consideradas. Os autores indicam que, para absorção química, a abordagem de estágios equilíbrio é menos precisa, e apontam ainda a ausência de base física na que considera estágios de equilíbrio com reações cinéticas, concluindo que as abordagens baseadas em taxas, também chamadas rate-based ou de não-equilíbrio, são mais apropriadas para descrever estes sistemas reativos por adotarem cálculos mais rigorosos, sobretudo quando consideram a cinética das reações.

$\mathrm{Na}$ abordagem de estágios de equilíbrio, assume-se que o gás e o líquido que entram em um estágio se misturam perfeitamente, de forma que o equilíbrio entre as fases limita a separação obtida. Assim, o gás e o líquido que deixam o estágio saem em equilíbrio entre si. No entanto, para sistemas reativos é a transferência de massa, e não o equilíbrio, que costuma limitar a separação dos componentes (KISTER et al., 1992).

A abordagem de não-equilíbrio costuma se basear na teoria de transferência de massa do duplo-filme, ilustrada nos modelos baseados em taxas da Figura 8, de acordo com a qual existe uma interface estável separando as fases líquida e gasosa, onde a transferência de massa 
é instantânea e, desta forma, o gás e o líquido encontram-se em equilíbrio. No entanto, próximas desta interface são admitidas regiões em cada uma das fases, denominadas filmes, onde o movimento dos fluidos é lento e a transferência de massa ocorre por difusão, gerando gradientes de concentração. Já no seio das fases, assume-se que o movimento dos fluidos é rápido o suficiente para promover uma distribuição uniforme do material. Desta forma, o equilíbrio existe apenas na interface, mas o líquido e o gás que deixam o estágio não se encontram em equilíbrio (KISTER et al., 2008).

Figura 8 - Representação da complexidade dos modelos de absorção química Transferência de massa

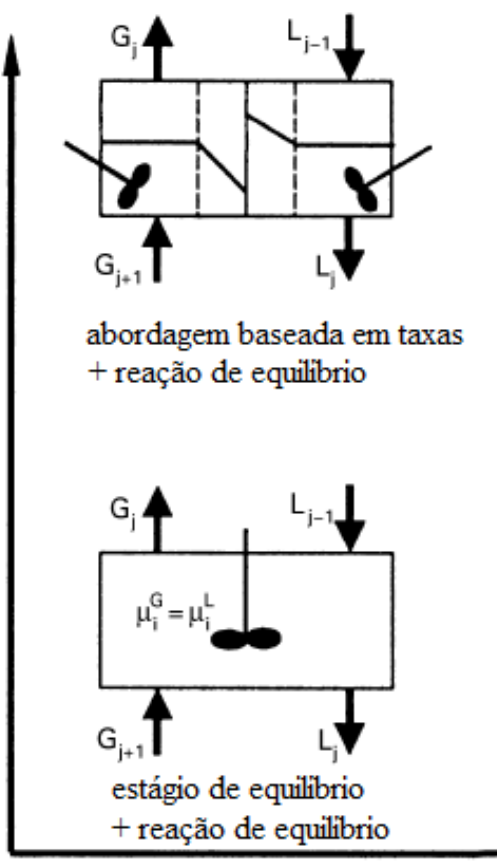

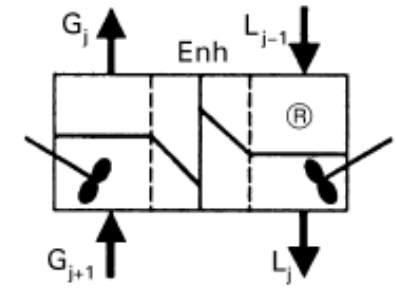

abordagem baseada em taxas + reação cinética

+ fator de intensificação

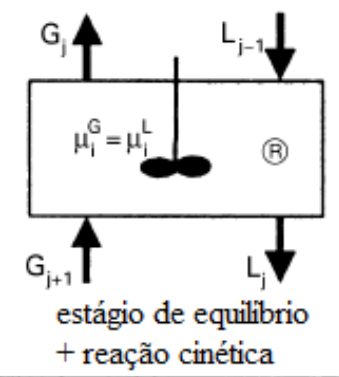

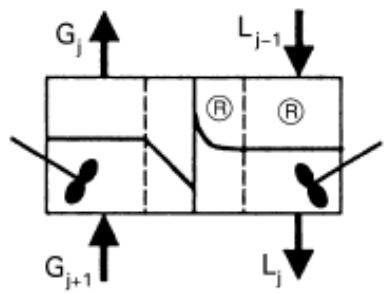

abordagem baseada em taxas + reação cinética + reação no filme + eletrólitos

Reação

Fonte: Autor “adaptado de” Kenig, Schneider e Górak, 2001

Tendo em vista que as velocidades das reações nos sistemas de absorção química podem variar de muito lentas a muito rápidas, ou instantâneas, consideram-se mais precisas as abordagens de não-equilíbrio que fazem uso da cinética destas reações. Dentre estas abordagens, há a que utiliza um fator de intensificação do fluxo de massa no filme (Enh) e considera a contribuição da cinética das reações $(\mathrm{R})$ no seio do líquido e outra que considera a contribuição da cinética das reações tanto no filme como no seio do líquido (KENIG; SCHNEIDER; GÓRAK, 2001). Uma vez que na primeira a contribuição das reações para a transferência de massa no filme é considerada pelo uso de um fator de intensificação, que é estimado a partir da implementação da cinética da reação em uma teoria de transferência de massa (VERSTEEG et al., 1997) e se mostra preciso apenas para alguns casos de reações 
simples - como ocorre com reações únicas e irreversíveis -, a segunda abordagem, que considera diretamente a contribuição da cinética das reações na transferência de massa através do filme, se apresenta como a mais precisa para representar os processos de absorção química; sobretudo quando estes apresentam esquemas complexos de reações paralelas e consecutivas, como ocorre com os sistemas de absorção química de gases ácidos com alcanolaminas (KUCKA et al., 2003).

Além da seleção de uma abordagem em relação à transferência de massa e às reações consideradas, a escolha de um modelo termodinâmico que descreva o sistema de forma satisfatória, tanto para descrever suas não idealidades em relação à transferência de massa como ao equilíbrio, é essencial para a modelagem de sistemas de absorção química; assim como são necessários modelos para a descrição do comportamento do sistema em relação à transferência de massa e, associadas a estes, correlações para a estimativa de coeficientes de transferência de massa (KISTER et al., 2008).

O modelo termodinâmico mais robusto para representar a fase líquida de sistemas que contam com a presença de eletrólitos, como é o caso dos sistemas de absorção química com alcanolaminas, é o electrolyte Non-random two-liquid (NRTL eletrolítico), também denominado electrolyte NRTL ou ELECNRTL. Este modelo representa os coeficientes de atividade de soluções aquosas concentradas em eletrólitos considerando tanto as interações de longo alcance entre íons, como as interações locais binárias de curto alcance entre todas as espécies, sejam elas molécula-molécula ou íon-molécula (AUSTGEN et al., 1991). Segundo Chen e colaboradores (1982), neste modelo a abordagem utilizada para representar as interações de longo alcance, forças eletrostáticas entre íons, emprega a equação estendida de Debye-Hückel proposta por Pitzer (1980) e a abordagem utilizada para representar as interações de curto alcance, como as forças eletrostáticas entre dipolos permanentes e as forças de indução entre dipolos permanentes e dipolos induzidos, emprega o modelo NRTL por Renon e Prausnitz (1968). Austgen e colaboradores (AUSTGEN et al., 1991; AUSTGEN et al., 1989) ajustaram os parâmetros destes modelos tanto para soluções de MEA, DEA e MDEA com $\mathrm{H}_{2} \mathrm{~S}$ e $\mathrm{CO}_{2}$ como para soluções de misturas MDEA com MEA ou DEA e $\mathrm{CO}_{2}$ a partir de dados de solubilidade destes sistemas disponíveis na literatura, como é detalhado em seus trabalhos.

Segundo Krishna e Wesselingh (1997), para a descrição do transporte de massa de misturas multicomponentes a formulação de Maxwell-Stefan fornece a abordagem mais conveniente, uma vez que considera tanto as não-idealidades termodinâmicas como a ação de campos externos de força, que em sistemas eletrolíticos são levados em conta pela introdução 
dos coeficientes de atividade dos componentes da solução e do gradiente de potencial eletrostático, respectivamente. Mais detalhes sobre esta abordagem é discutida em seu trabalho, com alguns exemplos de aplicações.

Os coeficientes de transferência de massa das fases líquida e gasosa podem ser estimados a partir de diversas correlações, que podem ser empíricas ou semi-empíricas e são desenvolvidas para tipos específicos de internos de colunas, de forma que as correlações desenvolvidas para recheios randômicos, por exemplo, não são adequadas para estimar os coeficientes obtidos em colunas com recheios estruturados.

Razi, Bolland e Svendsen (2012) fazem uma revisão sobre correlações disponíveis na literatura para a estimativa destes parâmetros em colunas com recheios estruturados e apontam que estas correlações apresentam diferentes precisões, limitações e faixas de aplicação. Em outro trabalho, Razi, Bolland e Svendsen (2013) testaram o desempenho de algumas correlações e cinéticas de reação na predição de resultados obtidos em uma planta piloto de absorção de $\mathrm{CO}_{2}$ proveniente de gases de combustão utilizando solução aquosa de MEA a 30\% em massa; o estudo foi conduzido utilizando o software Aspen Plus ${ }^{\circledR}$ e algumas das correlações testadas apresentaram resultados satisfatórios na predição da eficiência da separação, embora os perfis de temperatura obtidos para a fase gasosa não fossem muito precisos, sobretudo no topo da coluna. Dentre as correlações testadas no trabalho de Razi, Bolland e Svendsen (2013), a correlação desenvolvida por Hanley e Chen (2012) para recheios estruturados apresentou um desempenho satisfatório. Segundo os autores desta correlação, dados de experimentos com diversos sistemas químicos, incluindo sistemas de absorção de $\mathrm{CO}_{2}$ com soluções aquosas de alcanolaminas, e diferentes recheios foram considerados para o ajuste dos parâmetros da correlação desenvolvida. Neste trabalho, Hanley e Chen (2012) ainda mostraram que sua correlação consegue estimar com satisfatória precisão a seletividade entre $\mathrm{CO}_{2}$ e $\mathrm{H}_{2} \mathrm{~S}$ em sistemas de absorção química com solução aquosa de MDEA, definida como a relação entre a fração molar de $\mathrm{CO}_{2}$ pela fração molar de $\mathrm{H}_{2} \mathrm{~S}$ no gás, que por outras correlações foi superestimada.

Neste trabalho a abordagem de não-equilíbrio é aplicada considerando os efeitos da presença de eletrólitos no sistema e a cinética das reações, quando disponíveis, tanto no filme como no seio do líquido. Desta forma, são aplicados o modelo NRTL eletrolítico e a formulação de Maxwell-Stefan, como também a correlação desenvolvida por Hanley e Chen (2012) para a modelagem da absorção química do $\mathrm{CO}_{2}$ e do $\mathrm{H}_{2} \mathrm{~S}$ com soluções aquosas de alcanolaminas. A abordagem, o modelo e a correlação apresentados possuem modelos desenvolvidos no software Aspen Plus ${ }^{\circledR}$, que será utilizado para a condução das simulações. 


\subsection{REAÇÕES ENTRE GASES ÁCIDOS E SOLUÇÕES DE ALCANOLAMINAS}

Neste item é apresentada uma breve revisão bibliográfica sobre as principais abordagens que a literatura apresenta em relação ao estudo das reações entre os gases ácidos, $\mathrm{CO}_{2}$ e $\mathrm{H}_{2} \mathrm{~S}$, e as soluções aquosas de acanolaminas. Esta revisão visa orientar a seleção da abordagem de equilíbrio ou cinética para as reações dos sistemas estudados e apresentar as formas mais aceitas de como são descritas.

\subsubsection{Reações entre $\mathrm{H}_{2} \mathrm{~S}$ e soluções aquosas de alcanolaminas}

Segundo Danckwerts e Sharma (1966 apud BLAUWHOFF; VERSTEEG; VAN SWAAIJ, 1984), a reação reversível entre $\mathrm{H}_{2} \mathrm{~S}$ e acanolamina em solução aquosa pode ser considerada infinitamente rápida, uma vez que envolve apenas uma transferência de próton. Como consequência, Austgen (1989) aponta que esta reação é geralmente considerada instantânea em relação à transferência de massa.

O mecanismo descrito por Jou, Mather e Otto (1982) para a reação entre $\mathrm{H}_{2} \mathrm{~S}$ e MDEA pode ser adapatado para uma alcanolamina qualquer sob a forma apresentada na equação (6):

$H_{2} S+R R^{\prime} R^{\prime \prime} N \leftrightarrow R R^{\prime} R^{\prime \prime} N H^{+}+H S^{-}$

onde RR'R'N é a alcanolamina, sendo os radicais R, R' e R' grupos alquil ou alcanol, ou hidrogênio, no caso das alcanolaminas primárias e secundárias.

Desta forma, no estudo da absorção química de gases ácidos a abordagem de equilíbrio parece ser suficiente para o tratamento das reações entre $\mathrm{H}_{2} \mathrm{~S}$ e soluções aquosas de acanolaminas. Nestes estudos, as reações de equilíbrio costumam ser escritas como dissociações químicas, como as apresentadas nas equações de (7)-(10) (AUSTGEN; 1989).

$$
\begin{aligned}
& 2 \mathrm{H}_{2} \mathrm{O} \leftrightarrow \mathrm{H}_{3} \mathrm{O}^{+}+\mathrm{OH}^{-} \\
& \mathrm{H}_{2} \mathrm{O}+\mathrm{H}_{2} \mathrm{~S} \leftrightarrow \mathrm{H}_{3} \mathrm{O}^{+}+\mathrm{HS}^{-} \\
& \mathrm{H}_{2} \mathrm{O}+\mathrm{HS}^{-} \leftrightarrow \mathrm{H}_{3} \mathrm{O}^{+}+\mathrm{S}^{2-}
\end{aligned}
$$


$\mathrm{H}_{2} \mathrm{O}+\mathrm{RR}^{\prime} \mathrm{R}^{\prime \prime} \mathrm{NH}^{+} \leftrightarrow \mathrm{H}_{3} \mathrm{O}^{+}+\mathrm{RR}^{\prime} \mathrm{R}^{\prime \prime} \mathrm{N}$

\subsubsection{Reações entre $\mathrm{CO}_{2}$ e soluções aquosas de alcanolaminas}

Em seu estudo sobre as reações entre $\mathrm{CO}_{2}$ e soluções aquosas de alcanolaminas, Blauwhoff, Versteeg e van Swaaij (1984) indicam que, diferente das reações abordadas no item 3.3.1, as reações entre $\mathrm{CO}_{2}$ e soluções aquosas de alcanolaminas ocorrem a velocidades finitas e particulares para cada amina. Desta forma, a abordagem cinética se apresenta como a mais adequada para o tratamento destas reações. Blauwhoff, Versteeg e van Swaaij (1984) apontam ainda que o mecanismo que melhor representa as reações entre soluções de aminas primárias e secundárias com $\mathrm{CO}_{2}$, do ponto de vista cinético, é o mecanismo de zwitterion proposto por Danckwerts (1979), o qual parece se adequar bem aos dados cinéticos obtidos para as reações que aborda; adicionalmente, indicam que para a reação entre soluções aquosas de alcanolaminas terciárias e $\mathrm{CO}_{2} \mathrm{o}$ mecanismo de catálise básica de hidratação do $\mathrm{CO}_{2}$ proposto por Donaldson e Nguyen (1980) representa satisfatoriamente estes sistemas.

O mecanismo de zwitterion, ou sal anfótero, proposto por Danckwerts (1979) para descrever a reação entre $\mathrm{CO}_{2}$ e soluções de alcanolaminas primárias ou secundárias (RR'NH) foi inicialmente introduzido por Caplow (1968 apud DANCKWERTS, 1979), em seu estudo das velocidades de reação entre outras aminas e o $\mathrm{CO}_{2}$. Este mecanismo consiste na formação do zwitterion ( $\mathrm{RR}^{\prime} \mathrm{NH}^{+} \mathrm{COO}^{-}$) seguida pela remoção de um próton por uma base $\mathrm{B}$, que pode ser qualquer base presente no sistema, sendo destacadas a água $\left(\mathrm{H}_{2} \mathrm{O}\right)$, a hidroxila $\left(\mathrm{OH}^{-}\right)$e a amina primária ou secundária (RR'NH); como é representado nas reações descritas nas equações (11) e (12).

$\mathrm{CO}_{2}+\mathrm{RR}^{\prime} \mathrm{NH} \stackrel{k_{6} k_{-6}}{\longleftrightarrow} \mathrm{RR}^{\prime} \mathrm{NH}^{+} \mathrm{COO}^{-}$

$R R^{\prime} \mathrm{NH}^{+} \mathrm{COO}^{-}+B \stackrel{k_{B}}{\rightarrow} R R^{\prime} \mathrm{NCOO}^{-}+\mathrm{BH}^{+}$

onde $k_{6}$ e $k_{-6}$ são os coeficientes de velocidade de reação direta e inversa da reação (11), respectivamente, e $k_{B}$ o coeficiente de velocidade de reação direta da reação (12) com a base B.

Considerando a concentração de zwitterion em estado pseudo-estacionário, Danckwerts (1979) deriva as velocidades de reação indicadas na equação (13), que 
combinadas resultam na equação (14) para representar a velocidade de reação de formação do carbamato ( $\mathrm{RR}^{\prime} \mathrm{NCOO}^{-}$) contando com a contribuição das bases presentes na solução.

$$
\begin{aligned}
& r_{R}=k_{6}\left[\mathrm{CO}_{2}\right]\left[R R^{\prime} N H\right]-k_{-6}\left[R R^{\prime} N H^{+} \mathrm{COO}^{-}\right]=\left[R R^{\prime} \mathrm{NH}^{+} \mathrm{COO}^{-}\right] \sum k_{B}[B] \\
& r_{R}=\frac{k_{6}\left[\mathrm{CO}_{2}\right]\left[R R^{\prime} N H\right]}{1+\frac{k_{-6}}{\sum k_{B}[B]}}
\end{aligned}
$$

Segundo esse mecanismo, as reações entre aminas primárias ou secundárias com $\mathrm{CO}_{2}$ apresentam primeira ordem em relação a este e ordens que podem ser de primeira, fracionária entre um e dois, ou ainda de segunda ordem em relação às aminas, dependendo da limitação que cada reação oferece à velocidade de reação global e da contribuição das bases presentes no sistema. Conforme observado por Danckwerts (1979) se a formação do zwitterion é a etapa controladora da velocidade, então este é desprotonado antes que possa ser revertido a $\mathrm{CO}_{2} \mathrm{e}$ alcanolamina e o segundo termo do denominador da equação (14) será muito menor do que um, resultando em uma reação de primeira ordem em relação à amina. No entanto, se a desprotonação é a etapa controladora, o segundo termo do denominador da equação (14) será muito maior do que um, resultando em uma reação de ordem fracionária entre um e dois; como resultaria também no caso em que não houvesse etapa controladora. Adicionalmente, Danckwerts (1979) indica que para aminas primárias que não possuem impedimento estérico pronunciado, como a MEA, o primeiro caso é comumente observado, enquanto para aminas secundárias que são mais impedidas histericamente, como a DEA, o segundo caso é mais comum, podendo ser observada segunda ordem em relação à alcanolamina secundária se esta se encontrar pura.

No mecanismo proposto por Donaldson e Nguyen (1980) assume-se que ocorre uma ligação de hidrogênio entre a alcanolamina terciária livre e a água, que por sua vez torna-se muito mais reativa em relação ao $\mathrm{CO}_{2}$, resultando no efeito de catálise básica de hidratação do $\mathrm{CO}_{2}$ que é representado pela equação (15) (DONALDSON; NGUYEN, 1980 apud BLAUWHOFF; VERSTEEG; VAN SWAAIJ, 1984).

$\mathrm{RR}^{\prime} \mathrm{R}^{\prime \prime} \mathrm{N}+\mathrm{H}_{2} \mathrm{O}+\mathrm{CO}_{2} \rightarrow \mathrm{RR}^{\prime} \mathrm{R}^{\prime \prime} \mathrm{NH}^{+}+\mathrm{HCO}_{3}^{-}$ 
Para estas aminas, são observadas cinéticas de primeira ordem tanto em relação ao $\mathrm{CO}_{2}$ como em relação à alcanolamina. 


\section{METODOLOGIA}

Nesta seção é definida a metodologia aplicada para conduzir a simulação dos sistemas de absorção para a remoção dos gases ácidos de uma corrente de biogás. Inicialmente, pretende-se propor um sistema de absorção seletiva entre os gases ácidos, onde cada gás ácido é removido preferencialmente em uma seção de uma coluna de absorção, e os estudos de casos. A seguir são apresentados: a modelagem e os modelos aplicados para simular as colunas de absorção e dessorção no software Aspen Plus ${ }^{\circledR}$; o procedimento realizado para simular os estudos de casos e a aplicação do procedimento descrito para a simulação de estudos de casos experimentais de absorção química de $\mathrm{CO}_{2}$, disponíveis na literatura, para validar o modelo utilizado.

\subsection{DEFINIÇÃO DO PROCESSO DE ABSORÇÃO SELETIVA}

O processo proposto consiste na absorção seletiva dos gases ácidos em diferentes seções de uma coluna de absorção, onde a primeira é destinada a absorver preferencialmente o $\mathrm{H}_{2} \mathrm{~S}$ e a segunda é destinada à absorção do $\mathrm{CO}_{2}$, fazendo uso das propriedades revisadas das principais alcanolaminas utilizadas nestes processos. Portanto, além da diferença estrutural que pode existir entre as duas seções, em relação ao diâmetro e aos internos de cada uma, propõe-se também a utilização de diferentes solventes para garantir a separação mencionada. Desta forma, além de se facilitar o cumprimento das exigências em relação ao teor de gases ácidos no biometano, a corrente de gás com teor de $\mathrm{H}_{2} \mathrm{~S}$ reduzido é imediatamente direcionada à seção de separação do $\mathrm{CO}_{2}$ sem a necessidade de percorrer extensas tubulações ao longo da planta.

A regeneração dos solventes empregados é realizada em colunas de dessorção distintas. Assim, o gás dessorvido de cada solvente pode ser destinado a um tratamento específico de acordo com sua natureza, enquanto os solventes retornam cada um para a sua seção na coluna de absorção. Um esquema simplificado deste sistema é apresentado na Figura 9 e consiste em uma representação simplificada do processo. Embora seja apresentada apenas uma coluna de absorção, a simulação das seções desta coluna é conduzida separadamente, com uma simulação destinada a determinado sistema amina-gás ácido.

Nesse processo, o gás rico nos componentes ácidos (BG) é introduzido no fundo da coluna de absorção (ABS) e flui até o topo da primeira seção em contato contracorrente com uma solução aquosa de MDEA (SP-A1), introduzida no topo desta seção, que absorve 
preferencialmente o $\mathrm{H}_{2} \mathrm{~S}$. A solução rica em gases ácidos (SR-A1) é retirada no fundo desta seção e bombeada para trocadores de calor (TC-1), onde é aquecida (SR-D1), e então segue para o topo da coluna de dessorção (DES-1), onde entra em contato contracorrente com o vapor produzido no refervedor que carrega os gases ácidos da solução. São obtidos no topo desta coluna de dessorção os gases ácidos (GA-H2S) e no fundo a solução de alcanolamina pobre nestes componentes (SP-D1). Esta solução de alcanolamina pobre é enviada a trocadores de calor (TC-1) onde é resfriada, a princípio, com a solução que sai da coluna de absorção (SR-A1), e retorna à esta como uma solução com menor loading (SP-A1), fechando o ciclo de regeneração deste solvente e promovendo um melhor aproveitamento da energia fornecida ao processo. $\mathrm{O}$ gás com teor de $\mathrm{H}_{2} \mathrm{~S}$ reduzido é alimentado na seção de separação do $\mathrm{CO}_{2}$ da coluna de absorção (ABS) e flui até o topo da segunda seção em contato contracorrente com uma solução aquosa ou de MEA ou de DEA (SP-A1), introduzida no topo desta seção, para a absorção do $\mathrm{CO}_{2}$. A solução rica em $\mathrm{CO}_{2}$ (SR-A2) é retirada no fundo desta seção e bombeada para trocadores de calor (TC-2), onde é aquecida (SR-D2), e então segue para o topo da coluna de dessorção (DES-2), onde entra em contato contracorrente com o vapor produzido no refervedor que carrega do $\mathrm{CO}_{2}$ e algum resquício de $\mathrm{H}_{2} \mathrm{~S}$ absorvido. São obtidos no topo desta coluna de dessorção os gases ácidos (GA-CO2) e no fundo a solução de alcanolamina pobre nestes componentes (SP-D2). Esta solução de alcanolamina pobre é enviada a trocadores de calor (TC-2) onde é resfriada, a princípio, com a solução que sai da coluna de absorção (SR-A2), e retorna à esta como uma solução com menor loading (SP-A2), fechando o ciclo de regeneração deste solvente

Figura 9 - Esquema do sistema de absorção química seletiva

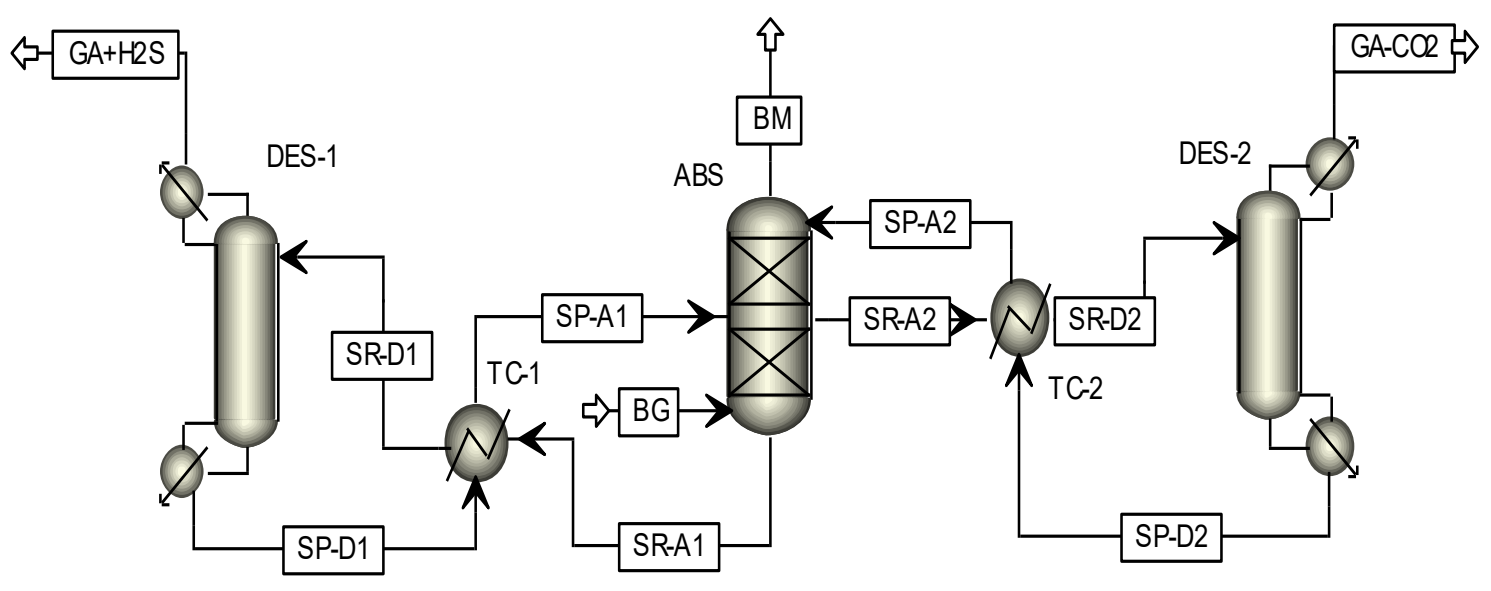

Fonte: Autor 
Os estudos de casos são definidos de acordo com o solvente utilizado e o gás removido preferencialmente em cada seção, como apresentado na Tabela 4.

Tabela 4 - Estudos de casos

\begin{tabular}{c|l|c}
\hline Caso & \multicolumn{1}{|c|}{ Solvente utilizado } & Gás removido preferencialmente \\
\hline 1 & solução aquosa de MDEA & $\mathrm{H}_{2} \mathrm{~S}$ \\
\hline 2 & solução aquosa de MEA & $\mathrm{CO}_{2}$ \\
\hline 3 & solução aquosa de DEA & $\mathrm{CO}_{2}$ \\
\hline \multicolumn{2}{l}{ Fonte: Autor }
\end{tabular}

A simulação deste processo é detalhada no item 4.2.3.2.

\subsection{SIMULAÇÃO DOS ESTUDOS DE CASOS}

Neste item será apresentada a modelagem de não-equilíbrio utilizada para a simulação da absorção química. A seguir serão apresentados as faixas de aplicação recomendadas e os modelos cinéticos e de equilíbrio utilizados para simular a absorção dos gases ácidos com alcanolamias. Finalmente serão descritos os procedimentos tomados para conduzir as simulações.

\subsubsection{Modelagem de não-equilíbrio utilizada para a simulação da absorção química}

A modelagem matemática utilizada para a simulação de sistemas de absorção química no software Aspen Plus ${ }^{\circledR}$ se baseia na teoria de transferência de massa do duplo-filme, apresentada no item 3.2.3, e consiste em equações de balanços materiais e de energia, taxas de massa e de calor, equilíbrio de fases e restrições em relação às composições em cada fase. Estas equações são aplicadas em cada seção ou estágio da coluna (ASPEN TECHNOLOGY, 2013b).

Nos balanços materiais, além das correntes de entrada e de saída no seio das fases líquida e gasosa, são consideradas as taxas de transferência de massa que ocorrem entre o filme e o seio de cada fase, seguindo a formulação de Maxwell-Stefan, e na interface entre os filmes da fase líquida e gasosa; além disso, as taxas de reação são calculadas em ambas as regiões de cada fase, ou no presente estudo, apenas no filme e no seio da fase líquida. $\mathrm{O}$ cálculo dos coeficientes de transferência de massa para as fases líquida e gasosa depende das propriedades físicas dos fluidos e do tipo de interno da coluna; para colunas que utilizam recheios estruturados corrugados metálicos pode ser empregada a correlação de Hanley e 
Chen (2012), mencionada no item 3.2.3, que também calcula a área interfacial para transferência de massa.

Nos balanços de energia são consideradas as entalpias associadas às correntes de entrada e de saída das correntes líquidas e gasosas no seio das fases, o calor que pode ser adicionado ou removido de cada fase por agentes externos e as taxas de transferência de calor que ocorrem entre o filme e o seio de cada fase, considerando tanto o calor trocado entre estas regiões como o calor de reação, bem como as taxas de transferência de calor na interface entre os filmes das fases líquida e gasosa. Os coeficientes de transferência de calor, das fases líquida e gasosa, são calculados pelo método de Chilton e Colburn que permite estimar estes coeficientes a partir do coeficiente de transferência de massa relacionado à cada fase e de propriedades físicas, de escoamento do fluido e geométricas.

As equações descritas para modelar os balanços mencionados, bem como as equações de equilíbrio e as restrições impostas ao sistema de absorção são apresentadas no Anexo A.

Para aumentar a precisão dos cálculos de transferência de massa e de calor realizados nos filmes de cada fase de um sistema reativo é possível discretizá-los, de forma que as equações descritas para estas regiões são aplicadas utilizando os coeficientes médios que consideram tantos pontos quantos forem indicados na discretização dos filmes, tornando os cálculos mais precisos, embora também mais exigentes em termos computacionais, quanto maior for o número de pontos especificados. A espessura de cada filme é determinada por meio da relação entre a difusividade média e o coeficiente de transferência de massa médio.

O cálculo do holdup, que consiste num parâmetro hidráulico definido como a quantidade de líquido presente na superfície do recheio (RAZI; BOLLAND; SVENDSEN, 2012), emprega correlações empíricas, como a de Bravo, Rocha e Fair (1992) disponível no software como Bravo et al. (1992); esta correlação é apresentada no Anexo B.

A forma como as condições de temperatura e pressão, as vazões molares e as composições do seio das fases são calculadas depende do modo de fluxo selecionado no software. No modo padrão, denominado Mixed, assume-se que as propriedades do seio das fases são iguais às de saída da seção, como ocorre em estágios de equilíbrio, sendo recomendado para colunas de pratos onde esta condição pode ser próxima da real. No entanto, para colunas recheadas são recomendados os modos Countercurrent ou VPlug, que assumem propriedades médias entre as de entrada e as de saída da seção; no primeiro modo tanto para o seio do líquido como para o seio do gás e no segundo apenas para o seio do gás, sendo as propriedades do seio do líquido e a pressão no seio do gás consideradas da mesma forma que no modo Mixed. Embora o modo Countercurrent forneça resultados mais acurados, é mais 
intensivo computacionalmente e pode ocasionar problemas de convergência com maior frequência do que o modo VPlug (ASPEN TECHNOLOGY, 2013c).

\subsubsection{Modelos de absorção de gases ácidos com alcanolaminas para simulação da absorção química}

Os modelos utilizados para a simulação dos estudos de caso propostos apresentam faixas de aplicação limitadas em relação às propriedades físicas dos sistemas estudados, bem como de acordo com os modelos experimentais para a estimativa de parâmetros termodinâmicos e reacionais.

As faixas de aplicação dos sistemas estudados são limitadas em relação à temperatura e à concentração da solução de alcanolamina. Os limites recomendados para a aplicação destes modelos, de acordo com dados da literatura em relação às propriedades dos sistemas e aos modelos experimentais, são apresentados na Tabela 5.

Tabela 5 - Faixas de aplicação das soluções de alcanolaminas

\begin{tabular}{l|c|c|c|c}
\hline \multicolumn{1}{c|}{ Parâmetro } & Unidade & MDEA & MEA & DEA \\
\hline Composição & $\%$ mássica de amina & 51,4 & 50 & 30 \\
\hline Temperatura & ${ }^{\circ} \mathrm{C}$ & $25-120$ & até 120 & até 140 \\
\hline Fonte: Aspen Technology, $2013 \mathrm{~d}$
\end{tabular}

Detalhes em relação aos bancos de dados de propriedades físicas dos sistemas indicados podem ser encontrados em Aspen Technology (2013e, 2013f, 2013g).

Os modelos reacionais disponíveis no software adotam abordagens coerentes com as que foram apresentadas no item 3.3. Nestes modelos é adotada a abordagem de equilíbrio para os sistemas com soluções aquosas de MDEA, MEA e DEA com $\mathrm{H}_{2} \mathrm{~S}$ e os parâmetros para o cálculo das constantes de equilíbrio são especificados de acordo com dados obtidos da literatura. Para as reações com $\mathrm{CO}_{2}$ são adotadas tanto a abordagem cinética, com parâmetros cinéticos obtidos da literatura, como reações de equilíbrio, cujas constantes são calculadas por meio da energia de Gibbs nos sistemas com MDEA e MEA e por meio de parâmetros especificados de acordo com dados obtidos da literatura para o sistema com DEA; estas reações de equilíbrio apresentam sua importância na medida em que tornam possível a representação de espécies do sistema que não são representadas nos modelos cinéticos.

As constantes de equilíbrio, calculadas para as reações de equilíbrio cujos parâmetros são especificados a partir de dados da literatura, são calculadas de acordo com a equação (16). 
$K_{e q}=e^{\left(A+\frac{B}{T}+C \ln (T)+D T\right)}$

onde $A, B, C$ e $D$ são os parâmetros obtidos da literatura e $T$ é a temperatura absoluta.

As velocidades das reações, para as quais é adotada a abordagem cinética, são calculadas pela lei de potência apresentada na equação (17), e os parâmetros $k_{R}$ e $E$ são especificados no software para cada reação.

$r_{R}=k_{R} T^{n} e^{\left(-\frac{E}{R T}\right)} \prod_{i=1}^{n r} c_{i}^{\alpha_{i}}$

onde $k_{R}$ é o fator pré-exponencial; $T$ é a temperatura absoluta; $n$ é o expoente da temperatura; $E$ é a energia de ativação; $R$ é a constante universal dos gases; $c_{i}$ é a concentração molar e $\alpha_{i}$ é o coeficiente estequiométrico do reagente, exceto quando este é a água, caso em que $\alpha_{i}=0$.

Na Tabela 6 são apresentadas as reações de equilíbrio dos sistemas estudados com a indicação dos parâmetros utilizados para o cálculo das constantes de equilíbrio, quando empregados no modelo, e sem a indicação destes quando a constante é calculada por meio da energia de Gibbs.

Tabela 6 - Reações de equilíbrio empregadas nos modelos de absorção

\begin{tabular}{|c|c|c|c|c|}
\hline Reação de equilíbrio & A & B & C & $\mathbf{D}$ \\
\hline \multicolumn{5}{|l|}{ Sistema com MDEA $^{[1]}$} \\
\hline$M D E A^{+}+\mathrm{H}_{2} \mathrm{O} \leftrightarrow M D E A+\mathrm{H}_{3} \mathrm{O}^{+}$ & - & - & - & - \\
\hline $2 \mathrm{H}_{2} \mathrm{O} \leftrightarrow \mathrm{H}_{3} \mathrm{O}^{+}+\mathrm{OH}^{-}$ & - & - & - & - \\
\hline $\mathrm{HCO}_{3}^{-}+\mathrm{H}_{2} \mathrm{O} \leftrightarrow \mathrm{CO}_{3}^{-2}+\mathrm{H}_{3} \mathrm{O}^{+}$ & - & - & - & - \\
\hline \multicolumn{5}{|l|}{ Sistema com MEA ${ }^{[2]}$} \\
\hline$M E A H^{+}+H_{2} O \leftrightarrow M E A+H_{3} O^{+}$ & - & - & - & - \\
\hline $2 \mathrm{H}_{2} \mathrm{O} \leftrightarrow \mathrm{H}_{3} \mathrm{O}^{+}+\mathrm{OH}^{-}$ & - & - & - & - \\
\hline $\mathrm{HCO}_{3}^{-}+\mathrm{H}_{2} \mathrm{O} \leftrightarrow \mathrm{CO}_{3}^{-2}+\mathrm{H}_{3} \mathrm{O}^{+}$ & - & - & - & - \\
\hline \multicolumn{5}{|l|}{ Sistema com DEA ${ }^{[3]}$} \\
\hline$D E A H^{+}+\mathrm{H}_{2} \mathrm{O} \leftrightarrow \mathrm{DEA}+\mathrm{H}_{3} \mathrm{O}^{+}$ & $-13,3373$ & $-4218,708$ & 0 & 0,00987175 \\
\hline $2 \mathrm{H}_{2} \mathrm{O} \leftrightarrow \mathrm{H}_{3} \mathrm{O}^{+}+\mathrm{OH}^{-}$ & 132,899 & $-13445,9$ & 22,4773 & 0 \\
\hline $\mathrm{HCO}_{3}^{-}+\mathrm{H}_{2} \mathrm{O} \leftrightarrow \mathrm{CO}_{3}^{-2}+\mathrm{H}_{3} \mathrm{O}^{+}$ & 216,049 & $-12431,7$ & 35,4819 & 0 \\
\hline \multicolumn{5}{|l|}{ Todos os sistemas $^{[4]}$} \\
\hline $\mathrm{H}_{2} \mathrm{~S}+\mathrm{H}_{2} \mathrm{O} \leftrightarrow \mathrm{HS}^{-}+\mathrm{H}_{3} \mathrm{O}^{+}$ & 214,582 & $-12995,4$ & $-33,5471$ & 0 \\
\hline $\mathrm{HS}^{-}+\mathrm{H}_{2} \mathrm{O} \leftrightarrow \mathrm{S}^{-2}+\mathrm{H}_{3} \mathrm{O}^{+}$ & $-9,742$ & $-8585,47$ & 0 & 0 \\
\hline
\end{tabular}

Fontes: Aspen Technology, 2013e [1], Aspen Technology, 2013f [2], Austgen, 1988 apud Aspen Technology, 2013g [3], [4] Austgen, 1988; Jou, 1982; Jou 1993a; Jou 1993b apud Aspen Technology, $2013 \mathrm{~g}$ 
As reações que utilizam a abordagem cinética nos sistemas estudados são apresentadas na Tabela 7, juntamente com os parâmetros cinéticos destas.

Tabela 7- Reações cinéticas empregadas nos modelos de absorção

\begin{tabular}{|c|c|c|c|c|}
\hline Reação cinética & $\mathbf{k}$ & E (J/kmol) & $\mathbf{n}$ & ordem \\
\hline \multicolumn{5}{|l|}{ Sistema com MDEA ${ }^{[1]}$} \\
\hline $\mathrm{MDEA}+\mathrm{CO}_{2}+\mathrm{H}_{2} \mathrm{O} \rightarrow \mathrm{MDEA^{+ } + \mathrm { HCO } _ { 3 } ^ { - }}$ & $2,22 \cdot 10^{7}$ & $3,7802 \cdot 10^{7}$ & 0 & 2 \\
\hline $\mathrm{MDEA}^{+}+\mathrm{HCO}_{3}^{-} \rightarrow \mathrm{MDEA}+\mathrm{CO}_{2}+\mathrm{H}_{2} \mathrm{O}$ & $1,0568 \cdot 10^{16}$ & $1,06445 \cdot 10^{8}$ & 0 & 2 \\
\hline \multicolumn{5}{|l|}{ Sistema com MEA $^{[2]}$} \\
\hline $\mathrm{MEA}+\mathrm{CO}_{2}+\mathrm{H}_{2} \mathrm{O} \rightarrow \mathrm{MEACOO}^{-}+\mathrm{H}_{3} \mathrm{O}^{+}$ & $9,77 \cdot 10^{10}$ & $4,12643 \cdot 10^{7}$ & 0 & 2 \\
\hline $\mathrm{MEACOO}^{-}+\mathrm{H}_{3} \mathrm{O}^{+} \rightarrow \mathrm{MEA}+\mathrm{CO}_{2}+\mathrm{H}_{2} \mathrm{O}$ & $3,23 \cdot 10^{19}$ & $6,55444 \cdot 10^{7}$ & 0 & 2 \\
\hline \multicolumn{5}{|l|}{ Sistema com DEA ${ }^{[3]}$} \\
\hline $\mathrm{DEA}+\mathrm{CO}_{2}+\mathrm{H}_{2} \mathrm{O} \rightarrow \mathrm{DEACOO} \mathrm{O}^{-}+\mathrm{H}_{3} \mathrm{O}^{+}$ & $6,48 \cdot 10^{6}$ & $2,1235 \cdot 10^{7}$ & 0 & 2 \\
\hline $\mathrm{DEACOO}-+\mathrm{H}_{3} \mathrm{O}^{+} \rightarrow \mathrm{DEA}+\mathrm{CO}_{2}+\mathrm{H}_{2} \mathrm{O}$ & $1,34 \cdot 10^{17}$ & $4,8136 \cdot 10^{7}$ & 0 & 2 \\
\hline \multicolumn{5}{|l|}{ Todos os sistemas ${ }^{[4]}$} \\
\hline $\mathrm{CO}_{2}+\mathrm{OH}^{-} \rightarrow \mathrm{HCO}_{3}^{-}$ & $4,32 \cdot 10^{13}$ & $5,54709 \cdot 10^{7}$ & 0 & 2 \\
\hline $\mathrm{HCO}_{3}^{-} \rightarrow \mathrm{CO}_{2}+\mathrm{OH}^{-}$ & $2,38 \cdot 10^{17}$ & $1,23305 \cdot 10^{8}$ & 0 & 1 \\
\hline
\end{tabular}

Fontes: Rinker, 1997 apud Aspen Technology 2013e [1], Hikita, 1977 apud Aspen Technology, 2013f [2], Rinker, 1996 apud Aspen Technology, 2013g [3], Pinset, 1956 apud Aspen Technology, 2013g [4]

\subsubsection{Procedimentos aplicados à simulação do processo de absorção química}

Neste item são descritos, inicialmente, os procedimentos tomados para simular colunas de absorção para a remoção do $\mathrm{CO}_{2}$ e do $\mathrm{H}_{2} \mathrm{~S}$ a fim de comparar o desempenho das soluções de alcanolaminas empregadas. A seguir são descritos os procedimentos tomados para simular o processo definido no item 4.1. Finalmente, os estudos de casos experimentais da absorção química de $\mathrm{CO}_{2}$ disponíveis na literatura são apresentados, bem como o procedimento aplicado para simulá-los a fim de validar o modelo utilizado.

\subsubsection{Simulação da absorção simultânea dos gases ácidos}

Nas simulações conduzidas para comparar o desempenho das soluções aquosas de MDEA, MEA, DEA foi configurada apenas uma coluna de absorção para cada sistema, na qual foram alimentadas as correntes de biogás e de solução de alcanolamina pobre, sem gases ácidos.

A corrente de biogás foi definida conforme especificado na Tabela 8, adotando uma vazão volumétrica de gás reportada na literatura (PETERSSON; WELLINGER, 2009); condições de temperatura e pressão, sendo a primeira um pouco inferior àquela definida como ótima para a condução da decomposição anaeróbia na faixa mesofílica e a segunda 
ligeiramente superior à pressão atmosférica para garantir a condução do processo em pressões positivas, e uma composição média adotada pelo autor, dentro dos limites apresentados na Tabela 1.

Tabela 8 - Especificações da corrente de biogás para as simulações

\begin{tabular}{l|c|c}
\hline \multicolumn{1}{c|}{ Parâmetro } & Unidade & Valor \\
\hline Temperatura & ${ }^{\circ} \mathrm{C}$ & 35 \\
\hline Pressão & $\mathrm{atm}$ & 1,05 \\
\hline Vazão volumétrica & $\mathrm{Nm}^{3} / \mathrm{h}$ & 1.000 \\
\hline Composição & & \\
\hline Metano $\left(\mathrm{CH}_{4}\right)$ & $\mathrm{kmol} / \mathrm{kmol}$ & 0,560 \\
\hline Dióxido de carbono $\left(\mathrm{CO}_{2}\right)$ & $\mathrm{kmol} / \mathrm{kmol}$ & 0,380 \\
\hline Água $\left(\mathrm{H}_{2} \mathrm{O}\right)$ & $\mathrm{kmol} / \mathrm{kmol}$ & 0,054 \\
\hline Sulfeto de hidrogênio $\left(\mathrm{H}_{2} \mathrm{~S}\right)$ & $\mathrm{kmol} / \mathrm{kmol}$ & 0,004 \\
\hline Nitrogênio $\left(\mathrm{N}_{2}\right)$ & $\mathrm{kmol} / \mathrm{kmol}$ & 0,002 \\
\hline
\end{tabular}

Fonte: Autor

As correntes de solvente foram especificadas em relação à vazão molar da solução; à composição mássica, dentro dos limites especificados na Tabela 5 e do item 3.2.1.; temperatura e pressão, conforme apresentado na Tabela 9.

Tabela 9 - Especificações das correntes de solvente para as simulações

\begin{tabular}{l|c|c|c|c}
\hline \multicolumn{1}{c|}{ Parâmetro } & Unidade & MDEA & MEA & DEA \\
\hline Temperatura & ${ }^{\circ} \mathrm{C}$ & 35 & 35 & 35 \\
\hline Pressão & $\mathrm{atm}$ & 1,05 & 1,05 & 1,05 \\
\hline Vazão molar & $\mathrm{kmol} / \mathrm{h}$ & 375 & 305 & 500 \\
\hline Composição & & & & \\
\hline \multicolumn{1}{c|}{ Água } & $\mathrm{kg} / \mathrm{kg}$ & 0,6 & 0,7 & 0,7 \\
\hline \multicolumn{1}{c|}{ DEA } & $\mathrm{kg} / \mathrm{kg}$ & 0,0 & 0,0 & 0,3 \\
\hline \multicolumn{1}{c|}{ MDEA } & $\mathrm{kg} / \mathrm{kg}$ & 0,4 & 0,0 & 0,0 \\
\hline MEA & $\mathrm{kg} / \mathrm{kg}$ & 0,0 & 0,3 & 0,0 \\
\hline
\end{tabular}

Fonte: Autor

As vazões molares destas correntes foram estimadas considerando um loading $(\mathrm{X})$ de gases ácidos de aproximadamente 0,5 kmol de gases ácidos por kmol de amina, assumindo a total absorção dos gases ácidos presentes no biogás, segundo a equação (18).

$$
X=\frac{n_{\mathrm{CO}_{2}}+n_{\mathrm{H}_{2} S}}{n_{A M}}
$$


onde $n_{\mathrm{CO}_{2}}$ e $n_{\mathrm{H}_{2} \mathrm{~S}}$ são os números de moles de $\mathrm{CO}_{2}$ e de $\mathrm{H}_{2} \mathrm{~S}$, respectivamente, presentes no biogás, e $n_{A M}$ é o número de moles de amina presente na solução pobre em gases ácidos. $\mathrm{O}$ detalhamento dos cálculos realizados para a estimativa dos valores destas correntes é apresentado no Apêndice A.

A coluna de absorção de cada sistema foi configurada utilizando o modelo RadFrac do software no modo Rate-Based, que emprega a modelagem apresentada no item 4.2.1. Não foram considerados condensador ou refervedor e a pressão no topo da coluna foi fixada em 1,04 atm. As fases consideradas eram líquido e vapor e optou-se pelo modo de convergência Strongly non-ideal liquid, recomendado pelo software para sistemas com soluções não-ideais que tendem a apresentar problemas de convergência durante as simulações. Os conjuntos de reações apresentados no item 4.2.2 foram considerados em todas as seções da coluna e a estimativa do holdup para os cálculos de equilíbrio, que precedem os cálculos de taxas, foi de $1 \cdot 10^{-3} \mathrm{~m}^{3}$, ou ajustado para valores menores, para facilitar a convergência das simulações, conforme recomendado em Aspen Technology (2013g). Adicionalmente, foi considerado um fator de condição da reação (reaction condition factor) de 0,9 para o sistema com MEA e o valor padrão de 0,5 para as reações com MDEA e DEA; conforme sugerido pelo software em Aspen Technology (2013e, 2013f, 2013g), uma vez que este fator pondera a contribuição de condições de composição e temperatura no filme entre a interface e o seio da fase para que sejam aplicadas no cálculo taxa de reação, sendo o fator escolhido a ponderação para a condição do seio do líquido e a diferença entre 1 e este fator a ponderação para a condição da interface, de forma que para reações rápidas, como é o caso das reações com MEA, valores próximos de 1 são mais indicados (ASPEN TECHNOLOGY, 2013h). Para cada sistema foram indicadas também temperaturas no topo e no fundo da coluna, derivadas da simulação preliminar de um vaso flash com as correntes apresentadas, visando facilitar a convergência da simulação.

Nesses projetos foram configuradas colunas com os recheios estruturados Sulzer Mellapak $250 \mathrm{Y}^{T M}, 500 \mathrm{Y}^{T M}$ e $750 \mathrm{Y}^{T M}$, para uma avaliação inicial da limitação da absorção em relação à transferência de massa, cada uma com cinco seções de 0,5 m. Esta altura das seções foi ajustada posteriormente para um valor próximo da altura equivalente a um estágio teórico (HETP) calculado pelo software para cada seção. As correlações selecionadas para o cálculo dos coeficientes de transferência de massa, do holdup e dos coeficientes de transferência de calor foram: HanleyStruc (2010), Bravo et al. (1992) e Chilton e Colburn, respectivamente, as quais foram indicadas no item 4.2.1. O modo de fluxo definido nas simulações foi o VPlug e os pontos adicionais de discretização do filme são apresentados na 
Tabela 10. Estes pontos podem variar entre os valores de 0 a 1 , sendo que o primeiro indica uma região mais próxima da interface e o segundo uma região mais próxima do seio do líquido. O diâmetro foi indicado como um parâmetro de projeto a ser calculado pelo software para a obtenção de uma fração da capacidade máxima do recheio na última seção da coluna de aproximadamente 0,5 ; visando manter a operação da coluna dentro dos limites recomendados pelo fabricante do recheio e a possibilidade de aumentar a vazão de solvente posteriormente, se necessário.

Definidos o diâmetro e a altura das seções, o número de seções - e consequentemente a altura da coluna - foi variado para avaliar a influência deste nas porcentagens de absorção dos gases ácidos e também em um parâmetro definido como a relação entre a massa de $\mathrm{H}_{2} \mathrm{~S}$ e o volume de $\mathrm{CH}_{4}$, formulado para representar a especificação da ANP em relação ao $\mathrm{H}_{2} \mathrm{~S}$ (BRASIL, 2015) de uma forma rigorosa, uma vez que considera apenas o volume do $\mathrm{CH}_{4}$ no biogás purificado.

Tabela 10 - Pontos de discretização do filme de líquido

\begin{tabular}{c|c}
\hline Ponto adicional & Localização \\
\hline 1 & 0,01 \\
\hline 2 & 0,1 \\
\hline 3 & 0,2 \\
\hline 4 & 0,3 \\
\hline 5 & 0,4 \\
\hline 6 & 0,5 \\
\hline 7 & 0,6 \\
\hline 8 & 0,7 \\
\hline 9 & 0,8 \\
\hline 11 & 0,9 \\
\hline 12 & 0,99 \\
\hline
\end{tabular}

Fonte: Autor

As porcentagens de absorção dos gases ácidos são definidas nas equações (19) e (20), bem como na relação entre a massa de $\mathrm{H}_{2} \mathrm{~S}$ e o volume de $\mathrm{CH}_{4}$, indicada na equação (21).

$$
\begin{aligned}
& \% A b s_{C_{2}}=\frac{n_{C O_{2}, B G}-n_{C O_{2}, B M}}{n_{C O_{2}, B G}} \cdot 100 \\
& \% A b s_{H_{2} S}=\frac{n_{H_{2} S, B G}-n_{H_{2} S, B M}}{n_{H_{2} S, B G}} \cdot 100
\end{aligned}
$$


$\mathrm{H}_{2} \mathrm{~S} / \mathrm{CH}_{4}=\frac{m_{\mathrm{H}_{2} \mathrm{~S}}}{V_{\mathrm{CH}_{4}\left(25^{\circ} \mathrm{C}, 1 \mathrm{~atm}\right)}}$

onde $n_{C O_{2}, B G}$ e $n_{H_{2} S, B G}$ são os números de moles de $\mathrm{CO}_{2}$ e de $\mathrm{H}_{2} \mathrm{~S}$ no biogás, respectivamente; $n_{C_{2}, B M}$ e $n_{H_{2} S, B M}$ são os números de moles de $\mathrm{CO}_{2}$ e de $\mathrm{H}_{2} \mathrm{~S}$ no biometano, respectivamente; obtidos como resultados da simulação; $m_{H_{2} S}$ é a massa de $\mathrm{H}_{2} \mathrm{~S}$ presente no biometano, também obtida como resultado da simulação, e $V_{C_{4}\left(25^{\circ} \mathrm{C}, 1 \mathrm{~atm}\right)}$ o volume de $\mathrm{CH}_{4}$ presente na corrente do biogás nas condições de temperatura e pressão de $25^{\circ} \mathrm{C}$ e 1 atm, cujo cálculo é detalhado no Apêndice B.

Os resultados destas simulações são apresentados e discutidos no item 5.2. 


\subsubsection{Simulação da absorção seletiva dos gases ácidos}

Nas simulações conduzidas para simular os casos definidos no item 4.1 foram configuradas, além de colunas de absorção, colunas de dessorção, bem como operações auxiliares como trocadores de calor e misturadores de correntes de reposição.

No Caso 1 foram alimentadas, inicialmente, as correntes de biogás, conforme especificado na Tabela 8, e de solução aquosa de MDEA, conforme especificado na Tabela 9. Nos Casos 2 e 3 a corrente gasosa alimentada foi a de biogás com teor reduzido de enxofre obtida no Caso 1 e as correntes líquidas foram as de MEA e DEA apresentadas na Tabela 9 para os Casos 2 e 3, respectivamente.

Dentre as colunas configuradas no item 4.2.3.1, foi selecionada aquela que apresentou o melhor desempenho na absorção seletiva do $\mathrm{H}_{2} \mathrm{~S}$, para o Caso 1 , e as que apresentaram o melhor desempenho na absorção do $\mathrm{CO}_{2}$, para os Casos 2 e 3 de acordo com os resultados obtidos nas simulações do item indicado. O número de seções das colunas dos Casos 2 e 3 foi variado, uma vez que nestas simulações foi alimentada nova corrente gasosa em relação à do item 4.2.3.1, e em todos os casos estudados este número foi fixado no valor que fornecia a separação desejada: especificada como $10 \mathrm{mg}$ de $\mathrm{H}_{2} \mathrm{~S}$ por $\mathrm{m}^{3}$ de $\mathrm{CH}_{4}\left(25{ }^{\circ} \mathrm{C}, 1 \mathrm{~atm}\right)$, para o Caso 1, e no valor para além do qual não foi observada melhora significativa na absorção do $\mathrm{CO}_{2}$ nos Casos 2 e 3. O diâmetro destas colunas foi ajustado nos casos em que a fração da capacidade máxima do recheio era menor do que 0,5 . A influência da cinética e da condição de equilíbrio das reações na absorção dos gases ácidos foi estudada por meio da variação da temperatura de alimentação do solvente entre 35 e $50{ }^{\circ} \mathrm{C}$, sendo a temperatura de alimentação fixada naquela que melhor contribuía para a separação pretendida em cada caso estudado. A composição do solvente também foi avaliada: no Caso 1 a fração mássica de MDEA foi variada entre 0,30 e 0,40; nos Casos 2 e 3 as frações mássicas de MEA e de DEA foram variadas entre 0,20 e 0,30 . A pressão no topo da coluna foi fixada em 1,04 atm no Caso 1 e em 1,03 atm nos Casos 2 e 3.

A coluna de dessorção de cada caso estudado foi configurada de forma semelhante à sua respectiva coluna de absorção: adotando os mesmos modelos; correlações; tipo de recheio; diâmetro e número de seções, cuja altura foi alterada nos casos em que os HETP calculados pelo software eram consideravelmente diferentes da altura adotada inicialmente. No entanto, seu desempenho foi avaliado de acordo com as porcentagens de dessorção definidas nas equações (22) e (23). O número de seções foi variado e fixado no valor para além do qual não foi observada melhora significativa na dessorção do $\mathrm{H}_{2} \mathrm{~S}$, para o Caso 1 , e 
na dessorção do $\mathrm{CO}_{2}$, para os Casos 2 e 3. Além disso, foram considerados tanto um condensador parcial, cuja temperatura do destilado foi fixada em $35^{\circ} \mathrm{C}$, como um refervedor, os quais são modelados como estágios de equilíbrio, embora as seções intermediárias da coluna tenham sido modeladas no modo Rate-Based com as mesmas condições especificadas no item 4.2.3.1 para as colunas de absorção. A pressão no topo da coluna foi fixada em 1,03 atm em todos os casos; a razão molar entre destilado e alimentação foi fixada em 0,010 no Caso 1, 0,050 no Caso 2 e 0,032 no Caso 3, visando tanto limitar a quantidade de solvente que sai nas correntes de destilado com os gases ácidos dessorvidos como facilitar a recirculação do solvente sem prejudicar o balanço material devido ao acúmulo daquele; a razão molar de refluxo foi fixada em 1 em todos os casos estudados.

$$
\begin{gathered}
{ }_{0 D e S_{C O_{2}}}=\frac{n_{\mathrm{CO}_{2}, \mathrm{DG}}+n_{\mathrm{CO}_{2}, \mathrm{DL}}}{n_{\mathrm{CO}_{2}, \mathrm{SR}}} \cdot 100 \\
{ }_{0 \text { Des }_{\mathrm{H}_{2} \mathrm{~S}}}=\frac{n_{\mathrm{H}_{2} \mathrm{~S}, \mathrm{DG}}+n_{\mathrm{H}_{2} \mathrm{~S}, \mathrm{DL}}}{n_{\mathrm{H}_{2} S, S R}} \cdot 100
\end{gathered}
$$

onde $n_{C O_{2}, D G}$ e $n_{H_{2} S, D G}$ são os números de moles de $\mathrm{CO}_{2}$ e de $\mathrm{H}_{2} \mathrm{~S}$ no gás que deixa a coluna de dessorção, respectivamente; $n_{C O_{2}, D L}$ e $n_{H_{2} S, D L}$ são os números de moles aparentes de $\mathrm{CO}_{2} \mathrm{e}$ de $\mathrm{H}_{2} \mathrm{~S}$ no condensado líquido que deixa a coluna de dessorção, respectivamente, e $n_{\mathrm{CO}_{2}, \mathrm{SR}} \mathrm{e}$ $n_{\mathrm{H}_{2} S, S R}$ são os números de moles aparentes de $\mathrm{CO}_{2}$ e de $\mathrm{H}_{2} \mathrm{~S}$ no solvente rico em gases ácidos que sai da coluna de absorção, respectivamente, os quais são calculados pela propriedade FAPP que considera todas as formas que estes gases assumem ao reagir com o solvente.

Um trocador de calor foi adicionado à simulação de cada caso estudado para promover o aquecimento da corrente de solvente rico em gases ácidos que deixa a coluna de absorção para ser introduzida na coluna de dessorção com a corrente de solvente pobre que deixa a coluna de dessorção. No modelo utilizado, HeatX, aplicou-se a abordagem que determina a máxima troca térmica possível para uma diferença de temperatura que deve ser obtida entre as temperaturas das correntes de fluído quente e de fluído frio que deixam o trocador de calor. Esta diferença de temperatura deve ser especificada, bem como o coeficiente global de troca térmica. A diferença de temperatura especificada foi de $10{ }^{\circ} \mathrm{C}$ em todos os casos, como é recomendado por Smith (1995) e Kemp et al. (2007), e o coeficiente global de troca térmica adotado, considerado constante neste modelo simplificado, foi de $170 \mathrm{Btu} /\left({ }^{\circ} \mathrm{F} \cdot \mathrm{ft}^{2} \mathrm{~h}\right)$ para todos os casos estudados, que representa um valor médio para este parâmetro em trocadores 
tubulares que promovem a troca térmica entre soluções de alcanolaminas (MEA e DEA), de acordo com dados apresentados por Shilling et al. (2008).

A correção da temperatura da corrente de solvente pobre, para que atingisse a temperatura especificada para o solvente na alimentação da coluna de absorção, foi realizada em um segundo trocador de calor, onde a temperatura final foi especificada para cada caso. Adicionalmente, foi incluído um misturador para que a vazão molar do solvente pobre fosse reajustada por meio da reposição do solvente (amina e água) perdido nas operações de absorção e de dessorção.

Finalmente, a corrente de solvente pobre com a temperatura e a vazão molar corrigidas foi alimentada à coluna de absorção, substituindo a corrente inicial que não continha gases ácidos. Uma vez que a porcentagem de absorção dos gases ácidos é alterada com esta modificação, e a especificação não mais é atingida, uma nova corrente de solução aquosa de alcanolamina, sem gases ácidos, foi adicionada à coluna de absorção de cada caso de estudo e sua vazão molar foi variada para que a especificação proposta para cada caso fosse novamente atingida, em relação ao $\mathrm{H}_{2} \mathrm{~S}$ para o Caso 1 e para a obtenção de aproximadamente $99 \%$ de absorção do $\mathrm{CO}_{2}$ nos Casos 2 e 3. As operações seguintes foram recalculadas com a nova vazão molar de solvente e o reajuste desta foi repetido até que a corrente de reposição de solvente livre de gases ácidos fosse significativamente reduzida, quando o ciclo do solvente foi então fechado. Caso a nova corrente de reposição de solvente apresentasse um valor impraticável - muito maior do que a corrente de solvente original - o ciclo do solvente era fechado sem esta reposição e a razão molar de refluxo da coluna de dessorção era alterada até que a corrente pobre em gases ácidos apresentasse um teor destes tal que não prejudicasse as especificações estabelecidas para cada caso estudado. Quando necessário, também o diâmetro das colunas foi alterado para permitir uma operação estável destas com a alteração da vazão de solvente.

O desempenho das colunas de dessorção também foi avaliado em relação à demanda energética percentual e à energia específica requerida, assim que o ciclo do solvente foi fechado. O primeiro parâmetro é definido como a porcentagem da energia disponível no biogás, considerando a energia obtida pelo produto do poder calorífico inferior do $\mathrm{CH}_{4}$ e a massa deste componente, que é requerida na dessorção, como indicado na equação (24). O segundo parâmetro é definido como a relação entre a quantidade de energia requerida para a dessorção dos gases ácidos e a quantidade em massa de gás ácido dessorvido, como é indicado nas equações (25) e (26), sendo a primeira em relação ao $\mathrm{H}_{2} \mathrm{~S}$ para utilização no Caso 1 e a segunda em relação ao $\mathrm{CO}_{2}$, utilizada nos Casos 2 e 3. 


$$
Q_{\%}=\frac{Q_{R}}{P C I \cdot m_{C_{4}}} \cdot 100
$$

$$
Q_{e s p, \mathrm{CO}_{2}}=\frac{Q_{R}}{m_{C O_{2}, D G}+m_{\mathrm{CO}_{2}, \mathrm{DL}}}
$$

$$
Q_{e s p, H_{2} S}=\frac{Q_{R}}{m_{H_{2} S, D G}+m_{H_{2} S, D L}}
$$

onde $Q_{R}$ é a energia requerida para a dessorção dos gases ácidos; PCI é o poder calorífico inferior do $\mathrm{CH}_{4} ; m_{\mathrm{CH}_{4}}$ é a massa de metano presente na corrente de biogás; $m_{C O_{2}, D G}$ e $m_{H_{2} S, D G}$ são as massas de $\mathrm{CO}_{2}$ e de $\mathrm{H}_{2} \mathrm{~S}$ no gás que deixa a coluna de dessorção, respectivamente, e $m_{C_{2}, D L}$ e $m_{H_{2} S, D L}$ são as massas aparentes de $\mathrm{CO}_{2}$ e de $\mathrm{H}_{2} \mathrm{~S}$ no condensado líquido que deixa a coluna de dessorção, respectivamente, as quais são calculadas pela propriedade WAPP que considera todas as formas que estes gases assumem ao reagir com o solvente.

$\mathrm{Na}$ figura 10 é apresentado um esquema geral dos sistemas configurados para simular os Casos 1, 2 e 3 com o ciclo de solvente fechado. Neste esquema, ABS é a coluna de absorção onde são introduzidas as correntes de solvente pobre em gases ácidos (SP-1) e a corrente de gás rica nestes gases (GR); TC-1 é o trocador de calor que promove o aquecimento da corrente de solvente rico em gases ácidos que deixa a coluna de absorção (SR-1) para ser introduzida na coluna de dessorção (SR-2) com a corrente de solvente pobre que deixa a coluna de dessorção (SP-2) que é resfriada (SP-3); DES é a coluna de dessorção onde os gases ácidos são dessorvidos nas correntes de destilado gasosa (GA) e líquida (COND); TC-2 é o trocador de calor onde a temperatura da corrente de solvente pobre SP-3 é ajustada para que atinja a temperatura especificada para o solvente na alimentação da coluna de absorção, obtendo-se a corrente SP-4; MIX é o misturador onde são alimentadas as correntes de reposição de solvente: água (H2O-R) e amina (AM-R), juntamente com o solvente pobre SP-4. O biogás com teor de $\mathrm{H}_{2} \mathrm{~S}$ reduzido, no Caso 1, ou o biometano, nos Casos 2 e 3 são representados pela corrente GP.

No Caso 2, o esquema apresentado na Figura 10 foi alterado com a inclusão de um vaso flash com temperatura fixada em $35^{\circ} \mathrm{C}$ alimentado pela corrente $\mathrm{GR}$, uma vez que no sistema com MEA a perda de solvente é mais pronunciada, tendo em vista que esta amina apresenta pressão de vapor mais elevada do que as demais consideradas nestes estudos, 
conforme pode ser observado na Tabela 3. Desta forma, promoveu-se uma separação de parte do solvente que seria perdida na corrente gasosa (GR) utilizando o vaso flash mencionado, sendo esta fração líquida recuperada alimentada ao misturador (MIX) para compor a corrente de solvente pobre (SP-1) que entra na coluna de absorção (ABS).

Figura 10 - Esquema geral dos sistemas dos Casos de estudo 1, 2 e 3

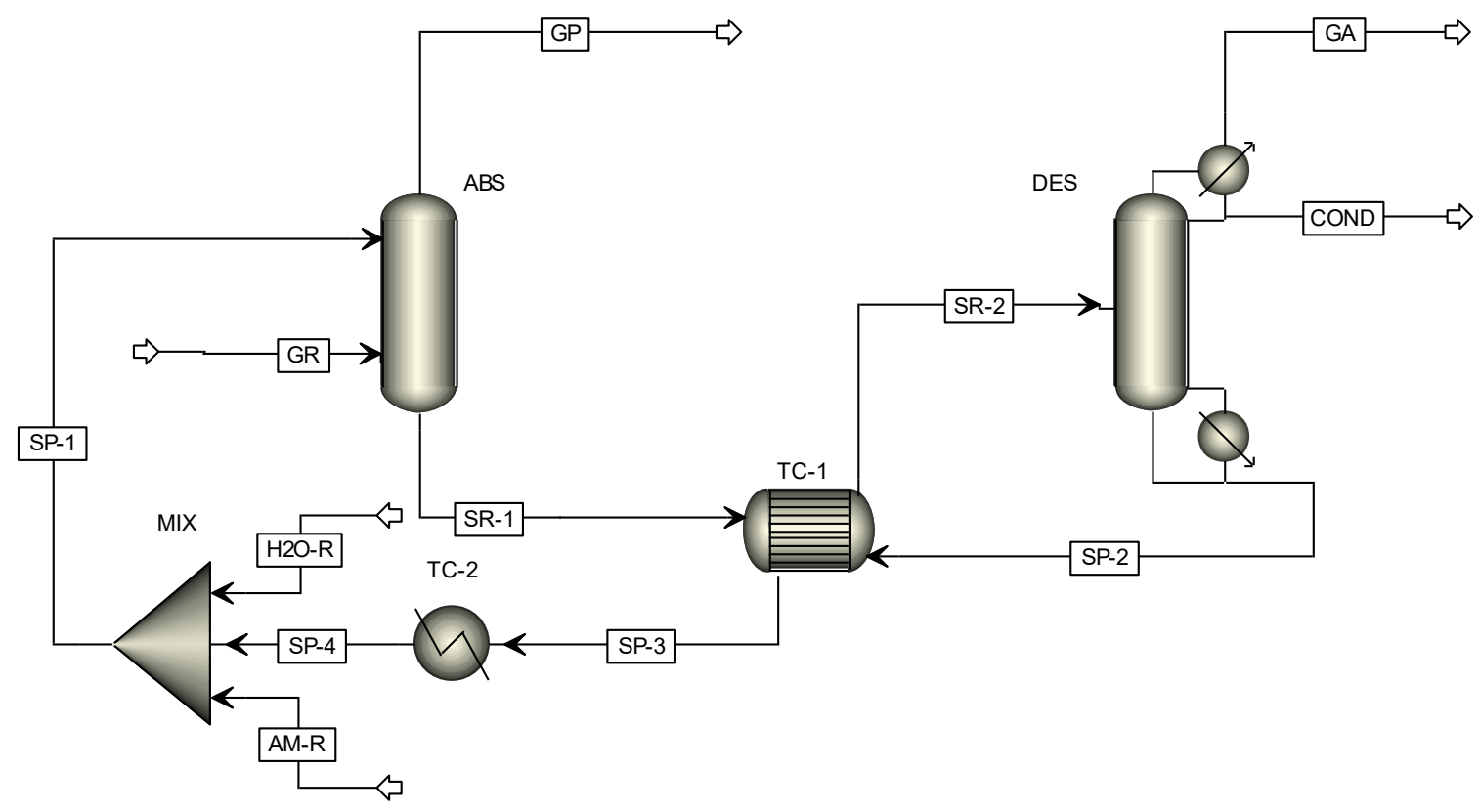

Fonte: Autor

Os resultados obtidos nestas simulações são apresentados e discutidos no item 5.3.

\subsubsection{Simulação dos estudos de casos experimentais obtidos na literatura}

Nas simulações conduzidas para reproduzir os resultados de estudos experimentais disponíveis na literatura foram considerados os experimentos 1 e 2 (E1 e E2) apresentados por Notz, Mangalapally e Hasse (2012). As simulações destes estudos experimentais objetivam validar a modelagem proposta para os estudos teóricos do presente trabalho, apresentada nos itens 4.2.1 e 4.2.2, utilizando procedimentos semelhantes aos descritos nos itens 4.2.3.1 e 4.2.3.2.

Segundo Notz, Mangalapally e Hasse (2012), os experimentos E1 e E2 foram realizados em uma planta piloto destinada à absorção do $\mathrm{CO}_{2}$ de uma corrente de gases de pós-combustão, produzida por um queimador de gás comercial projetado para o aquecimento de residências, com solução aquosa de MEA. Em seu trabalho, a planta é descrita 
detalhadamente, no presente trabalho é focada a descrição das colunas de absorção e de dessorção simuladas a fim de validar o modelo utilizado nos estudos aqui propostos.

De acordo com Notz, Mangalapally e Hasse (2012), a coluna de absorção possui uma altura de 4,2 m à qual é acoplada, no topo, uma seção de lavagem de 0,42 m; ambas com diâmetro de $0,125 \mathrm{~m}$ e recheio estruturado Sulzer Mellapak $250 \mathrm{Y}^{T M}$. Nesta coluna, o solvente pobre em $\mathrm{CO}_{2}$ é alimentado no topo da primeira seção descrita e a água de lavagem no topo da segunda seção para a recuperação de parte do solvente que é carregado com o gás pobre em $\mathrm{CO}_{2}$; parte desta água de lavagem é retirada da coluna de absorção por uma saída no fundo da seção de lavagem a fim de evitar o acúmulo de água no sistema. A coluna de dessorção desta planta possui uma altura de 2,52 m à qual também é acoplada, no topo, a uma seção de lavagem de 0,42 m; ambas com diâmetro de 0,125 m e recheio estruturado Sulzer Mellapak $250 \mathrm{Y}^{T M}$. Nesta coluna, o solvente rico em $\mathrm{CO}_{2}$ é alimentado no topo da primeira seção descrita, no entanto, diferente da coluna de absorção, a seção de lavagem da coluna de dessorção é alimentada pela fração líquida de refluxo de destilado que é condensado no topo desta seção em um trocador de calor. O fornecimento de energia para a geração de vapor de stripping é promovido pelo aquecimento do solvente que flui do topo para o fundo desta coluna por elementos elétricos.

As colunas descritas foram simuladas de forma isolada no software Aspen Plus ${ }^{\circledR}$ seguindo os procedimentos adotados nos itens 4.2.3.1 e 4.2.3.3 em relação: à divisão da altura das colunas em seções, aos modelos das colunas, às correlações adotadas, às discretizações aplicadas e ao condicionamento das reações. Os dados de processo alimentados na simulação, obtidos no trabalho de Notz, Mangalapally e Hasse (2012), são apresentados na Tabela 11. Para a corrente de solvente alimentada à coluna de dessorção, a vazão e a composição correspondem às indicadas na saída da coluna de absorção, uma vez que estes parâmetros não foram especificados na entrada da coluna de dessorção no esquema detalhado de cada experimento apresentado pelos autores, enquanto a temperatura desta corrente corresponde à especificada na entrada da coluna de dessorção, após o solvente rico ter sido previamente aquecido em um trocador de calor. 
Tabela 11 - Dados dos processos dos estudos de casos E1 e E2

\begin{tabular}{|c|c|c|c|c|}
\hline Operação & $\begin{array}{r}\text { Parâmetro } \\
\end{array}$ & Unidade & E1 & E2 \\
\hline \multirow{18}{*}{ Absorção } & Temperatura do gás & ${ }^{\circ} \mathrm{C}$ & 48,1 & 48,15 \\
\hline & Pressão do gás & mbar & 1004,49 & 1009,66 \\
\hline & Vazão mássica do gás & $\mathrm{kg} / \mathrm{h}$ & 72 & 72,4 \\
\hline & Composição do gás & & & \\
\hline & Nitrogênio $\left(\mathrm{N}_{2}\right)$ & $\mathrm{g} / \mathrm{g}$ & 0,743 & 0,672 \\
\hline & Oxigênio $\left(\mathrm{O}_{2}\right)$ & $\mathrm{g} / \mathrm{g}$ & 0,101 & 0,094 \\
\hline & Água $\left(\mathrm{H}_{2} \mathrm{O}\right)$ & $\mathrm{g} / \mathrm{g}$ & 0,071 & 0,069 \\
\hline & Dióxido de carbono $\left(\mathrm{CO}_{2}\right)$ & $\mathrm{g} / \mathrm{g}$ & 0,085 & 0,165 \\
\hline & Temperatura do solvente & ${ }^{\circ} \mathrm{C}$ & 40,03 & 40,18 \\
\hline & Vazão mássica do solvente & $\mathrm{kg} / \mathrm{h}$ & 200,1 & 200,0 \\
\hline & Composição do solvente & & & \\
\hline & Água $\left(\mathrm{H}_{2} \mathrm{O}\right)$ & $\mathrm{g} / \mathrm{g}$ & 0,673 & 0,653 \\
\hline & Amina (MEA) & $\mathrm{g} / \mathrm{g}$ & 0,275 & 0,284 \\
\hline & Dióxido de carbono $\left(\mathrm{CO}_{2}\right)$ & $\mathrm{g} / \mathrm{g}$ & 0,052 & 0,063 \\
\hline & Temperatura de entrada da água de lavagem & ${ }^{\circ} \mathrm{C}$ & 47,87 & 37,43 \\
\hline & Vazão mássica de entrada da água de lavagem & $\mathrm{kg} / \mathrm{h}$ & 30,87 & 55,06 \\
\hline & Vazão mássica de saída da água de lavagem & $\mathrm{kg} / \mathrm{h}$ & 28,53 & 53,29 \\
\hline & Pressão de operação da coluna & atm & $\sim 1$ & $\sim 1$ \\
\hline \multirow{10}{*}{ Dessorção } & Temperatura do solvente & ${ }^{\circ} \mathrm{C}$ & 112,85 & 108,56 \\
\hline & Vazão mássica do solvente & $\mathrm{kg} / \mathrm{h}$ & 206,5 & 207,4 \\
\hline & Composição do solvente & & & \\
\hline & Água $\left(\mathrm{H}_{2} \mathrm{O}\right)$ & $\mathrm{g} / \mathrm{g}$ & 0,661 & 0,634 \\
\hline & Amina (MEA) & $\mathrm{g} / \mathrm{g}$ & 0,265 & 0,274 \\
\hline & Dióxido de carbono $\left(\mathrm{CO}_{2}\right)$ & $\mathrm{g} / \mathrm{g}$ & 0,074 & 0,092 \\
\hline & Vazão total de destilado & $\mathrm{kg} / \mathrm{h}$ & 6,71 & 7,55 \\
\hline & Temperatura do destilado & ${ }^{\circ} \mathrm{C}$ & 18,33 & 18,33 \\
\hline & Carga térmica no refervedor & $\mathrm{W}$ & 6475,3 & 6758,8 \\
\hline & Pressão de operação da coluna & mbar & 1999,1 & 1999,5 \\
\hline
\end{tabular}

Fonte: Notz, Mangalapally e Hasse, 2012

O desempenho das colunas de absorção e de dessorção dos casos experimentais descritos foram avaliados, tanto pelos autores do trabalho experimental como no presente trabalho teórico, em relação à porcentagem de absorção de $\mathrm{CO}_{2}$ e em relação à energia específica requerida para dessorção do $\mathrm{CO}_{2}$, respectivamente, calculados a partir das equações (19) e (25). No entanto, na equação (19) o número de moles de $\mathrm{CO}_{2}$ no biogás $\left(n_{\mathrm{CO}_{2}, B G}\right)$ corresponde ao número de moles de $\mathrm{CO}_{2}$ no gás de combustão e o número de moles de $\mathrm{CO}_{2}$ no biometano $\left(n_{\mathrm{CO}_{2}, \mathrm{BM}}\right)$ corresponde ao número de moles de $\mathrm{CO}_{2}$ no gás de combustão purificado. A porcentagem de absorção e a energia específica requerida para a dessorção do $\mathrm{CO}_{2}$ que foram obtidas nos experimentos conduzidos por Notz, Mangalapally e Hasse (2012) são apresentadas na Tabela 12. 
Tabela 12 - Porcentagem de absorção e energia específica dos casos E1 e E2

\begin{tabular}{l|c|c|c}
\hline \multicolumn{1}{c|}{ Parâmetro } & Unidade & E1 & E2 \\
\hline$\%$ Abs & $\%$ & 75,9 & 51,3 \\
\hline $\mathrm{Q}_{\mathrm{esp}}$ & $\mathrm{GJ} / \mathrm{t}$ & 5,01 & 3,98 \\
\hline
\end{tabular}

Fonte: Notz, Mangalapally e Hasse, 2012

Os autores indicaram em seu trabalho que o parâmetro que avalia o consumo energético na operação de dessorção, apresentado neste trabalho, não considera as perdas de calor que ocorrem na planta piloto, uma vez que foram aplicados balanços energéticos para a estimativa das perdas de calor, as quais foram subtraídas dos valores obtidos na planta.

Os resultados obtidos nestas simulações são apresentados e discutidos no item 5.1. 


\section{RESULTADOS}

Nesta seção são apresentados e discutidos os resultados obtidos, primeiramente, na simulação dos estudos de casos experimentais da literatura apresentados no item 4.2.3.3, seguidos pelos resultados das simulações indicadas no item 4.2.3.1 e então pelos resultados obtidos nos estudos de casos detalhados no item 4.2.3.2.

\subsection{RESULTADOS DAS SIMULAÇÕES DOS ESTUDOS DE CASOS EXPERIMENTAIS}

Os resultados obtidos nos estudos de casos experimentais conduzidos por Notz, Mangalapally e Hasse (2012), E1 e E2, são apresentados nas Figuras 11 (a) e 11 (b), para a porcentagem de absorção e para a energia específica requerida para a dessorção do $\mathrm{CO}_{2}$, respectivamente, onde são comparados com os resultados obtidos nas simulações realizadas neste trabalho para validar a modelagem utilizada. As linhas tracejadas delimitam desvios de $\pm 15 \%$ em relação ao valor experimental na Figura 11 (a) e de $\pm 25 \%$ na Figura 11 (b).

Figura 11 - Comparação entre os resultados experimentais e simulados dos casos E1 e E2

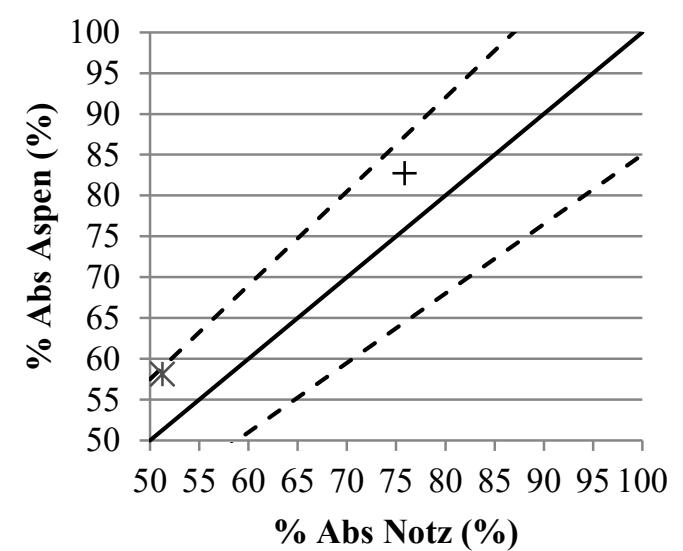

(a)

$+\mathrm{E} 1$ *E 2

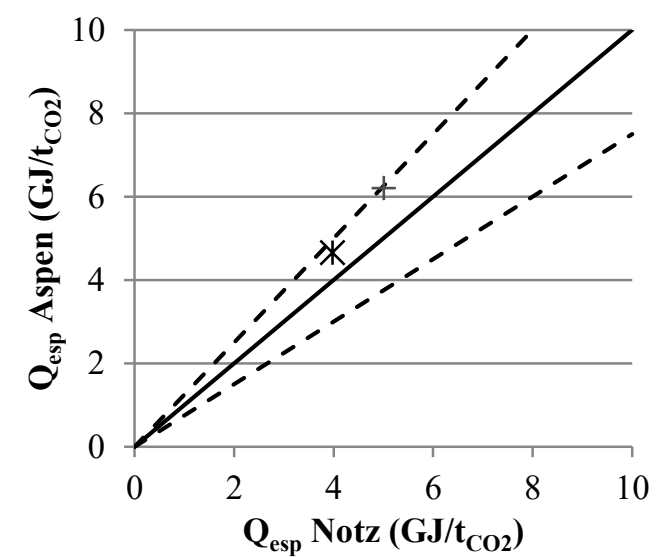

(b)

$+\mathrm{E} 1$ *E 2

Fonte: Autor

Legenda: (a) Comparação entre os resultados obtidos para a porcentagem de absorção (b) Comparação entre os resultados obtidos para a energia específica requerida para a dessorção do $\mathrm{CO}_{2}$.

Em todos os resultados obtidos nas simulações os valores obtidos para os parâmetros avaliados foram superestimados em relação àqueles obtidos experimentalmente por Notz, Mangalapally e Hasse (2012), como se pode observar nas Figuras 11 (a) e 11 (b), onde os desvios para a porcentagem de absorção são de até 15\% e os desvios para a energia específica 
são de até $25 \%$. Estes desvios dos resultados obtidos nas simulações em relação aos obtidos experimentalmente foram considerados aceitáveis, levando-se em conta que os resultados das simulações contam com os desvios resultantes da utilização de correlações empíricas para o cálculo dos coeficientes de transferência de massa e de calor; além disso, os resultados experimentais também apresentam seus próprios desvios intrínsecos resultantes tanto da operação da planta, como dos equipamentos de medição das variáveis monitoradas.

\subsection{RESULTADOS DAS SIMULAÇÕES DE ABSORÇÃO SIMULTÂNEA}

As colunas de absorção configuradas para a comparação do desempenho das soluções aquosas de alcanolaminas apresentaram resultados semelhantes em termos do diâmetro da coluna, para a obtenção de uma capacidade máxima do recheio de 0,5 , e da altura das seções, para valores próximos dos HETP calculados pelo software, quando utilizado o mesmo tipo de recheio. Desta forma, em todos os sistemas a coluna de absorção foi configurada com o mesmo diâmetro (mesmo quando a capacidade máxima do recheio era um pouco inferior a 0,5, uma vez que com o aumento do número de seções tanto esta capacidade como a perda de carga na coluna aumentavam gradativamente) e altura de seção para determinado tipo de recheio, como é apresentado na Tabela 13.

Tabela 13 - Diâmetro da coluna e altura de seção das colunas de absorção simultânea

\begin{tabular}{|c|c|c|c|}
\hline Sistema & Recheio & Diâmetro (m) & $\mathbf{h}_{\mathrm{p}}(\mathbf{m})$ \\
\hline MDEA/MEA/DEA & Sulzer Mellapak $250 \mathrm{Y}^{T M}$ & 0,65 & 0,40 \\
\hline MDEA/MEA/DEA & Sulzer Mellapak $500 \mathrm{Y}^{T M}$ & 0,75 & 0,25 \\
\hline MDEA/MEA/DEA & Sulzer Mellapak $750 \mathrm{Y}^{T M}$ & 0,80 & 0,20 \\
\hline
\end{tabular}

Fonte: Autor

O número de seções foi variado de 5 a 25 para comparar o desempenho das soluções de alcanolaminas em relação à porcentagem de absorção de $\mathrm{CO}_{2}$, à porcentagem de absorção de $\mathrm{H}_{2} \mathrm{~S}$ e ao parâmetro definido como a relação entre a massa de $\mathrm{H}_{2} \mathrm{~S}$ e o volume de $\mathrm{CH}_{4} \mathrm{e}$ os resultados obtidos são apresentados nas Figuras 12 (a), (b) e (c); 13 (a), (b) e (c) e 14 (a), (b) e (c); respectivamente.

A partir dos resultados mostrados nas Figuras 12 (a), (b) e (c), observou-se que o sistema que emprega solução aquosa de MEA apresentou o melhor desempenho em relação à absorção de $\mathrm{CO}_{2}$, uma vez que necessita de uma altura de coluna menor para a obtenção de uma porcentagem de absorção superior àquelas obtidas em qualquer outro sistema, enquanto o sistema que utiliza solução aquosa de MDEA apresentou o pior desempenho entre os sistemas 
estudados e, desta forma, o sistema com DEA apresentou um comportamento intermediário entre aqueles. Estas observações corroboram com aquelas obtidas na literatura que apontam para uma absorção mais rápida com a MEA, seguida pela DEA e então pela MDEA. Adicionalmente, observou-se que a transferência de massa desempenha um papel significativo na absorção do $\mathrm{CO}_{2}$ em todos os sistemas estudados, de forma que quanto maior a área superficial disponível para esta transferência, melhor é o resultado em termos da porcentagem de absorção para determinada altura de coluna.

Figura 12 - Porcentagem de absorção de $\mathrm{CO}_{2}$ em função da altura da coluna

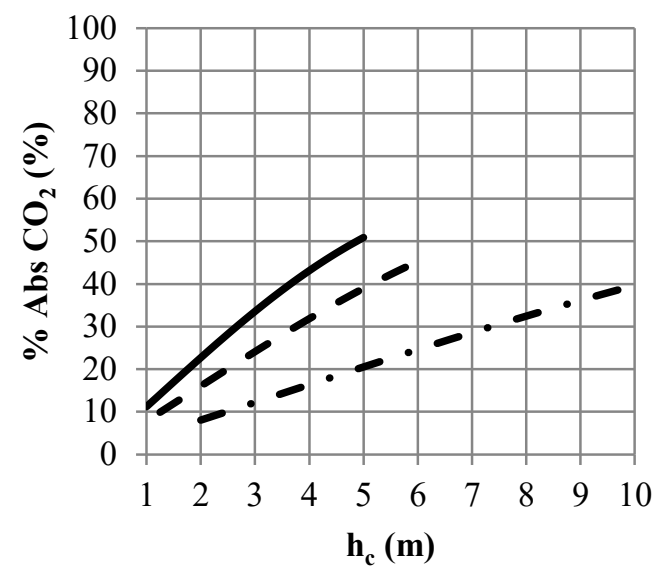

(a)

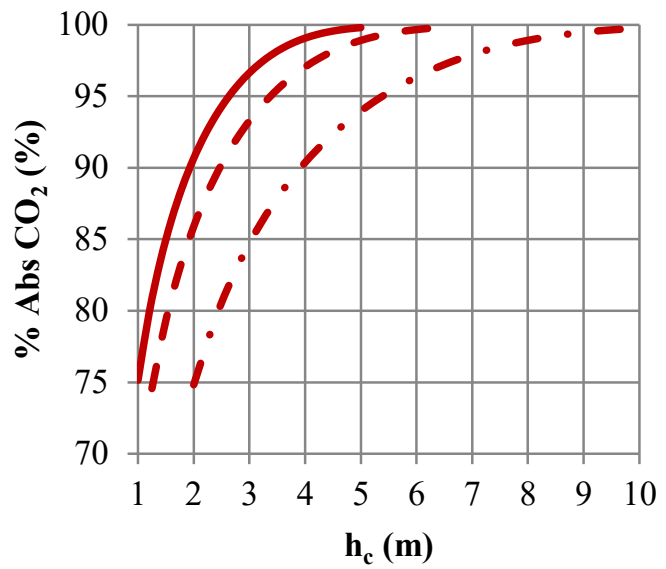

(b)

$-.250 . Y-500 . Y-750 . Y$

$-\cdot 250 . \mathrm{Y}$

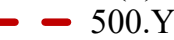
$750 . \mathrm{Y}$

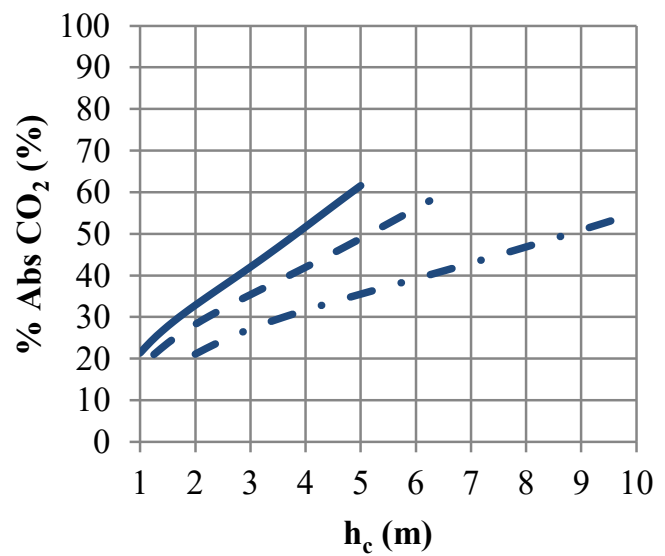

(c)

$-\cdot 250 . \mathrm{Y}-\mathrm{-} 500 . \mathrm{Y} \longrightarrow 750 . \mathrm{Y}$

Fonte: Autor

Legenda: (a) Resultados obtidos para a absorção de gases ácidos com MDEA. (b) Resultados obtidos para a absorção de gases ácidos com MEA. (c) Resultados obtidos para a absorção de gases ácidos com DEA

Com base nos resultados apresentados nas Figuras 13 (a), (b) e (c) observou-se que o sistema com solução aquosa de MDEA apresentou o melhor desempenho em relação à 
absorção do $\mathrm{H}_{2} \mathrm{~S}$ quando comparado com aqueles que empregavam MEA ou DEA, uma vez que para a obtenção de uma dada porcentagem de absorção deste gás, a altura de recheio da coluna necessária para atingir tal especificação se mostrou menor para o sistema com MDEA do que para os demais sistemas.

Figura 13 - Porcentagem de absorção de $\mathrm{H}_{2} \mathrm{~S}$ em função da altura da coluna

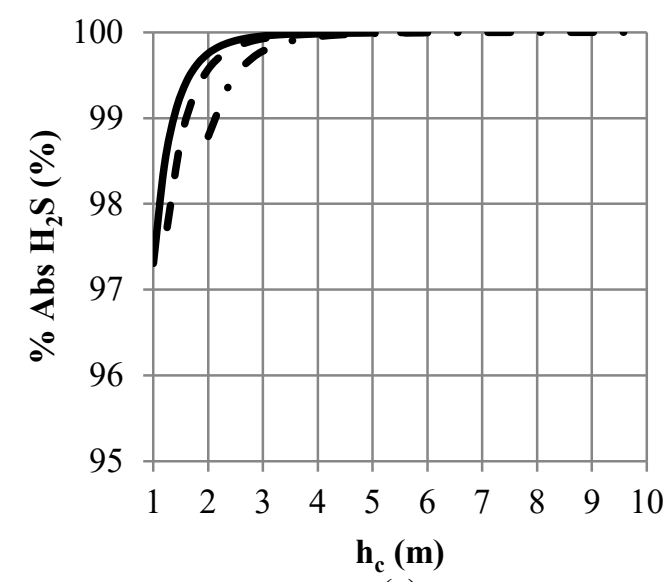

(a)

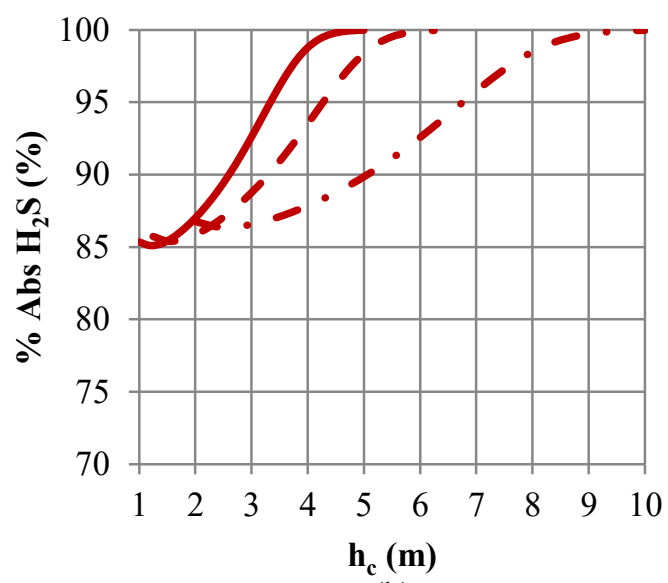

(b)

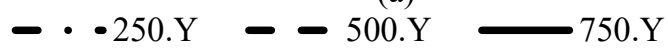

$-\cdot 250 . \mathrm{Y}-200 . \mathrm{Y}$ $750 . Y$

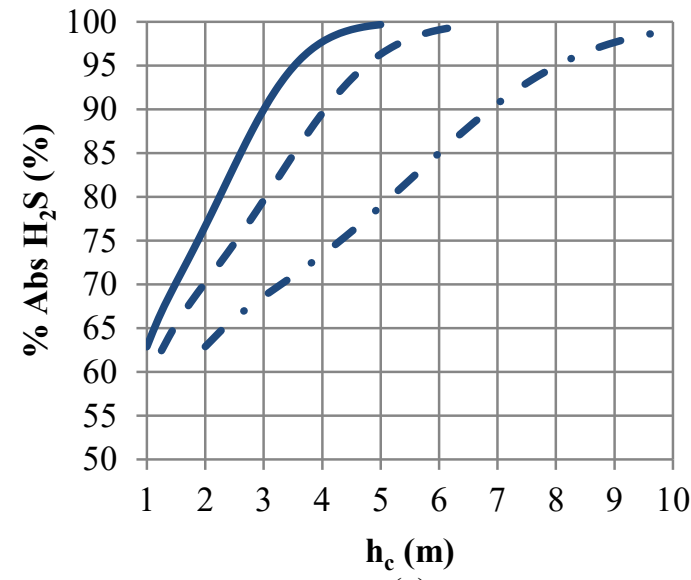

(c)

$-\cdot 250 . \mathrm{Y}-200 . \mathrm{Y}$ 750.Y

Fonte: Autor

Legenda: (a) Resultados obtidos para a absorção de gases ácidos com MDEA. (b) Resultados obtidos para a absorção de gases ácidos com MEA. (c) Resultados obtidos para a absorção de gases ácidos com DEA

Considerando ainda o baixo desempenho do sistema com solução aquosa de MDEA para a remoção do $\mathrm{CO}_{2}$, como foi observado a partir dos resultados da Figura 12 (a), constatou-se a adequação da MDEA para a absorção seletiva do $\mathrm{H}_{2} \mathrm{~S}$, como era esperado segundo as observações obtidas na literatura. Em relação à transferência de massa, observouse, de acordo com os resultados apresentados nas Figuras 13 (a), (b) e (c), que o aumento da 
área superficial disponível para esta transferência contribui com o aumento da porcentagem de absorção do gás ácido, neste caso o $\mathrm{H}_{2} \mathrm{~S}$, sobretudo nos sistemas que empregam MEA e DEA, uma vez que no sistema que utiliza MDEA este aumento na porcentagem de absorção com o aumento da área superficial foi menos significativo.

Figura 14 - Relação $\mathrm{H}_{2} \mathrm{~S} / \mathrm{CH}_{4}$ em função da altura da coluna

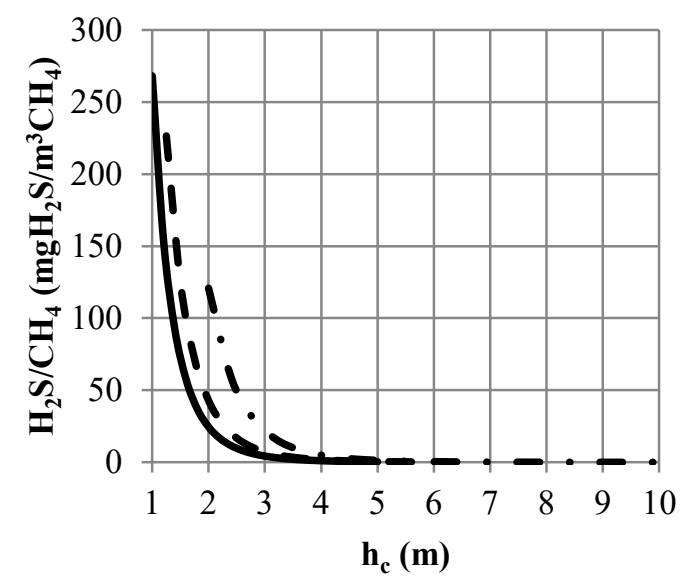

$-\cdot 250 . Y-500 . Y-750 . Y$

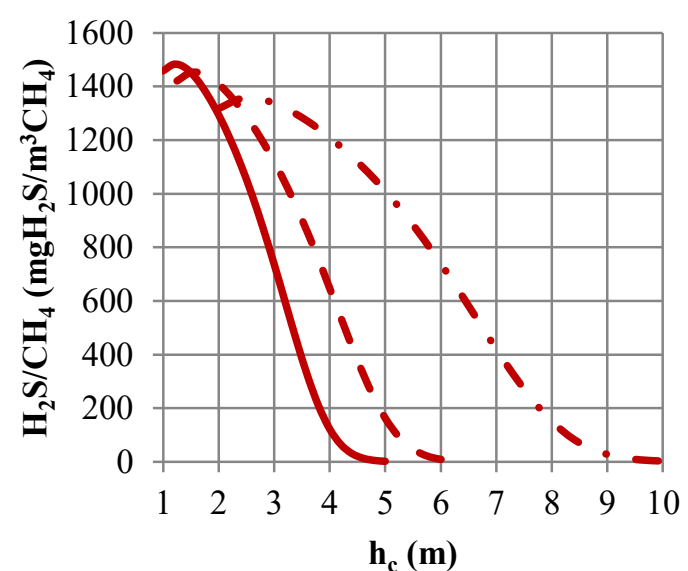

(b)
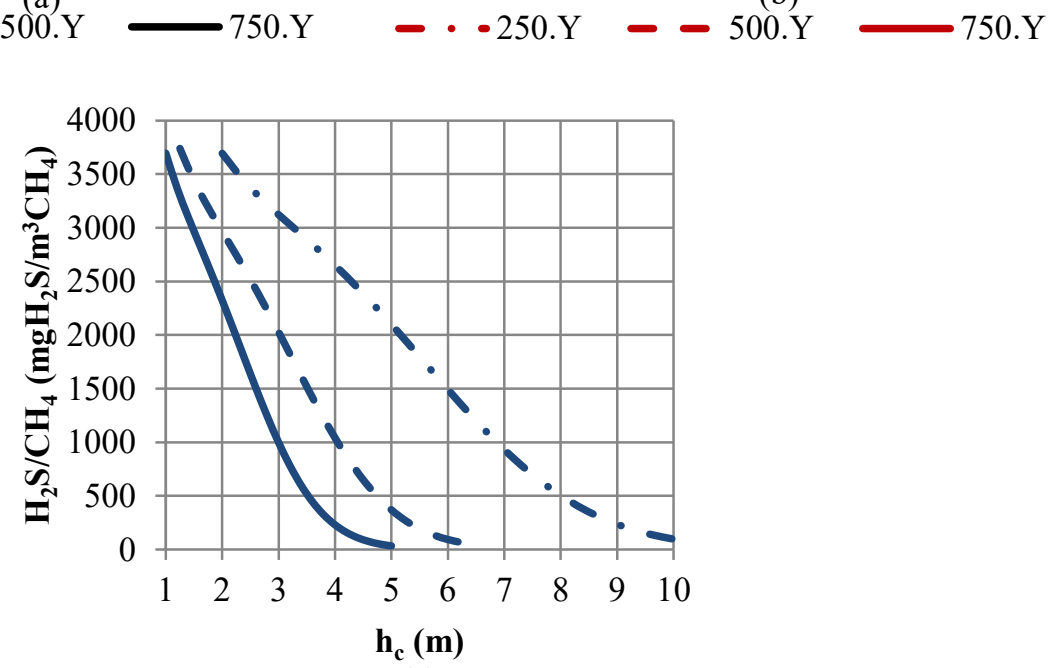

$-\cdot 250 . \mathrm{Y}-500 . \mathrm{Y}$

$750 . Y$

Fonte: Autor

Legenda: (a) Resultados obtidos para a absorção de gases ácidos com MDEA. (b) Resultados obtidos para a absorção de gases ácidos com MEA. (c) Resultados obtidos para a absorção de gases ácidos com DEA

A partir dos resultados apresentados nas Figuras 14 (a), (b) e (c) observou-se que o sistema que apresentou o melhor desempenho em relação ao parâmetro $\mathrm{H}_{2} \mathrm{~S} / \mathrm{CH}_{4}$ foi o que emprega a solução aquosa de MDEA, como era esperado de acordo com os resultados apresentados nas Figuras 13 (a), (b) e (c). Desta forma, as mesmas observações feitas para a avaliação do desempenho em relação à porcentagem de absorção de $\mathrm{H}_{2} \mathrm{~S}$ são válidas em relação ao parâmetro definido como a relação entre a massa de $\mathrm{H}_{2} \mathrm{~S}$ e o volume de $\mathrm{CH}_{4}$, que 
corroboram com a proposta de absorção seletiva do $\mathrm{H}_{2} \mathrm{~S}$ com MDEA e absorção do $\mathrm{CO}_{2}$ com MEA e DEA.

Os resultados obtidos nestas simulações auxiliaram na seleção da configuração das colunas de absorção dos casos definidos no item 4.2.3.2, cujos resultados são apresentados na sequência deste trabalho.

\subsection{RESULTADOS DA SIMULAÇÃO DE ABSORÇÃO SELETIVA}

Neste item serão apresentados os resultados obtidos para as simulações descritas no item 4.2.3.2.

\subsubsection{Resultados do Caso 1}

A partir dos resultados apresentados no item 5.3.1 foi selecionada, para a absorção seletiva do $\mathrm{H}_{2} \mathrm{~S}$ com solução aquosa de MDEA, a coluna com recheio estruturado Sulzer Mellapak $250 \mathrm{Y}^{T M}$.

A altura total de recheio foi fixada em 3,6 m, uma vez que com esta altura a especificação para a relação entre a massa de $\mathrm{H}_{2} \mathrm{~S}$ e o volume de $\mathrm{CH}_{4}$ foi atingida, como pode ser observado na Figura 15.

Figura 15 - Relação $\mathrm{H}_{2} \mathrm{~S} / \mathrm{CH}_{4}$ em função da altura da coluna para o Caso 1

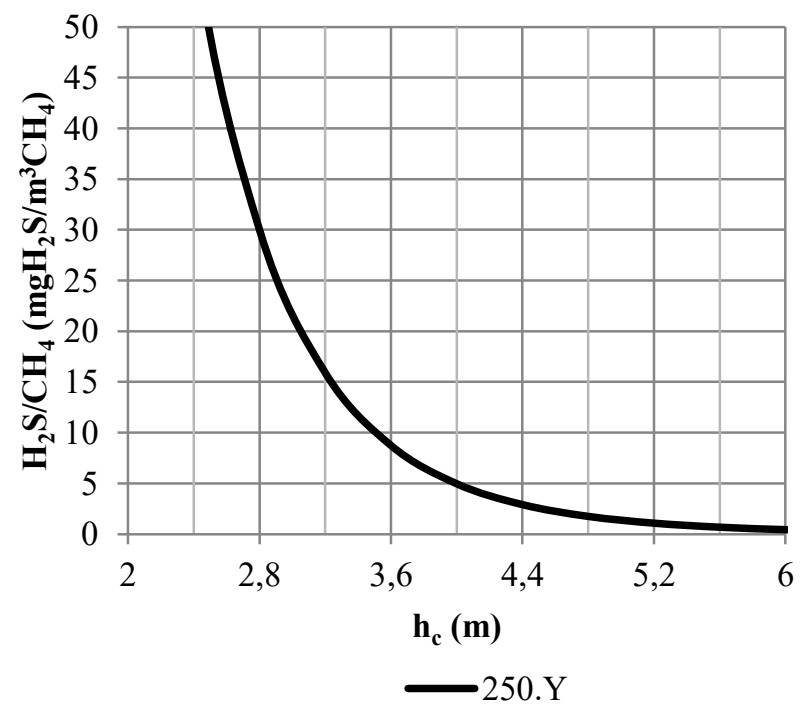

Fonte: Autor 
Nesta coluna, a fração da capacidade máxima do recheio era inferior a 0,5 , de forma que seu diâmetro foi ajustado de $0,65 \mathrm{~m}$ para $0,6 \mathrm{~m}$ a fim de obter uma capacidade máxima do recheio de 0,5 e dar prosseguimento ao estudo da influência de outros parâmetros neste sistema.

Um dos parâmetros estudados foi a temperatura do solvente e sua influência na absorção dos gases ácidos, que indicaria tanto limitações cinéticas, no caso da absorção do $\mathrm{CO}_{2}$, como um possível deslocamento do equilíbrio químico, no caso da absorção do $\mathrm{H}_{2} \mathrm{~S}$. Os resultados obtidos são apresentados na Figura 16.

Figura 16 - Influência da temperatura do solvente na absorção dos gases ácidos: Caso 1

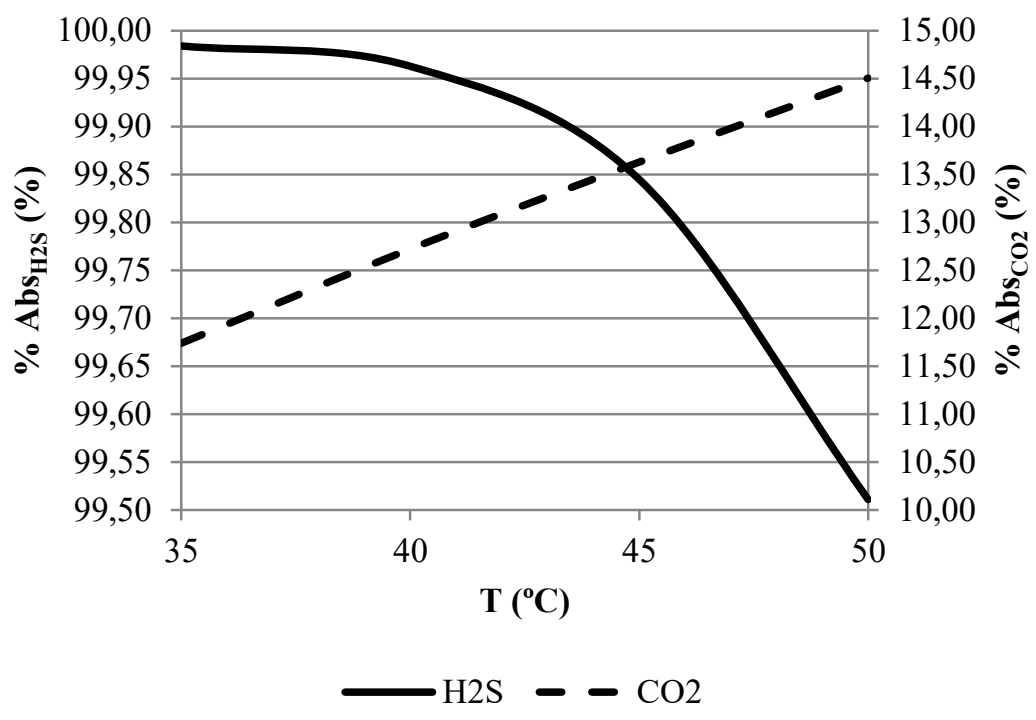

Fonte: Autor

A partir dos resultados apresentados na Figura 16, verificou-se que com o aumento da temperatura a porcentagem de absorção do $\mathrm{CO}_{2}$ aumenta enquanto a do $\mathrm{H}_{2} \mathrm{~S}$ diminui, o que indica que há um favorecimento da cinética da reação do primeiro com a solução de MDEA e um deslocamento do equilíbrio da reação do segundo com a solução da alcanolmina no sentido de formação dos reagentes. Embora o deslocamento mencionado seja pouco significativo, a temperatura do solvente foi mantida em $35^{\circ} \mathrm{C}$ a fim de se obter uma maior seletividade ao $\mathrm{H}_{2} \mathrm{~S}$.

Na sequência, foi estudada a influência da composição do solvente, variando a fração mássica de MDEA na solução, mas mantendo a vazão molar de solvente constante. Os resultados obtidos são apresentados na Figura 17.

A partir dos resultados observados na Figura 17, verificou-se que o emprego de soluções de MDEA com concentrações menores beneficiaram a absorção do $\mathrm{H}_{2} \mathrm{~S}$, mas 
causaram um efeito inverso em relação à absorção do $\mathrm{CO}_{2}$. Este comportamento pode ser explicado pelo desfavorecimento da cinética das reações com o $\mathrm{CO}_{2}$, o que pode propiciar um deslocamento das reações de equilíbrio com $\mathrm{H}_{2} \mathrm{~S}$ no sentido de formação dos produtos, e assim, favorecer a absorção do $\mathrm{H}_{2} \mathrm{~S}$. Desta forma, a composição do solvente foi alterada para uma fração de 0,3 em massa de MDEA.

Figura 17 - Influência da composição do solvente na absorção dos gases ácidos: Caso 1

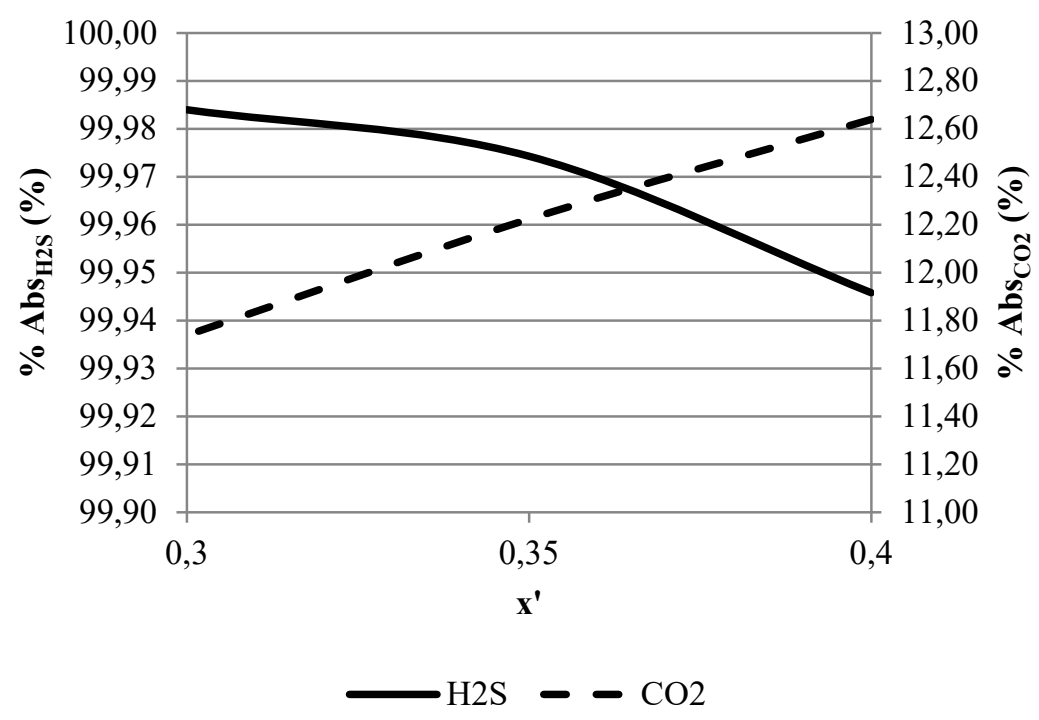

Fonte: Autor

A seguir foi configurada a coluna de dessorção. Para esta coluna também foi utilizado o recheio estruturado Sulzer Mellapak $250 \mathrm{Y}^{T M}$ e o diâmetro foi mantido igual ao da coluna de absorção deste sistema, com 0,6 m; mas a altura das seções foi ajustada para $0,5 \mathrm{~m}$, o qual representa um valor mais próximo dos HETP calculados pelo software para esta coluna.

Os resultados da porcentagem de dessorção do $\mathrm{H}_{2} \mathrm{~S}$ em função da altura de recheio da coluna são apresentados na Figura 18.

Por meio dos resultados apresentados na Figura 18, observou-se que para alturas superiores a aproximadamente $8 \mathrm{~m}$ o ganho em relação à porcentagem de $\mathrm{H}_{2} \mathrm{~S}$ dessorvido torna-se pouco representativo. Desta forma, esta altura foi fixada para se dar prosseguimento ao estudo deste caso.

$\mathrm{Na}$ sequência, foi realizada a variação da vazão de solvente isento em gases ácidos, para o ajuste da corrente de solvente pobre nestes gases, visando manter a especificação de no máximo $10 \mathrm{mg}$ de $\mathrm{H}_{2} \mathrm{~S}$ por $\mathrm{m}^{3}$ de $\mathrm{CH}_{4}\left(25^{\circ} \mathrm{C}\right.$, 1 atm $)$ na corrente do gás com teor de $\mathrm{H}_{2} \mathrm{~S}$ reduzido obtida no topo da coluna de absorção deste caso de estudo. No entanto, como esta 
vazão foi estimada em mais do que $1000 \mathrm{kmol} / \mathrm{h}$ de solvente no primeiro ajuste, sua correção foi considerada impraticável, uma vez que era mais do que 2,5 vezes maior do que a vazão alimentada inicialmente e comprometia a operação tanto da coluna de absorção, como da coluna de dessorção configuradas. Desta forma, o ajuste da corrente de solvente pobre em gases ácidos foi realizada, com o sistema de regeneração do solvente fechado, pelo ajuste da razão molar de refluxo na coluna de dessorção. O aumento deste parâmetro promoveu o favorecimento da dessorção dos gases ácidos, que implicava no empobrecimento do solvente regenerado, e foi estimado em 6,8 .

Figura 18 - Porcentagem de dessorção de $\mathrm{H}_{2} \mathrm{~S}$ em função da altura da coluna: Caso 1

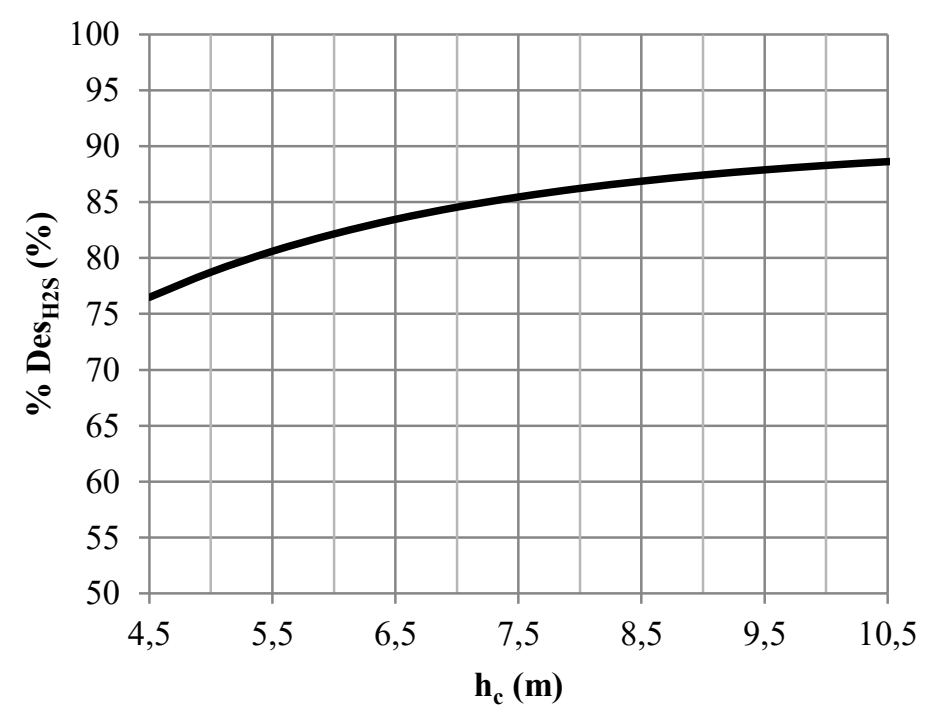

Fonte: Autor

Os resultados obtidos para o processo, com o ciclo do solvente fechado, são apresentados na Tabela 14.

Tabela 14 - Resultados obtidos no Caso 1

\begin{tabular}{l|c|c}
\hline \multicolumn{1}{c|}{ Parâmetro } & Unidade & Valor \\
\hline $\mathrm{H}_{2} \mathrm{~S} / \mathrm{CH}_{4}$ & $\mathrm{mgH}_{2} \mathrm{~S} / \mathrm{m}^{3} \mathrm{CH}_{4}$ & 10,0 \\
\hline $\mathrm{Q}_{\mathrm{esp}, \mathrm{H} 2 \mathrm{~S}}$ & $\mathrm{GJ} / \mathrm{kgH}_{2} \mathrm{~S}$ & 0,424 \\
\hline $\mathrm{Q}_{\%}$ & $\%$ & 12,9 \\
\hline Fonte: Autor & \multicolumn{3}{|c}{}
\end{tabular}

Como se pode observar, a especificação imposta foi alcançada, porém a um custo energético elevado. 
A corrente de biogás com teor reduzido de $\mathrm{H}_{2} \mathrm{~S}$ obtida neste caso, que foi alimentada nos Casos 2 e 3, é apresentada na Tabela 15, sendo especificada em relação à temperatura, pressão, vazão molar e composição.

Tabela 15 - Especificações da corrente de biogás com teor reduzido de $\mathrm{H}_{2} \mathrm{~S}$

\begin{tabular}{l|c|c}
\hline \multicolumn{1}{c|}{ Parâmetro } & Unidade & Valor \\
\hline Temperatura & ${ }^{\circ} \mathrm{C}$ & 35,8 \\
\hline Pressão & atm & 1,04 \\
\hline Vazão molar & $\mathrm{kmol} / \mathrm{h}$ & 42,268 \\
\hline Composição & & \\
\hline Metano $\left(\mathrm{CH}_{4}\right)$ & $\mathrm{kmol} / \mathrm{kmol}$ & 0,591 \\
\hline Dióxido de carbono $\left(\mathrm{CO}_{2}\right)$ & $\mathrm{kmol} / \mathrm{kmol}$ & 0,354 \\
\hline Água $\left(\mathrm{H}_{2} \mathrm{O}\right)$ & $\mathrm{kmol} / \mathrm{kmol}$ & 0,053 \\
\hline Sulfeto de hidrogênio $\left(\mathrm{H}_{2} \mathrm{~S}\right)$ & $\mathrm{ppm}$ & 4 \\
\hline Nitrogênio $\left(\mathrm{N}_{2}\right)$ & $\mathrm{kmol} / \mathrm{kmol}$ & 0,002 \\
\hline
\end{tabular}

Fonte: Autor

\subsubsection{Resultados do Caso 2}

A partir dos resultados apresentados no item 5.3.1 foi selecionada, para a absorção do $\mathrm{CO}_{2}$ com solução aquosa de MEA, a coluna com recheio estruturado Sulzer Mellapak 750 $\mathrm{Y}^{T M}$, com 0,8 m de diâmetro e altura de uma seção de $0,2 \mathrm{~m}$.

Os resultados da porcentagem de absorção em função da altura de recheio da coluna, obtidos para a nova alimentação, são apresentados na Figura 19.

Figura 19 - Porcentagem de absorção de $\mathrm{CO}_{2}$ em função da altura da coluna: Caso 2

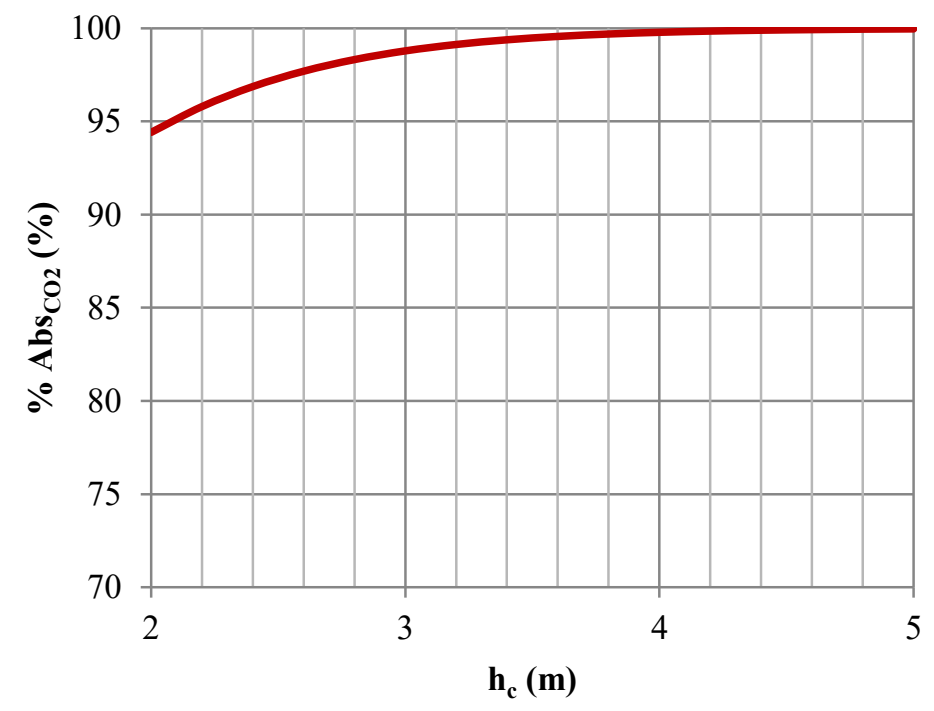

Fonte: Autor 
Por meio dos resultados apresentados na Figura 19, observou-se que para alturas de recheio acima de $4 \mathrm{~m}$ o aumento da porcentagem de absorção de $\mathrm{CO}_{2}$ era pouco significativo, de forma que esta altura foi fixada para se dar prosseguimento ao estudo da influência de outros parâmetros sobre este sistema.

Os resultados obtidos para o estudo da influência da temperatura do solvente na absorção do $\mathrm{CO}_{2}$ são apresentados na Figura 20.

Figura 20 - Influência da temperatura do solvente na absorção do $\mathrm{CO}_{2}$ : Caso 2

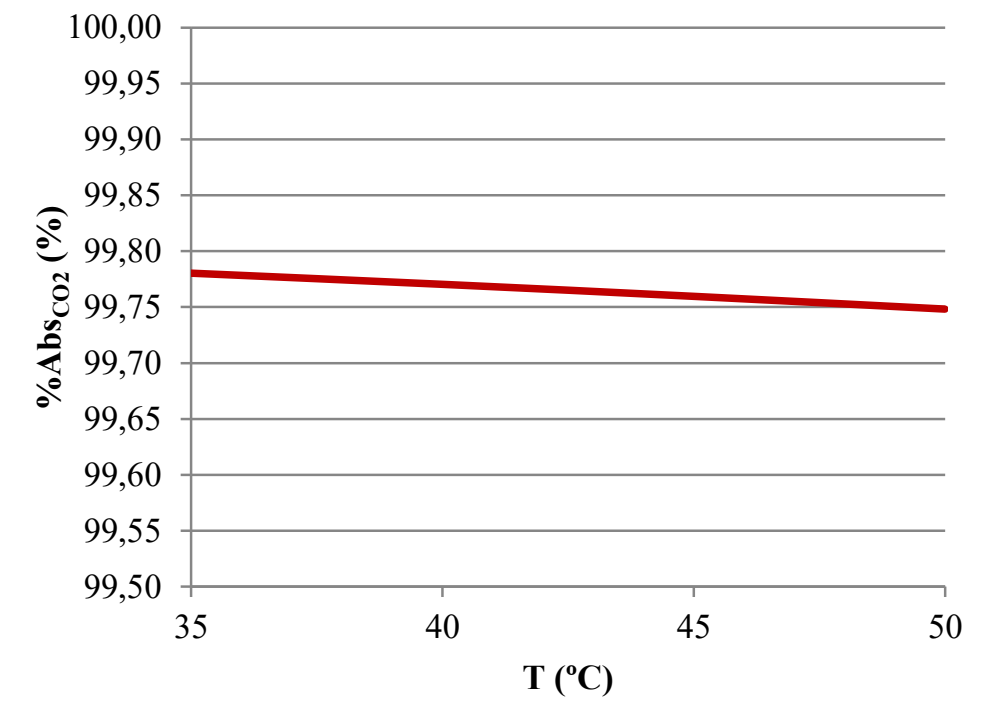

Fonte: Autor

A partir dos resultados apresentados na Figura 20, verificou-se que o aumento da temperatura não interfere significativamente na absorção do $\mathrm{CO}_{2}$, o que indica que neste sistema a cinética da reação do $\mathrm{CO}_{2}$ com a solução aquosa de MEA não é um fator limitante. Desta forma, a temperatura do solvente foi mantida em $35^{\circ} \mathrm{C}$.

A seguir foi estudada a influência da composição do solvente, variando a fração mássica de MEA na solução, mas mantendo a vazão molar de solvente constante. Os resultados obtidos são apresentados na Figura 21.

Por meio dos resultados observados na Figura 21, verificou-se que o emprego de soluções de MEA com concentrações menores prejudicaram a absorção do $\mathrm{CO}_{2}$, o que era esperado, uma vez que a redução da concentração de alcanolamina diminui a velocidade de reação da solução daquela com o $\mathrm{CO}_{2}$, tendo em vista que a concentração de um dos reagentes, a MEA, é reduzida. Desta forma, a composição do solvente foi mantida, com uma fração de 0,3 em massa de MEA. 
Figura 21 - Influência da composição do solvente na absorção do $\mathrm{CO}_{2}$ : Caso 2

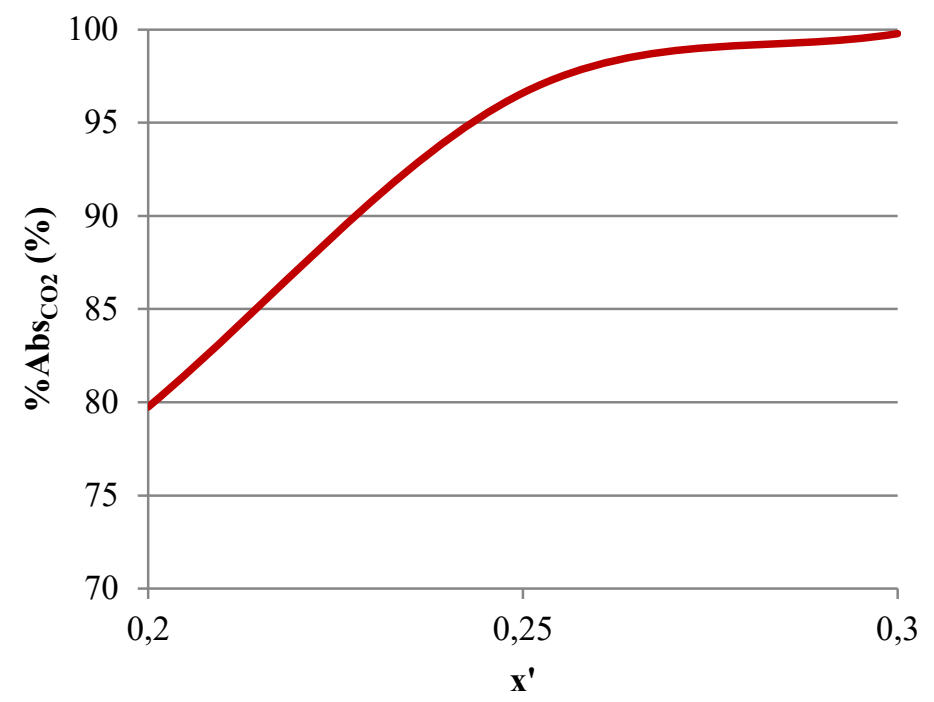

Fonte: Autor

Na sequência, foi configurada a coluna de dessorção. Para esta coluna também foi utilizado o recheio estruturado Sulzer Mellapak $750 \mathrm{Y}^{T M}$ e tanto o diâmetro como a altura das seções foram mantidas iguais aos da coluna de absorção deste sistema: $0,8 \mathrm{~m}$ e 0,2 m, respectivamente.

Os resultados da porcentagem de dessorção do $\mathrm{CO}_{2}$ em função da altura de recheio da coluna são apresentados na Figura 22.

Figura 22 - Porcentagem de dessorção de $\mathrm{CO}_{2}$ em função da altura da coluna: Caso 2

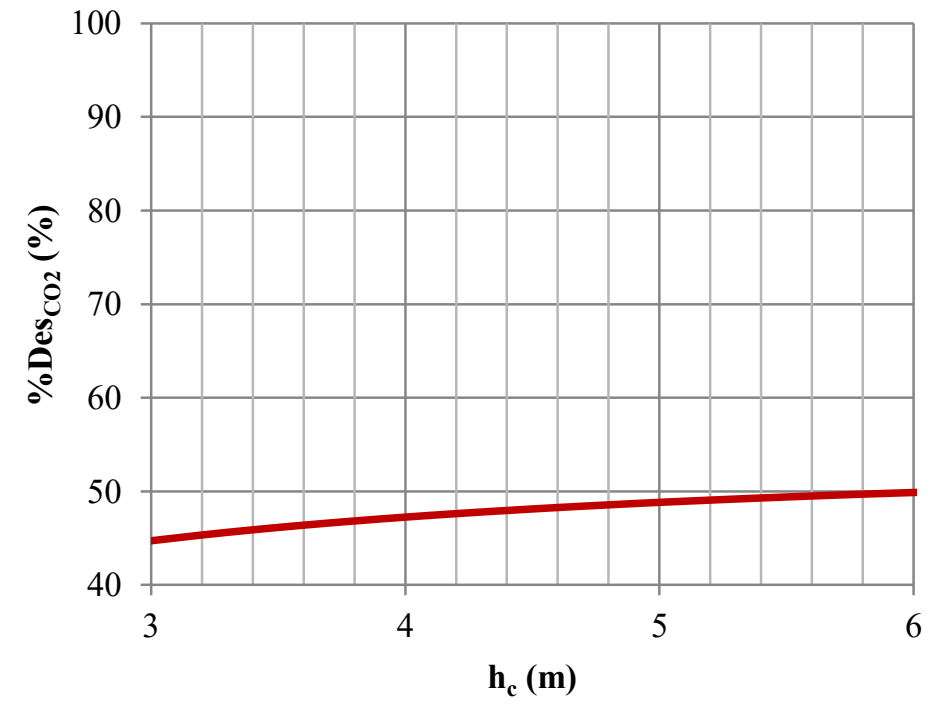

Fonte: Autor 
Por meio dos resultados apresentados na Figura 22, observou-se que para alturas superiores a aproximadamente $4 \mathrm{~m}$ o ganho em relação à porcentagem de $\mathrm{CO}_{2}$ dessorvido torna-se pouco representativo. Desta forma, esta altura foi fixada para se dar prosseguimento ao estudo deste caso.

A seguir foi realizada a variação da vazão de solvente isento em gases ácidos, para o ajuste da corrente de solvente pobre naqueles, visando obter uma porcentagem de absorção de $\mathrm{CO}_{2}$ de aproximadamente $99 \%$. A quantidade de solvente livre que foi somada à de solvente pobre foi de aproximadamente $227 \mathrm{kmol} / \mathrm{h}$, resultando em uma corrente de solvente pobre em $\mathrm{CO}_{2}$ de $532 \mathrm{kmol} / \mathrm{h}$. Para que a coluna de dessorção mantivesse uma operação estável após esta alteração, seu diâmetro teve que ser aumentado, e foi fixado em 0,9 m. Os resultados obtidos, para o processo com ciclo do solvente fechado, são apresentados na Tabela 16.

\begin{tabular}{l|c|c}
\multicolumn{3}{l}{ Tabela 16 - Resultados obtidos no Caso 2 } \\
\hline \multicolumn{1}{c}{ Parâmetro } & Unidade & Valor \\
\hline$\% \mathrm{Abs}_{\mathrm{CO} 2}$ & $\%$ & 98,8 \\
\hline $\mathrm{Q}_{\mathrm{esp}, \mathrm{CO} 2}$ & $\mathrm{GJ} / \mathrm{tCO}_{2}$ & 6,35 \\
\hline $\mathrm{Q}_{\%}$ & $\%$ & 20,6 \\
\hline Fo
\end{tabular}

Fonte: Autor

Como se pode observar, a porcentagem de absorção de $\mathrm{CO}_{2}$ foi obtida com um valor próximo ao especificado e a um custo energético razoável, se comparado com aqueles obtidos nos experimentos conduzidos por Notz, Mangalapally e Hasse (2012), embora elevado quando considerado o consumo de mais de $20 \%$ da energia disponível, como é evidenciado pelo valor do parâmetro $\mathrm{Q}_{\%}$.

A corrente de biometano obtida neste caso, após o resfriamento no tanque flash, é apresentada na Tabela 17, sendo especificada em relação à temperatura, pressão, vazão molar e composição tanto em base úmida como em base seca.

Observando-se os resultados apresentados na Tabela 17, verifica-se que a especificação da Resolução ${ }^{\circ}$ 8/2015 da ANP em relação ao teor de $\mathrm{CO}_{2}$ no biometano é atingida, considerando-se tanto a base úmida como a base seca em que a composição é apresentada, uma vez que o teor deste gás é menor do que $1 \%$, enquanto o máximo permitido pela Resolução é de 3\%. No entanto, para a obtenção de um teor de $\mathrm{CH}_{4}$ maior do que 96,5\%, como requer a Resolução, é necessário submeter o biometano obtido a um processo de remoção do vapor de água presente neste gás. 
Tabela 17 - Especificações da corrente de biometano obtida no Caso 2

\begin{tabular}{l|c|c}
\hline \multicolumn{1}{c|}{ Parâmetro } & Unidade & Valor \\
\hline Temperatura & ${ }^{\circ} \mathrm{C}$ & 35,0 \\
\hline Pressão & $\mathrm{atm}$ & 1,03 \\
\hline Vazão molar & $\mathrm{kmol} / \mathrm{h}$ & 26,613 \\
\hline Composição em base úmida & & \\
\hline Metano $\left(\mathrm{CH}_{4}\right)$ & $\mathrm{kmol} / \mathrm{kmol}$ & 0,939 \\
\hline Dióxido de carbono $\left(\mathrm{CO}_{2}\right)$ & $\mathrm{kmol} / \mathrm{kmol}$ & 0,007 \\
\hline Água $\left(\mathrm{H}_{2} \mathrm{O}\right)$ & $\mathrm{kmol} / \mathrm{kmol}$ & 0,051 \\
\hline Sulfeto de hidrogênio $\left(\mathrm{H}_{2} \mathrm{~S}\right)$ & $\mathrm{ppb}$ & 6,00 \\
\hline Nitrogênio $\left(\mathrm{N}_{2}\right)$ & $\mathrm{kmol} / \mathrm{kmol}$ & 0,003 \\
\hline Composição em base seca & & \\
\hline Metano $\left(\mathrm{CH}_{4}\right)$ & $\mathrm{kmol} / \mathrm{kmol}$ & 0,9895 \\
\hline Dióxido de carbono $\left(\mathrm{CO}_{2}\right)$ & $\mathrm{kmol} / \mathrm{kmol}$ & 0,0074 \\
\hline Sulfeto de hidrogênio $\left(\mathrm{H}_{2} \mathrm{~S}\right)$ & $\mathrm{ppb}$ & 6,32 \\
\hline Nitrogênio $\left(\mathrm{N}_{2}\right)$ & $\mathrm{kmol} / \mathrm{kmol}$ & 0,0032 \\
\hline Fond & &
\end{tabular}

Fonte: Autor

\subsubsection{Resultados do Caso 3}

A partir dos resultados apresentados no item 5.3.1 foi selecionada, para a absorção do $\mathrm{CO}_{2}$ com solução aquosa de DEA, a coluna com recheio estruturado Sulzer Mellapak 750 $\mathrm{Y}^{T M}$, com $0,8 \mathrm{~m}$ de diâmetro e altura de uma seção de $0,2 \mathrm{~m}$.

Os resultados da porcentagem de absorção em função da altura de recheio da coluna, obtidos para a nova alimentação, são apresentados na Figura 23.

Figura 23 - Porcentagem de absorção de $\mathrm{CO}_{2}$ em função da altura da coluna: Caso 3

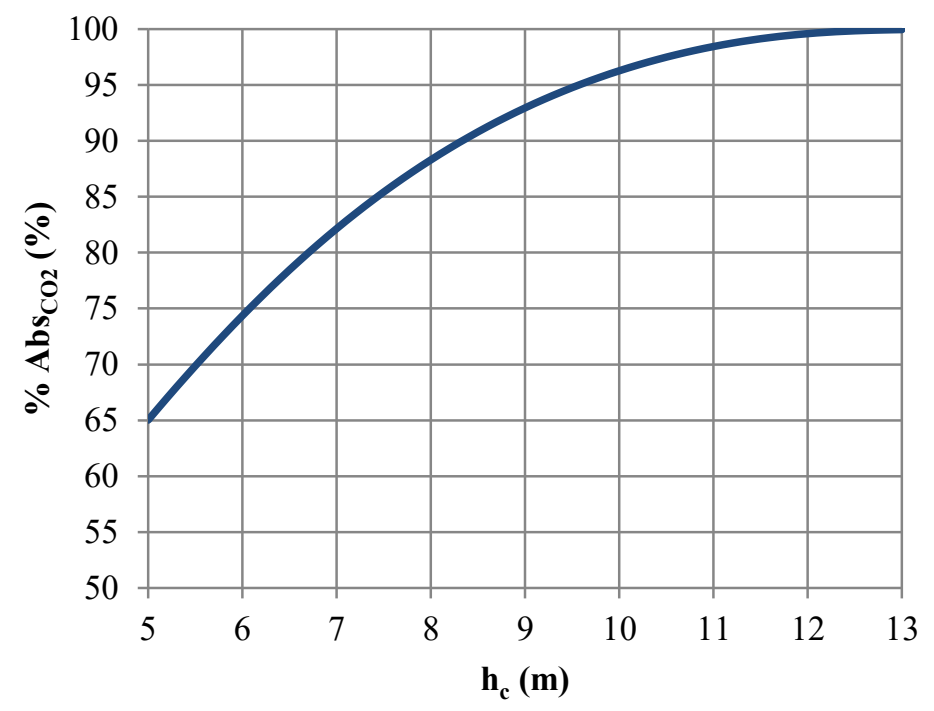

Fonte: Autor 
Por meio dos resultados apresentados na Figura 23, observou-se que para alturas de recheio acima de $12 \mathrm{~m}$ o aumento da porcentagem de absorção de $\mathrm{CO}_{2}$ era pouco significativo. Desta forma, esta altura foi fixada para se dar prosseguimento ao estudo da influência de outros parâmetros sobre este sistema.

Os resultados obtidos para o estudo da influência da temperatura do solvente na absorção do $\mathrm{CO}_{2}$ são apresentados na Figura 24.

Figura 24 - Influência da temperatura do solvente na absorção do $\mathrm{CO}_{2}$ : Caso 3

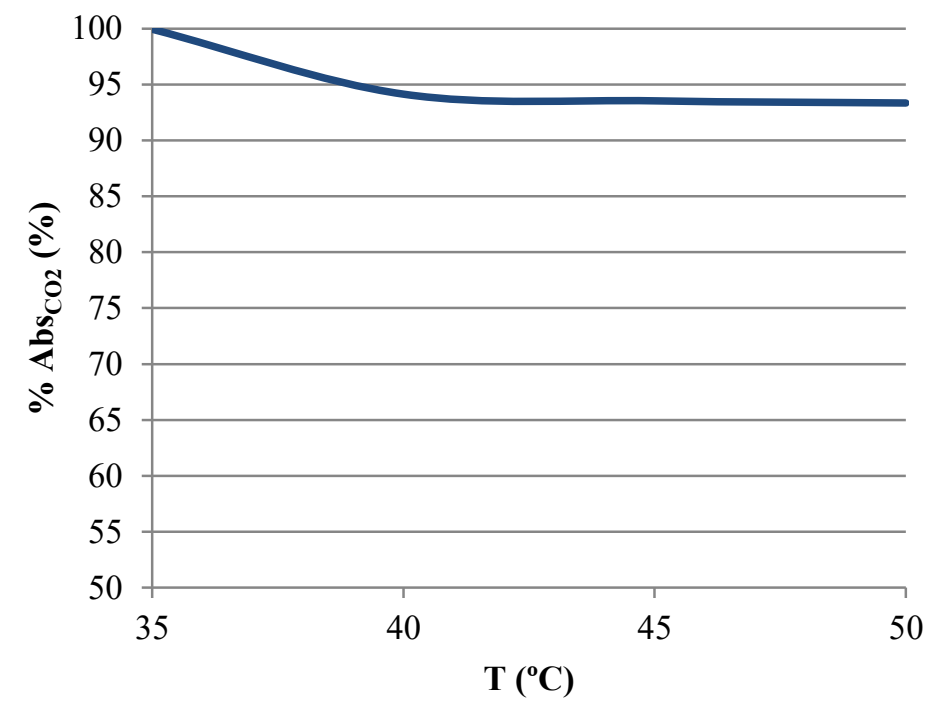

Fonte: Autor

A partir dos resultados apresentados na Figura 24, verificou-se que o aumento da temperatura interfere negativamente na absorção do $\mathrm{CO}_{2}$, o que indica que também neste sistema a cinética da reação do $\mathrm{CO}_{2}$ com a solução aquosa de DEA não é um fator limitante. Desta forma, a temperatura do solvente foi mantida em $35^{\circ} \mathrm{C}$.

Na sequência, foi estudada a influência da composição do solvente, variando a fração mássica de DEA na solução, mas mantendo a vazão molar de solvente constante. Os resultados obtidos são apresentados na Figura 25.

Por meio dos resultados observados na Figura 25, verificou-se que o emprego de soluções de DEA com concentrações menores prejudicaram a absorção do $\mathrm{CO}_{2}$. Este comportamento, similar ao observado para o Caso 2, também pode ser atribuído à diminuição da velocidade de reação da solução da alcanolamina com o $\mathrm{CO}_{2}$, tendo em vista que neste caso a concentração de DEA é reduzida com a diminuição de sua concentração na solução. 
Desta forma, a composição do solvente foi mantida, com uma fração de 0,3 em massa de DEA.

Figura 25 - Influência da composição do solvente na absorção do $\mathrm{CO}_{2}$ : Caso 3

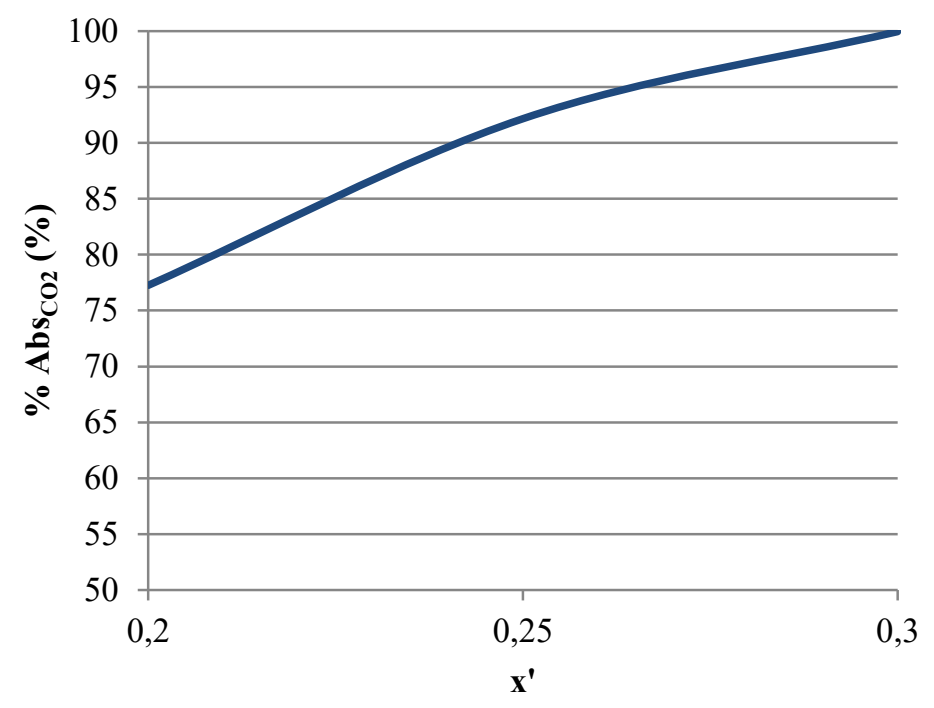

Fonte: Autor

A seguir, foi configurada a coluna de dessorção. Nesta coluna também foi utilizado o recheio estruturado Sulzer Mellapak $750 \mathrm{Y}^{T M}$ e tanto o diâmetro como a altura das seções foram mantidas iguais aos da coluna de absorção deste sistema: $0,8 \mathrm{~m}$ e $0,2 \mathrm{~m}$, respectivamente.

Os resultados da porcentagem de dessorção do $\mathrm{CO}_{2}$ em função da altura de recheio da coluna são apresentados na Figura 26.

Por meio dos resultados apresentados na Figura 26, observou-se que para alturas superiores a aproximadamente $6 \mathrm{~m}$ o ganho em relação à porcentagem de $\mathrm{CO}_{2}$ dessorvido torna-se pouco representativo. Desta forma, esta altura foi fixada para se dar prosseguimento ao estudo deste caso.

Na sequência, foi realizada a variação da vazão de solvente isento em gases ácidos, para o ajuste da corrente de solvente pobre nestes gases, visando obter uma porcentagem de absorção de $\mathrm{CO}_{2}$ de aproximadamente $99 \%$. A quantidade de solvente livre que foi somada à de solvente pobre foi de aproximadamente $9 \mathrm{kmol} / \mathrm{h}$, resultando em uma corrente de solvente pobre em $\mathrm{CO}_{2}$ de $509 \mathrm{kmol} / \mathrm{h}$. 
Figura 26 - Porcentagem de dessorção de $\mathrm{CO}_{2}$ em função da altura da coluna: Caso 3

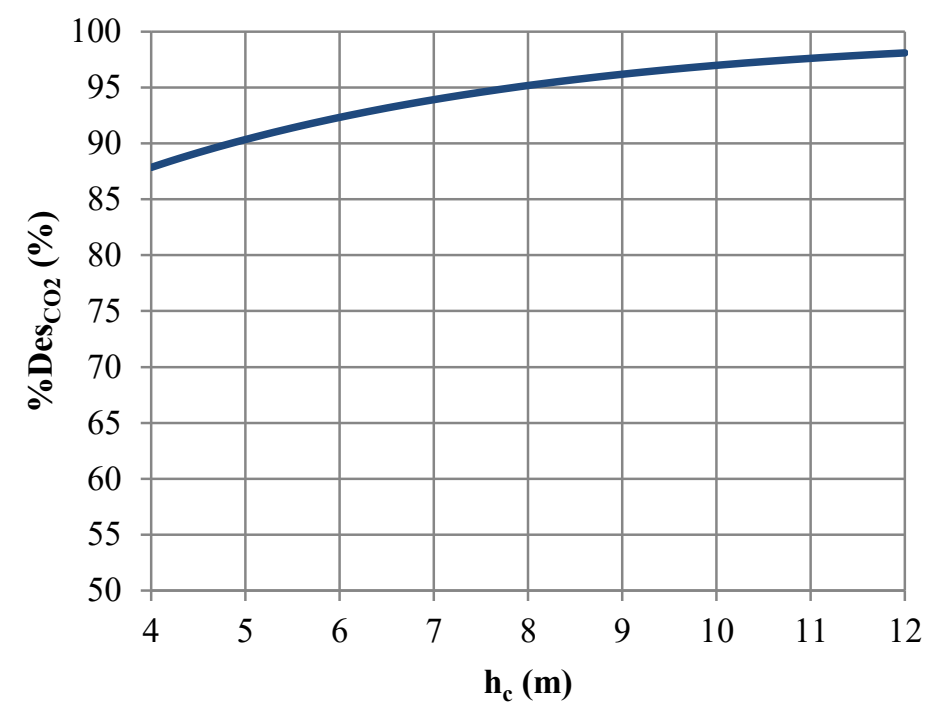

Fonte: Autor

Os resultados obtidos, para o processo com ciclo do solvente fechado, são apresentados na Tabela 18.

Tabela 18 - Resultados obtidos no Caso 3

\begin{tabular}{l|c|c}
\hline \multicolumn{1}{c|}{ Parâmetro } & Unidade & Valor \\
\hline$\% \mathrm{Abs}_{\mathrm{CO} 2}$ & $\%$ & 99,1 \\
\hline $\mathrm{Q}_{\mathrm{esp}, \mathrm{CO} 2}$ & $\mathrm{GJ} / \mathrm{tCO} 2$ & 4,71 \\
\hline $\mathrm{Q}_{\%}$ & $\%$ & 15,3 \\
\hline
\end{tabular}

Fonte: Autor

Como se pode observar, a porcentagem de absorção de $\mathrm{CO}_{2}$ foi obtida com um valor próximo ao especificado e a um custo energético razoável, se comparado com aqueles obtidos nos experimentos conduzidos por Notz, Mangalapally e Hasse (2012), que se apresentou mais atrativo do que aquele obtido no Caso 2, embora a demanda energética também seja elevada.

A corrente de biometano obtida neste caso é apresentada na Tabela 19, sendo especificada em relação à temperatura, pressão, vazão molar e composição tanto em base úmida como em base seca.

A partir dos resultados apresentados na Tabela 19, verifica-se que a especificação da Resolução $n^{\circ}$ 8/2015 da ANP em relação ao teor de $\mathrm{CO}_{2}$ no biometano é atingida, considerando-se tanto a base úmida como a base seca em que a composição é apresentada, uma vez que o teor máximo permitido por esta Resolução é de 3\% e teor obtido foi de menos 
de $1 \%$. Entretanto, para a obtenção de um teor de $\mathrm{CH}_{4}$ maior do que $96,5 \%$, como requer a Resolução, é necessário submeter o biometano obtido a um processo de secagem.

Tabela 19 - Especificações da corrente de biometano obtida no Caso 3

\begin{tabular}{l|c|c}
\multicolumn{1}{c|}{ Parâmetro } & Unidade & Valor \\
\hline Temperatura & ${ }^{\circ} \mathrm{C}$ & 35,4 \\
\hline Pressão & $\mathrm{atm}$ & 1,03 \\
\hline Vazão molar & $\mathrm{kmol} / \mathrm{h}$ & 26,58 \\
\hline Composição em base úmida & & \\
\hline Metano $\left(\mathrm{CH}_{4}\right)$ & $\mathrm{kmol} / \mathrm{kmol}$ & 0,940 \\
\hline Dióxido de carbono $\left(\mathrm{CO}_{2}\right)$ & $\mathrm{kmol} / \mathrm{kmol}$ & 0,005 \\
\hline Água $\left(\mathrm{H}_{2} \mathrm{O}\right)$ & $\mathrm{kmol} / \mathrm{kmol}$ & 0,052 \\
\hline Sulfeto de hidrogênio $\left(\mathrm{H}_{2} \mathrm{~S}\right)$ & $\mathrm{ppb}$ & 62,0 \\
\hline Nitrogênio $\left(\mathrm{N}_{2}\right)$ & $\mathrm{kmol} / \mathrm{kmol}$ & 0,003 \\
\hline Composição em base seca & & \\
\hline Metano $\left(\mathrm{CH}_{4}\right)$ & $\mathrm{kmol} / \mathrm{kmol}$ & 0,9916 \\
\hline Dióxido de carbono $\left(\mathrm{CO}_{2}\right)$ & $\mathrm{kmol} / \mathrm{kmol}$ & 0,0053 \\
\hline Sulfeto de hidrogênio $\left(\mathrm{H}_{2} \mathrm{~S}\right)$ & $\mathrm{ppb}$ & 65,4 \\
\hline Nitrogênio $\left(\mathrm{N}_{2}\right)$ & $\mathrm{kmol} / \mathrm{kmol}$ & 0,0032 \\
\hline Fon & &
\end{tabular}

Fonte: Autor 


\section{CONCLUSÕES}

Neste trabalho foram realizados o estudo e a proposta de um processo para avaliar o desempenho de soluções aquosas de MDEA, MEA, e DEA empregadas na separação do $\mathrm{CO}_{2}$ e do $\mathrm{H}_{2} \mathrm{~S}$ presentes em uma corrente de biogás aplicando a abordagem de não-equilíbrio, visando comparar as demandas de solvente e de energia requerida para a regeneração do solvente em cada estudo de caso.

O estudo proposto foi realizado por meio de simulações no software Aspen Plus ${ }^{\circledR}$ e a modelagem utilizada foi validada por meio da simulação de estudos de casos experimentais disponíveis na literatura, conduzidos em uma planta piloto de absorção química do $\mathrm{CO}_{2}$ de uma corrente de gases de pós-combustão com solução aquosa de MEA. Os resultados obtidos nas simulações realizadas para reproduzir estes estudos de casos apresentaram desvios para a porcentagem de absorção de até $15 \%$ e desvios para a energia específica de até $25 \%$ em relação aos obtidos na referência, os quais foram considerados aceitáveis, considerando que os resultados das simulações contam com os desvios resultantes da utilização de correlações empíricas para o cálculo dos coeficientes de transferência de massa e de calor; além dos desvios experimentais resultantes tanto da operação da planta, como dos equipamentos de medição das variáveis monitoradas.

Os estudos iniciais de absorção dos gases ácidos indicaram um melhor desempenho da solução aquosa de MEA para a absorção do $\mathrm{CO}_{2}$ e da solução aquosa de MDEA para a absorção do $\mathrm{H}_{2} \mathrm{~S}$, considerando a altura de recheio da coluna requerida para a obtenção de uma dada porcentagem de absorção. Como o desempenho da solução aquosa de MDEA para a absorção do $\mathrm{CO}_{2}$ foi o pior entre os sistemas considerados, a seletividade desta alcanolamina em relação ao $\mathrm{H}_{2} \mathrm{~S}$ foi constatada. Nestes estudos também foi verificado que o aumento da área superficial disponível para transferência de massa contribui com o aumento da porcentagem de absorção tanto do $\mathrm{CO}_{2}$ como do $\mathrm{H}_{2} \mathrm{~S}$ nos sistemas com MDEA, MEA e DEA, embora no sistema com MDEA o aumento da porcentagem de absorção do $\mathrm{H}_{2} \mathrm{~S}$ não seja muito pronunciado.

A partir das simulações dos estudos de casos teóricos propostos neste trabalho, que visavam atingir as especificações da Resolução $n^{\circ}$ 8/2015 da ANP em relação aos teores de $\mathrm{H}_{2} \mathrm{~S}$ e de $\mathrm{CO}_{2}$ no biometano, observou-se que nos Casos 2 e 3 a energia específica do processo, de 6,35 e 4,71 GJ por tonelada de $\mathrm{CO}_{2}$ dessorvido, respectivamente, se mostrou razoável quando comparada com os resultados obtidos na literatura, entre 3,98 e 5,01 GJ por tonelada de $\mathrm{CO}_{2}$ dessorvido. Para o Caso 1 a energia específica requisitada foi de 0,424 GJ 
por quilograma de $\mathrm{H}_{2} \mathrm{~S}$ dessorvido, a qual pode ser relacionada com a especificação mais rigorosa quanto à limitação da quantidade de $\mathrm{H}_{2} \mathrm{~S}$ no gás purificado, o que implicou para este processo na obtenção de uma corrente de solvente pobre com baixo teor de gases ácidos, que para ser obtida requer elevado fornecimento de energia, uma vez que a força motriz relacionada à concentração é reduzida na dessorção conforme a solução rica em gases ácidos é empobrecida nestes. Quando considerada a demanda energética percentual, verifica-se que todos os casos estudados requisitaram quantidades consideráveis da energia disponível no biogás, uma vez que os valores apresentados para estes parâmetros foram de 12,9\%, 20,6\% e $15,3 \%$ para os Casos 1, 2 e 3, respectivamente.

Dentre os casos simulados para a absorção do $\mathrm{CO}_{2}$, aquele que apresentou o melhor desempenho em termos energéticos foi o que empregou solução aquosa de DEA, pois como foi apontado, necessitou de menos energia na etapa de dessorção. Este caso também se destacou em relação à vazão molar circulante de solvente, que foi de 509 kmol por hora, enquanto para o caso com MEA foram requeridos $532 \mathrm{kmol}$ por hora de solvente devido à maior necessidade de reposição resultante da maior dificuldade de dessorção do $\mathrm{CO}_{2}$ da solução desta amina. No entanto, as alturas de recheio de coluna necessárias para as operações de absorção e de dessorção foram menores para o caso com MEA, ambas de 4 metros, do que para o caso com DEA, onde foram requeridas alturas de 12 metros para a coluna de absorção e de 6 metros para a de dessorção; embora o diâmetro requerido para a coluna de dessorção tenha sido maior no caso com MEA, 0,9 metros, do que no caso com DEA, que foi de 0,8 metros.

Desta forma, este trabalho apresentou como principal contribuição a obtenção de valores de parâmetros que possibilitaram a comparação do desempenho das principais alcanolaminas comerciais em relação às demandas de solvente, de energia e também às dimensões das colunas configuradas para cada sistema, visando a remoção dos gases ácidos presentes em uma corrente de biogás, bem como a proposta da absorção seletiva que permite o pós-tratamento dos gases ácidos removidos em plantas de dimensões menores, atendendo assim aos objetivos definidos para este estudo. 


\section{SUGESTÕES PARA TRABALHOS FUTUROS}

Neste trabalho, o desempenho das alcanolaminas: MDEA, MEA e DEA na remoção do $\mathrm{CO}_{2}$ e do $\mathrm{H}_{2} \mathrm{~S}$ presentes em uma corrente de biogás foi avaliado em relação às demandas de solvente, de energia e também em relação aos equipamentos dimensionados para esta aplicação.

Ainda assim, os cenários estudados podem ser ampliados por meio de estudos complementares, que podem contemplar:

a) a otimização do dimensionamento das colunas configuradas para cada caso de estudo, considerando, por exemplo, uma fração da capacidade máxima do recheio estruturado de 0,7 para garantir melhor eficiência em sua utilização;

b) a aplicação de outras correlações para o cálculo dos coeficientes de transferência de massa;

c) a utilização de internos diferentes dos contemplados neste trabalho, como os recheios randômicos;

d) a configuração de um Processo Claus para dar continuidade ao tratamento do $\mathrm{H}_{2} \mathrm{~S}$, com a produção de enxofre elementar;

e) a elaboração de análises preliminares de risco dos processos estudados;

f) análises econômicas dos casos estudados. 


\section{REFERÊNCIAS}

ADBA - ANAEROBIC DIGESTION \& BIOGAS ASSOCIATION. The practical guide to AD: an introduction to developing and operating digestion facilities in the UK. London, 2013. Disponível em: < http://adbioresources.org/library/purchase-the-practical-guide-to-ad $>$. Acesso em: 03 maio 2016.

ASPEN TECHNOLOGY, Inc. Maximum capacity calculations for packing. In: Aspen Plus Help. 2013a. Software. Aspen Plus ${ }^{\circledR}$. Version 8.4.

ASPEN TECHNOLOGY, Inc. Mathematical basis. In: Aspen Plus Help. Aspentech Inc, 2013b. Software. Aspen Plus ${ }^{\circledR}$. Version 8.4.

ASPEN TECHNOLOGY, Inc. Flow models. In: Aspen Plus Help. Aspentech Inc, 2013c. Software. Aspen Plus ${ }^{\circledR}$. Version 8.4.

ASPEN TECHNOLOGY, Inc. Using electrolyte amine data packages. In: Aspen Plus Help. Aspentech Inc, 2013d. Software. Aspen Plus ${ }^{\circledR}$. Version 8.4.

ASPEN TECHNOLOGY, Inc. Rate-based model of the $\mathbf{C O}_{2}$ capture process by MDEA using Aspen Plus ${ }^{\circledR}$. Burlington, 2013e. Aspen Plus ${ }^{\circledR}$. Version 8.4.

ASPEN TECHNOLOGY, Inc. Rate-based model of the $\mathbf{C O}_{2}$ capture process by DEA using Aspen Plus ${ }^{\circledR}$. Burlington, 2013f.

ASPEN TECHNOLOGY, Inc. Rate-based model of the $\mathbf{C O}_{2}$ capture process by MEA using Aspen Plus ${ }^{\circledR}$. Burlington, 2013g.

ASPEN TECHNOLOGY, Inc. Film reactions. In: Aspen Plus Help. Aspentech Inc, 2013 h. Software. Aspen Plus ${ }^{\circledR}$. Version 8.4.

ASPEN TECHNOLOGY, Inc. HanleyStruc (2010) correlation. In: Aspen Plus Help. Aspentech Inc, 2013i. Software. Aspen Plus ${ }^{\circledR}$. Version 8.4.

ASPEN TECHNOLOGY, Inc. Chilton and Colburn method. In: Aspen Plus Help. Aspentech Inc, 2013j. Software. Aspen Plus ${ }^{\circledR}$. Version 8.4.

ASPEN TECHNOLOGY, Inc. Bravo et al. (1992) holdup correlation. In: Aspen Plus Help. Aspentech Inc, 2013k. Software. Aspen Plus ${ }^{\circledR}$. Version 8.4.

AUSTGEN, D. M. A model of vapor-liquid equilibria for acid gas-alkanolamine-water systems. 1989. 358 f. Dissertação (Ph. D. em Engenharia Química) - University of Texas, Austin, 1989. Disponível em: < https://utexas.influuent.utsystem.edu/en/publications/modelof-vapor-liquid-equilibria-for-aqueous-acid-gas-alkanolamin-2>. Acesso em: 08 mar. 2016.

AUSTGEN, D. M. et al. Model of vapor-liquid equilibria for aqueous acid gas-alkanolamine systems. 2: representation of $\mathrm{H}_{2} \mathrm{~S}$ and $\mathrm{CO}_{2}$ solubility in aqueous MDEA and $\mathrm{CO}_{2}$ solubility in aqueous mixtures of MDEA with MEA or DEA. Ind. Eng. Chem. Res., v. 30, p. 543555, 1991. Disponível em: 
$<$ http://pubs.acs.org/doi/abs/10.1021/ie00051a016?journalCode=iecred $>$. Acesso em: 08 mar. 2016.

AUSTGEN, D. M. et al. Model of vapor-liquid equilibria for aqueous acid gas-alkanolamine systems using the electrolyte-NRTL equation. Ind. Eng. Chem. Res., v. 28, p. 1060-1073, 1989. Disponível em: < http://pubs.acs.org/doi/abs/10.1021/ie00091a028>. Acesso em: 08 mar. 2016.

BLAUWHOFF, P. M. M.; VERSTEEG, G. F.; VAN SWAAIJ, W. P.M. A study on the reaction between $\mathrm{CO}_{2}$ and alkanolamines in aqueous solutions. Chem. Eng. Sci., v. 39, n. 2, p. 207-225, 1984. Disponível em:

$<$ http://www.sciencedirect.com/science/article/pii/0009250984800214>. Acesso em: 28 fev. 2016.

BRASIL. Resolução ANP n ${ }^{\circ}$ 8, de 30 de janeiro de 2015. Diário Oficial da União, Ministério de Minas e Energia, Brasília, DF, 2 fev. 2015. Seção 1, p. 100-101. Disponível em:

$<$ http://pesquisa.in.gov.br/imprensa/jsp/visualiza/index.jsp?data=02/02/2015\&jornal=1\&pagi na $=100 \&$ totalArquivos=156>. Acesso em: 05 abr. 2016.

CHEN, C-C. et al. Local composition model for excess Gibbs energy of electrolyte systems. Part I: single solvent, single completely dissociated electrolyte systems. AIChE J., v.28, p. 588-596, 1982. Disponível em:

$<$ http://onlinelibrary.wiley.com/doi/10.1002/aic.690280410/abstract>. Acesso em: 23 abr. 2016.

CLARIANT. Genosorb ${ }^{\circledR}$ 1983: absorption fluid. 2013. Disponível em:

$<$ https://www.clariant.com/Solutions/Products/2013/12/09/18/27/Genosorb-1843>. Acesso em: 04 abr. 2016.

COMGÁS. Qualidade do produto e serviço: pressão. 2015. Disponível em:

$<$ http://www.comgas.com.br/pt/empresa/concessao/Paginas/qualidadeProdutoServicoPressao.aspx>. Acesso em: 5 abr. 2016.

DANCKWERTS, P.V. The reaction of $\mathrm{CO}_{2}$ with ethanolamines. Chem. Eng. Sci., v. 34, p. 443-346, 1979. Disponível em:

$<$ http://www.sciencedirect.com/science/article/pii/0009250979850873>. Acesso em: 07 mar. 2016.

EPE - EMPRESA DE PESQUISA ENERGÉTICA. Estudo das condições estabelecidas no tratado de Quito e resoluções internacionais de sua atualização. 2007. Disponível em: $<$ http://www.epe.gov.br/Petroleo/Documents/Estudos_29/EPE\%20$\% 201 \% \mathrm{C} 2 \% \mathrm{BA} \% 20$ Biocombust $\% \mathrm{C} 3 \%$ ADveis\%20x\%20MDL.pdf $>$. Acesso em: 13 mar. 2016.

FEAM - FUNDAÇÃO ESTADUAL DE MEIO AMBIENTE; FIEMG - FEDERAÇÃO DAS INDÚSTRIAS DE MINAS GERAIS; GIZ - AGÊNCIA DE COOPERAÇÃO BRASIL E ALEMANHA. Guia técnico ambiental de biogás na agroindústria. Belo Horizonte, 2015. Disponível em:

$<$ http://www7.fiemg.com.br/Cms_Data/Contents/central/Media/Documentos/Biblioteca/PDFs /FIEMG/MeioAmbiente/2015/CARTILHA-BIOGAS.pdf>. Acesso em: 29 mar. 2016. 
FNR - FACHAGENTUR NACHWACHSENDE ROHSTOFFE E. V. Guia prático do biogás: geração e utilização. 5. ed. Gülzow, 2010. Disponível em:

$<$ https://www.cidades.gov.br/images/stories/ArquivosSNSA/probiogas/guia-pratico-dobiogas.pdf>. Acesso em: 25 fev. 2016

FRAUENKRON, M. et al. Ethanolamines and propanolamines. In: Ullmann's encyclopedia of industrial Chemistry. 7 th. Weinheim: Wiley-VCH, 2011, 13 v. p. 405-431.

GÓRAK, A.; OLUJIC, Z. Distillation: equipment and processes. London: Academic Press, 2014. Disponível em: < http://www.sciencedirect.com/science/book/9780123868787>. Acesso em: 17 maio 2016.

HAMMER, G. et al. Natural Gas. In: Ullmann's encyclopedia of industrial Chemistry. 7 th. Weinheim: Wiley-VCH, 2011, 23 v. p. 739-792.

HANLEY, B., CHEN, C-C. New mass-transfer correlations for packed towers. AIChE J., v.58, p. 132-152, 2012. Disponível em:

$<$ http://onlinelibrary.wiley.com/doi/10.1002/aic.12574/full>. Acesso em: 04 jun. 2016.

HILLER, H. et al. Gas Production. In: Ullmann's encyclopedia of industrial Chemistry. 7 th. Weinheim: Wiley-VCH, 2011, 16 v. p. 403-578.

JOU, F. Y.; MATHER, A. E.; OTTO, F. D. Solubility of $\mathrm{H}_{2} \mathrm{~S}$ and $\mathrm{CO}_{2}$ in aqueous methyldiethanolamine solutions. Ind. Eng. Chem. Proc. Des. Dev., v. 21, p. 539-544, 1982. Disponível em: < http://pubs.acs.org/doi/abs/10.1021/i200019a001>. Acesso em: 06 mar. 2016.

KEMP, I.C. et al. Key concepts of pinch analysis. In: integration. 2 nd. Amsterdam: Butterworth-Heinemann, 2007. p. 15-40.

KENIG, E. Y.; SCHNEIDER, R.; GÓRAK, A. Reactive absorption: optimal process design via optimal modelling. Chem. Eng. Sci., v. 56, p. 343-350, 2001. Disponível em:

$<$ http://www.sciencedirect.com/science/article/pii/S0009250900002347>. Acesso em: 14 jun. 2016.

KISTER, H. Z. et al. Distillation design. New York: MacGraw-Hill, Inc., 1992.

KISTER, H. Z. et al. Equipment for distillation, gas absorption, phase dispersion, and phase separation. In: MALONEY, J. O. et al. Perry's chemical engineer's handbook. 8 th . United States of America: MacGraw-Hill, Inc., 2008. p. 14.1-14.129.

KOHL, A.; NIELSEN, R. Gas purification. 5 th. Texas: Gulf Publishing Company, 1997. Disponível em: < http://www.sciencedirect.com/science/book/9780884152200>. Acesso em: 26 out. 2015.

KRISHNA, R.; WESSELINGH, J. A. The Maxwell-Stefan approach to mass transfer. Chem. Eng. Sci., v. 58, p. 861-911, 1997. Disponível em:

$<$ http://www.sciencedirect.com/science/article/pii/S0009250996004587>. Acesso em: 15 mar. 2016. 
KUCKA, L. et al. On the modelling and simulation of sour gas absorption by aqueous amine solutions. Chem. Eng. Sci., v. 58, p. 3571-3578, 2003. Disponível em:

$<$ http://www.sciencedirect.com/science/article/pii/S0009250903002550>. Acesso em: 16 maio 2016.

MCCABE, W. L.; SMITH, J. C.; HARRIOTT, P. Unit operations of chemical engineering. 5 th. New York: McGraw-Hill, Inc., 1993.

NASSER JUNIOR, R. Otimização das colunas de absorção da recuperação de acetona na produção de Filter Tow por meio de estudos fenomenológicos e análise estatística. 2009. 223 p. Tese (Doutorado em Engenharia) - Escola Politécnica da Universidade de São Paulo, São Paulo, 2009. Disponível em: < http://www.teses.usp.br/teses/disponiveis/3/3137/tde18122009-141222/pt-br.php>. Acesso em: 14 set. 2016

NOTZ, R.; MANGALAPALLY, H. P; HASSE, H. Post combustion $\mathrm{CO}_{2}$ capture by reactive absorption: pilot plant description and results of systematic studies with MEA. Int. J.

Greenh. Gas Con., v. 6, p. 84-112, 2012. Disponível em:

$<$ http://www.sciencedirect.com/science/article/pii/S1750583611002143>. Acesso em: 15 jul. 2016.

NYNS, E.-J. Methane. In: Ullmann's encyclopedia of industrial Chemistry. 7 th. Weinheim: Wiley-VCH, 2011, 23 v. p. 13-23.

O'LEARY, P. R.; TCHOBANOGLOUS, G. Landfilling. In: TCHOBANOGLOUS, G. et al. Handbook of solid waste management. 2 ed. New York: MacGraw-Hill, Inc., 2002. p. 14.114.93.

PETERSSON, A.; WELLINGER, A. Biogas upgrading technologies: developments and innovations. IEA Bioenergy, 2009. Disponível em: < http://www.iea-biogas.net/files/datenredaktion/download/publi-task37/upgrading_rz_low_final.pdf $>$. Acesso em: 30 mar. 2016.

RAZI, N.; BOLLAND, O.; SVENDSEN, H. Review of design correlations for $\mathrm{CO}_{2}$ absorption into MEA using structured packings. Int. J. Greenh. Gas Con., v. 9, p. 193-219, 2012. Disponível em:

$<$ http://www.sciencedirect.com/science/article/pii/S1750583612000618>. Acesso em: 15 maio 2016.

RAZI, N.; BOLLAND, O.; SVENDSEN, H. Validation of mass transfer correlations for $\mathrm{CO}_{2}$ absorption with MEA using pilot data. Int. J. Greenh. Gas Con., v. 19, p. 478-491, 2013. Disponível em: < http://www.sciencedirect.com/science/article/pii/S1750583613003599>. Acesso em: 15 maio 2016.

RIO DE JANEIRO (Estado). Lei n. 6361, de 18 de dezembro de 2012. Rio de Janeiro: ALERJ, Poder Executivo, Rio de Janeiro, RJ, 20 jan. 2012. Disponível em: $<$ http://alerjln1.alerj.rj.gov.br/CONTLEI.NSF/e9589b9aabd9cac8032564fe0065abb4/f0294f2 b42bc949483257ada00673a4a?OpenDocument>. Acesso em: 23 jun. 2016.

SÃO PAULO (Estado). Decreto n. 58.659, de 4 de dezembro de 2012. Diário Oficial [do] Estado de São Paulo, Poder Executivo, São Paulo, SP, 5 dez. 2012. Seção 1, p. 1.Disponível 
em: <http://www.al.sp.gov.br/repositorio/legislacao/decreto/2012/decreto-5865904.12.2012.html>. Acesso em: 23 jun. 2016.

SCGÁS - COMPANHIA DE GÁS DE SANTA CATARINA. Regulamento de instalações prediais: gás natural. 2013. Disponível em:

<http://www.scgas.com.br/uploads/RIP_SCGAS.pdf>. Acesso em: 29 mar. 2016.

SCHLAUER, J.; KRIEBEL, M. Absorprion. In: Ullmann's encyclopedia of industrial Chemistry. 7 ed. Weinheim: Wiley-VCH, 2011, 1 v. p. 47-71.

SGC - SVENSKT GASTEKNISKT CENTER AB. Basic data on biogas. 2 ed. Malmö, 2012. Disponível em:

$<$ http://www.sgc.se/ckfinder/userfiles/files/BasicDataonBiogas2012.pdf >. Acesso em: 23 fev. 2016.

Sherlock Holmes. Direção de Guy Ritchie. Amsterdam: Warner, 2009. DVD.

SHILLING, R. L. et al. Heat-transfer equipment. In: MALONEY, J. O. et al. Perry's chemical engineer's handbook. 8 ed. United States of America: MacGraw-Hill, Inc., 2008. p. 11.1-11.121.

SMITH, R. Heat exchanger network and utilities: energy targets. In: . Chemical process design. New York: McGraw-Hill, 1995. p. 159-212.

THRÄN, D. et al. Biomethane: status and factors affecting Market development and trade. IEA Task 40 and Task 37 Joint Study, 2014. Disponível em: < http://www.ieabiogas.net/files/daten-redaktion/download/Technical\%20Brochures/biomethane-status2014.pdf>. Acesso em: 01 abr. 2016.

VERSTEEG, G. F. et al. Approximation for the enhancement factor applicable to reversible reactions of finite rate in chemically loaded solutions. Chem. Eng. Sci. ,v. 52, p. 4547-4459, 1997. Disponível em:

$<$ http://www.sciencedirect.com/science/article/pii/S0009250997002984>. Acesso em: 15 mar. 2016. 
APÊNDICE A - Detalhamento do cálculo das vazões molares das soluções de alcanolaminas 
Nesta seção será apresentado o detalhamento do cálculo das correntes de alcanolaminas para a obtenção de $\mathrm{X}$ de aproximadamente 0,5 , definido na equação (18), em relação as correntes que entram na coluna de absorção.

Para o cálculo destas vazões foi utilizada a equação (1a), cujo detalhamento é apresentado nas equações (2a), (3a) e (4a) para as soluções com apenas uma amina.

$$
n_{\text {solução }}=\frac{n_{A M}}{x_{A M}}
$$

$$
n_{A M I N A}=\left(\frac{n_{\mathrm{CO}_{2}}+n_{\mathrm{H}_{2} S}}{X}\right)
$$

$n_{\mathrm{CO}_{2}}+n_{\mathrm{H}_{2} \mathrm{~S}}=\frac{V_{B G(273,15 \mathrm{~K}, 1 \mathrm{~atm})}\left(y_{\mathrm{CH}_{4}}+y_{\mathrm{H}_{2} S}\right) 1[\mathrm{~atm}]}{0,082\left[\frac{\mathrm{m}^{3} \cdot \mathrm{atm}}{\mathrm{kmol} \cdot \mathrm{K}}\right] \cdot 273,15[\mathrm{~K}]}$

$$
x_{A M}=\frac{x_{A M}^{\prime} / M_{A M}}{\left(x_{A M}^{\prime} / M_{A M}\right)+\left(x_{H_{2} O}^{\prime} / M_{H_{2} O}\right)}
$$

onde $n_{A M}$ representa o número de moles de amina na solução pobre em gases ácidos; $x_{A M}$ a fração molar da amina; $V_{B G(273,15 K, 1 a t m)}$ o volume de biogás nas condições normais; $y_{C H_{4}} \mathrm{e}$ $y_{H_{2} S}$ as frações molares de $\mathrm{CO}_{2}$ e $\mathrm{H}_{2} \mathrm{~S}$ na corrente de biogás, respectivamente; $x_{A M}^{\prime}$ a fração mássica da amina e $M_{A M}$ a massa molar da amina.

Para as soluções com mais de uma amina, a equação (4a) foi substituída pela equação (5a).

$x_{A M}=\frac{\left(x_{A M, 1}^{\prime} / M_{A M, 1}\right)+\left(x_{A M, 2}^{\prime} / M_{A M, 2}\right)}{\left(x_{A M, 1}^{\prime} / M_{A M, 1}\right)+\left(x_{A M, 2}^{\prime} / M_{A M, 2}\right)+\left(x_{H_{2} O}^{\prime} / M_{H_{2} O}\right)}$

onde $x_{A M, 1}^{\prime}$ e $x_{A M, 2}^{\prime}$ representam as frações mássicas das aminas e $M_{A M, 1}$ e $M_{A M, 2}$ as massas molares das aminas.

As massas molares das aminas consideradas foram de: 119,164 kg/kmol para a MDEA, $105,137 \mathrm{~kg} / \mathrm{kmol}$ para a DEA e $61,084 \mathrm{~kg} / \mathrm{kmol}$ para a MEA, obtidas em Aspen Technology (2013e; 2013f; 2013g), respectivamente; o volume de biogás nas condições 
normais e as frações molares de $\mathrm{CO}_{2}$ e $\mathrm{H}_{2} \mathrm{~S}$ foram de: $1000 \mathrm{Nm}^{3}, 0,38$ e 0,004, respectivamente, obtidos da Tabela 8 . 
APÊNDICE B - Detalhamento do cálculo do volume de $\mathrm{CH}_{4}$ 
Nesta seção será apresentado o detalhamento do cálculo do volume de $\mathrm{CH}_{4}$ indicado na equação (21).

Para o cálculo deste parâmetro, foi considerado o volume de $\mathrm{CH}_{4}$ presente na corrente de biogás nas condições normais, que correspondem à temperatura de $273,15 \mathrm{~K}$ e à pressão de $1 \mathrm{~atm}$, definido na Tabela 8 conforme apresentado na equação (1b).

$V_{C H_{4}(273,15 K, 1 \mathrm{~atm})}=V_{B G(273,15 \mathrm{~K}, 1 \mathrm{~atm})} y_{\mathrm{CH}_{4}}$

onde $V_{B M(273,15 K, 1 \mathrm{~atm})}$ representa o volume de biogás nas condições normais e $y_{C H_{4}}$ a fração molar de $\mathrm{CH}_{4}$.

Este volume foi corrigido para a temperatura de $25^{\circ} \mathrm{C}(298,15 \mathrm{~K})$ - condição indicada nas especificações da ANP - de acordo com a equação (2b).

$V_{C H_{4}\left(25^{\circ} \mathrm{C}, 1 \mathrm{~atm}\right)}=\frac{V_{C H_{4}(273,15 \mathrm{~K}, 1 \mathrm{~atm})} \cdot 298,15}{273,15}$

Desta forma, o volume de $\mathrm{CH}_{4}$ considerado na equação (48) foi de:

$$
V_{C H_{4}\left(25^{\circ} \mathrm{C}, 1 \mathrm{~atm}\right)}=\frac{1000 \cdot 0,56 \cdot 298,15}{273,15}=611 \mathrm{~m}^{3}
$$


ANEXO A - Detalhamento das equações utilizadas para a modelagem da absorção reativa no software Aspen Plus ${ }^{\circledR}$ 
Neste item será apresentada a base matemática utilizada para simular sistemas de absorção química no software Aspen Plus ${ }^{\circledR}$. O esquema de uma seção, ou estágio, $j$ de uma coluna onde estes cálculos são aplicados é indicado na Figura 1A. A numeração destas seções é iniciada no topo da coluna (ASPEN TECHNOLOGY, 2013b).

Figura 1A - Estágio/seção j considerado para a modelagem de nãoequilíbrio

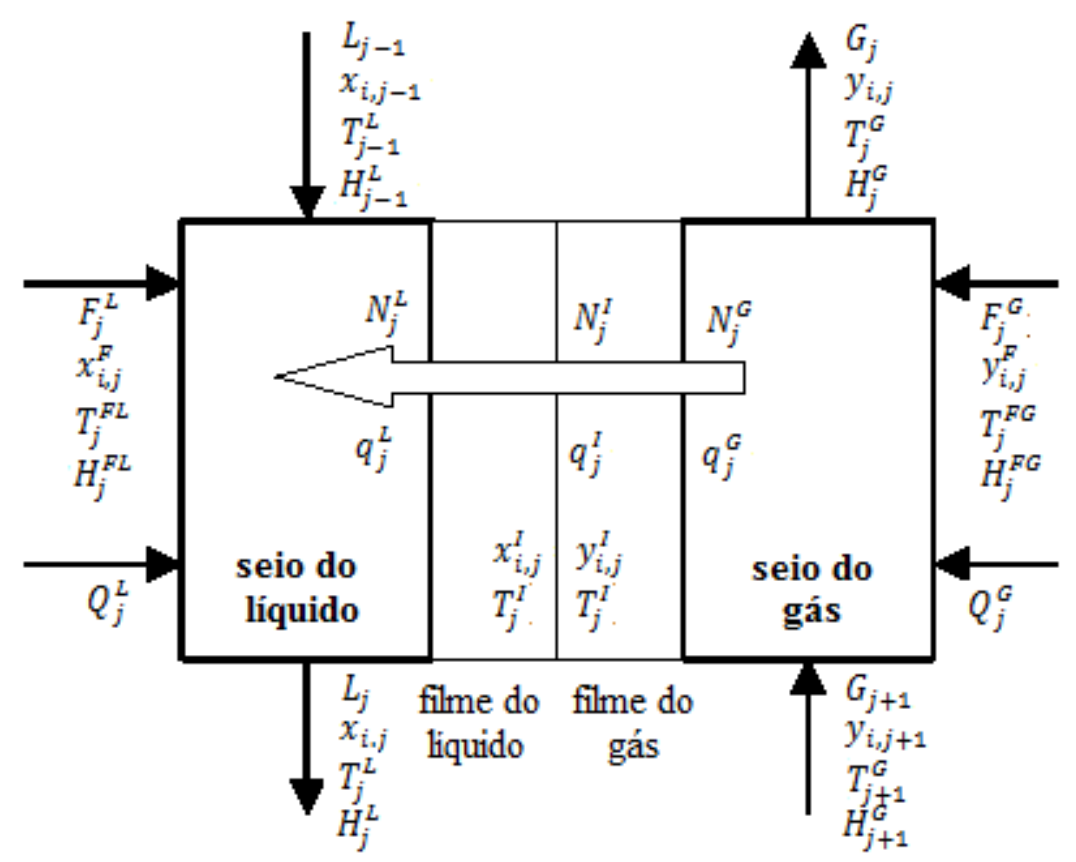

Fonte: Autor “adaptado de” Aspen Technology, 2013b

Os balanços materiais parciais realizados no seio do líquido, no seio do gás, no filme do líquido e no filme do gás são apresentados nas equações (1A), (2A), (3A) e (4A), respectivamente (ASPEN TECHNOLOGY, 2013b).

$F_{j}^{L} x_{i, j}^{F}+L_{j-1} x_{i, j-1}+N_{i, j}^{L}+r_{i, j}^{L}-L_{j} x_{i, j}=0$

$F_{j}^{G} y_{i, j}^{F}+G_{j+1} y_{i, j+1}-N_{i, j}^{G}+r_{i, j}^{G}-G_{j} y_{i, j}=0$

$N_{i, j}^{I}+r_{i, j}^{f L}-N_{i, j}^{L}=0$

$N_{i, j}^{G}+r_{i, j}^{f G}-N_{i, j}^{I}=0$ 
onde $F, L$ e $G$ são as vazões molares de alimentação, de líquido e de gás, respectivamente; $N$ representa as taxas de transferência de massa; $r$ as taxas de reação e $x$ e $y$ as composições das fases líquido e gás, respectivamente.

Nas equações (5A), (6A), (7A) e (8A), são apresentados os balanços de energia realizados no seio do líquido, no seio do gás, no filme do líquido e no filme do gás, respectivamente (ASPEN TECHNOLOGY, 2013b).

$$
\begin{aligned}
& F_{j}^{L} H_{j}^{F L}+L_{j-1} H_{j-1}^{L}+Q_{j}^{L}+q_{j}^{L}-L_{j} H_{j}^{L}=0 \\
& F_{j}^{G} H_{j}^{F G}+G_{j+1} H_{j+1}^{G}+Q_{j}^{G}-q_{j}^{G}-G_{j} H_{j}^{G}=0 \\
& q_{j}^{I}-q_{j}^{L}=0 \\
& q_{j}^{G}-q_{j}^{I}=0
\end{aligned}
$$

onde $H, Q$ e $q$ representam as entalpias, os calores adicionados à uma seção e as taxas de transferência de calor, respectivamente. No cálculo das entalpias o software leva em conta as entalpias de formação das substâncias, de forma que os calores das reações se tornam termos implícitos nas equações.

O equilíbrio de fases na interface é representado pela equação (9A) (ASPEN TECHNOLOGY, 2013b).

$y_{i, j}^{I}-K_{i, j} x_{i, j}^{I}=0$

onde $K_{i}$ é a constante de equilíbrio que mede a tendência de vaporização de uma substância.

As restrições impostas a este conjunto de equações são apresentadas nas equações (10A), (11A), (12A) e (13A) (ASPEN TECHNOLOGY, 2013b).

$$
\sum_{i=1}^{n} x_{i, j}-1=0
$$




$$
\begin{aligned}
& \sum_{i=1}^{n} y_{i, j}-1=0 \\
& \sum_{i=1}^{n} x_{i, j}^{I}-1=0 \\
& \sum_{i=1}^{n} y_{i, j}^{I}-1=0
\end{aligned}
$$

O equacionamento das taxas de massa calculadas para os filmes de líquido e de gás seguem a formulação de Maxwell-Stefan e é descrito nas equações (14A) e (15A) (ASPEN TECHNOLOGY, 2013b).

$$
\begin{aligned}
& {\left[\Gamma_{j}^{L}\right]\left(x_{j}^{I}-x_{j}\right)+\Delta \phi_{j}^{E}\left(x_{j} z_{j}\right)-\left[\mathbf{R}_{j}^{L}\right]\left(\mathbf{N}_{j}^{L}-\mathrm{N}_{t}^{L} \boldsymbol{x}_{j}\right)=0} \\
& {\left[\Gamma_{j}^{G}\right]\left(\boldsymbol{y}_{j}^{I}-\boldsymbol{y}_{j}\right)-\left[\mathbf{R}_{j}^{G}\right]\left(\mathbf{N}_{j}^{G}-\mathrm{N}_{t}^{G} \boldsymbol{y}_{j}\right)=0}
\end{aligned}
$$

onde $\boldsymbol{\Gamma}$ representa a matriz dos coeficientes termodinâmicos, que leva em conta as não idealidades do sistema; $\Delta \phi^{E}$ a força motriz causada pelo potencial elétrico e $\mathbf{R}$ a matriz do inverso dos coeficientes de transferência de massa. Um detalhamento das equações (14A) e (15A) equações é apresentado no Anexo C.

O cálculo dos coeficientes de transferência de massa para as fases líquida e gasosa em colunas de recheios estruturados corrugados metálicos pode ser realizado utilizando a correlação de Hanley e Chen (2012), denominada HanleyStruc (2010), que também calcula a área interfacial para transferência de massa. Estes cálculos são apresentados nas equações (16A), (17A) e (18A) (ASPEN TECHNOLOGY, 2013i).

$$
\begin{aligned}
& k_{i, k}^{L}=0,33 R e_{L, i, k} S c_{L, i, k}^{1 / 3}\left(\frac{c_{L} D_{i, k}^{L}}{d_{h}}\right) \\
& k_{i, k}^{G}=0,0084 R e_{G, i, k} S c_{G, i, k}^{1 / 3}\left(\frac{c_{G} D_{i, k}^{G}}{d_{h}}\right)\left(\frac{\cos \theta}{\cos \frac{\pi}{4}}\right)^{-7,15}
\end{aligned}
$$


$a^{I}=a_{e} A_{t} h_{p}$

onde $k_{i, k}$ representa os coeficientes binários de transferência de massa, Re o número de Reynolds, $S c$ o número de Schmidt, $c$ as concentrações molares, $D_{i, k}$ as difusividades, $d_{h}$ o diâmetro hidráulico, $\theta$ o ângulo da corrugação, $a^{I}$ a área interfacial para transferência de massa, $a_{e}$ a área superficial efetiva por unidade de volume da coluna, $A_{t}$ a área da seção transversal da coluna e $h_{p}$ a altura da seção de recheio. Um detalhamento desta correlação é apresentado no Anexo D.

O equacionamento das taxas de calor calculadas para os filmes de líquido e de gás é descrito nas equações (19A) e (20A) (ASPEN TECHNOLOGY, 2013b).

$$
\begin{aligned}
& a_{j}^{I} h_{j}^{L}\left(T_{j}^{I}-T_{j}^{L}\right)-q_{j}^{L}+\sum_{i=1}^{n} N_{i, j}^{L} \bar{H}_{i, j}^{L}=0 \\
& a_{j}^{I} h_{j}^{G}\left(T_{j}^{G}-T_{j}^{I}\right)-q_{j}^{G}+\sum_{i=1}^{n} N_{i, j}^{G} \bar{H}_{i, j}^{G}=0
\end{aligned}
$$

onde $h$ é o coeficiente de transferência de calor, $T$ é a temperatura e $\bar{H}$ é a entalpia parcial.

Os coeficientes de transferência de calor, para as fases líquida e gasosa, são calculados pelo método de Chilton e Colburn (ASPEN TECHNOLOGY, 2013j apud TAYLOR; KRISHNA, 1993) a partir dos coeficientes binários de transferência de massa, segundo as equações (21A) e (22A).

$$
\begin{aligned}
& h_{j}^{L}=\bar{k}_{j}^{L} \bar{\rho}_{j}^{L} C_{p_{j}}{ }_{j}\left(\frac{\lambda_{j}^{L}}{\bar{\rho}_{j}^{L} C_{p_{j}}{ }^{L} \bar{D}_{j}^{L}}\right)^{2 / 3} \\
& h_{j}^{G}=\bar{k}_{j}^{G} \bar{\rho}_{j}^{G} C_{p_{j}}{ }_{j}\left(\frac{\lambda_{j}^{G}}{\bar{\rho}_{j}^{G} C_{p_{j}}^{G} \bar{D}_{j}^{G}}\right)^{2 / 3}
\end{aligned}
$$


onde $\bar{k}$ representa o coeficiente de transferência de massa médio, $\bar{\rho}$ a densidade molar, $C_{p}$ a capacidade calorífica molar específica, $\bar{\lambda}$ a condutividade térmica e $\bar{D}$ a difusividade média. Um detalhamento destas equações é apresentado no Anexo E. 
ANEXO B - Detalhamento da correlação Bravo et al. (1992) 
Nesta seção será apresentado o detalhamento matemático fornecido em Aspen Technology (2013k) para a correlação Bravo et al. (1992) utilizada para o cálculo do holdup, conforme apontado no item 4.2.1.

O holdup volumétrico da fase líquida é calculado segundo a equação (1B).

$h_{L}=h_{t} h_{p} A_{t}$

onde $h_{t}$ representa o holdup fracionário, calculado de acordo com a equação (2B).

$h_{t}=\left(4 \frac{F_{t}}{S}\right)^{2 / 3}\left(\frac{3 \mu^{L} u_{s}^{L}}{\rho_{t}^{L} g_{e f f} \varepsilon \operatorname{sen} \theta}\right)^{1 / 3}$

onde $F_{t}$ representa o fator de correção para o holdup total devido à área molhada efetiva, $S$ a altura inclinada da corrugação, $\mu$ as viscosidades dos fluidos, $u_{s}$ as velocidades superficiais dos fluidos, $\rho_{t}$ as densidades dos fluidos, $g_{e f f}$ a gravidade efetiva e $\varepsilon$ representa a fração de vazio do recheio.

O fator de correção para o holdup total devido à área molhada efetiva e a gravidade efetiva são calculados segundo as equações (3B) e (4B).

$F_{t}=\frac{29,12\left(W e_{L} F r_{L}\right)^{0,15} S^{0,359}}{\operatorname{Re}_{L}^{0,2} \varepsilon^{0,6}(\operatorname{sen} \theta)^{0,3}(1-0,93 \cos \gamma)}$

$g_{e f f}=g\left(\frac{\rho_{t}^{L}-\rho_{t}^{G}}{\rho_{t}^{L}}\right)\left(1-\frac{\Delta P / \Delta Z}{\Delta P / \Delta Z_{f}}\right)$

onde $F r_{L}, R e_{L}$ e $W e_{L}$ representam os números adimensionais de Froude, Reynolds e Weber para o líquido, respectivamente; $\gamma$ o ângulo de contato entre a superfície sólida e o filme líquido; $\Delta P / \Delta Z$ a perda de carga por unidade de altura de recheio e $\Delta P / \Delta Z_{f}$ a perda de carga por unidade de altura de recheio no ponto de inundação definido como $1025 \mathrm{~Pa} / \mathrm{m}$.

Os números adimensionais: Froude, Reynolds e Weber do líquido são calculados tomando com base na dimensão $S$ da corrugação, conforme indicado nas equações (5B), (6B) e (7B). 


$$
F r_{L}=\frac{\left(u_{s}^{L}\right)^{2}}{S g}
$$

$$
R e_{L}=\frac{u_{s}^{L} \rho_{t}^{L} S}{\mu^{L}}
$$

$$
W e_{L}=\frac{\left(u_{s}^{L}\right)^{2} \rho_{t}^{L} S}{\sigma}
$$

O valor do cosseno do ângulo de contato entre a superfície sólida e o filme líquido depende do valor da tensão superficial do líquido, segundo os critérios indicados em (8B).

$$
\begin{aligned}
& \cos \gamma=5,211 \cdot 10^{-16,835 \sigma} \text { se } \sigma \geq 0,055 \frac{\mathrm{N}}{\mathrm{m}} \\
& \cos \gamma=0,9 \text { se } \sigma<0,055 \mathrm{~N} / \mathrm{m}
\end{aligned}
$$

A perda de carga por unidade de altura de recheio é calculada segundo a equação (9B).

$$
\frac{\Delta P}{\Delta Z}=\frac{\Delta P}{\Delta Z_{d}}\left(\frac{1}{1-(0,614+71,35 S) h_{f}}\right)
$$

onde $\Delta P / \Delta Z_{d}$ representa a perda de carga por unidade de altura de recheio seco, calculada pela equação (10B).

$\frac{\Delta P}{\Delta Z_{d}}=\frac{0,177 \rho_{t}^{G}}{S \varepsilon^{2}(\operatorname{sen} \theta)^{2}}\left(u_{s}^{G}\right)^{2}+\frac{88,774 \mu^{G}}{S^{2} \varepsilon \operatorname{sen} \theta} u_{s}^{G}$ 
ANEXO C - Detalhamento das equações de taxas de massa 
Nesta seção será apresentado o detalhamento matemático fornecido em Aspen Technology (2013b) para os elementos das matrizes $\left[\boldsymbol{\Gamma}_{j}^{L}\right],\left[\boldsymbol{\Gamma}_{j}^{G}\right],\left[\mathbf{R}_{j}^{L}\right]$ e $\left[\mathbf{R}_{j}^{G}\right]$ apresentadas nas equações (14A) e (15A).

Os coeficientes termodinâmicos das matrizes $\left[\boldsymbol{\Gamma}_{j}^{L}\right]$ e $\left[\boldsymbol{\Gamma}_{j}^{G}\right]$ são apresentados nas equações (1C), para a primeira matriz, e (2C), para a segunda matriz.

$$
\begin{gathered}
\Gamma_{i, k, j}^{L}=\delta_{i, k}+x_{i, j}-\left.\frac{\partial \ln \varphi_{i, j}^{L}}{\partial x_{k, j}}\right|_{T_{j}^{L}, P_{j}, \Sigma} \\
\Gamma_{i, k, j}^{G}=\delta_{i, k}+y_{i, j}-\left.\frac{\partial \ln \varphi_{i, j}^{G}}{\partial y_{k, j}}\right|_{T_{j}^{G}, P_{j}, \Sigma}
\end{gathered}
$$

onde $\delta_{i, k}$ representa o delta de Kronecker, com valor de 1 para $i=k$ e 0 para os demais casos; $\varphi$ os coeficientes de fugacidade e o símbolo $\Sigma$ indica que as frações molares de todos os componentes, exceto o $k$, estão fixas.

Os elementos que representam o inverso dos coeficientes de transferência de massa das matrizes $\left[\mathbf{R}_{j}^{L}\right]$ e $\left[\mathbf{R}_{j}^{G}\right]$ são apresentados nas equações (3C) e (4C), para a primeira matriz, e (5C) e (6C), para a segunda matriz.

$$
\begin{aligned}
& \mathrm{R}_{i, i, j}^{L}=\frac{x_{i, j}}{\bar{\rho}_{j}^{L} a_{j}^{I} k_{i, n, j}^{L}}+\sum_{\substack{m=1 \\
m \neq i}}^{n} \frac{x_{m, j}}{\bar{\rho}_{j}^{L} a_{j}^{I} k_{i, m, j}^{L}} \operatorname{para} i=1, \ldots, n-1 \\
& \mathrm{R}_{i, k, j}^{L}=-x_{i, j}\left(\frac{1}{\bar{\rho}_{j}^{L} a_{j}^{I} k_{i, k, j}^{L}}-\frac{1}{\bar{\rho}_{j}^{L} a_{j}^{I} k_{i, n, j}^{L}}\right) \operatorname{para} i=1, \ldots, n-1, i \neq k \\
& \mathrm{R}_{i, i, j}^{G}=\frac{y_{i, j}}{\bar{\rho}_{j}^{G} a_{j}^{I} k_{i, n, j}^{G}}+\sum_{m=1}^{n} \frac{y_{m, j}}{\bar{\rho}_{j}^{G} a_{j}^{I} k_{i, m, j}^{G}} \operatorname{para} i=1, \ldots, n-1 \\
& \mathrm{R}_{i, k, j}^{G}=-y_{i, j}\left(\frac{1}{\bar{\rho}_{j}^{G} a_{j}^{I} k_{i, k, j}^{G}}-\frac{1}{\bar{\rho}_{j}^{G} a_{j}^{I} k_{i, n, j}^{G}}\right) \operatorname{para} i=1, \ldots, n-1, i \neq k
\end{aligned}
$$

onde $\bar{\rho}$ representa as densidades molares. 
ANEXO D - Detalhamento da correlação HanleyStruc (2010) 
Nesta seção será apresentado o detalhamento matemático fornecido em Aspen Technology (2013i) para a correlação HanleyStruc (2010), utilizada para o cálculo dos coeficientes binários de transferência de massa e da área interfacial para transferência de massa apresentados nas equações (16A), (17A) e (18A).

O diâmetro hidráulico e a área superficial efetiva por unidade de volume da coluna são calculados segundo as equações (1D) e (2D), respectivamente.

$$
d_{h}=\frac{4 \varepsilon}{a_{p}}
$$

$a_{e}=0,5386 a_{p} \operatorname{Re}_{G, i, k}^{0,1455} \operatorname{Re}_{L, i, k}^{-0,1526} W e_{L}^{0,2} \mathrm{Fr}_{L}^{-0,2}\left(\frac{\rho_{t}^{G}}{\rho_{t}^{L}}\right)^{-0,033}\left(\frac{\mu^{G}}{\mu^{L}}\right)^{0,090}\left(\frac{\cos \theta}{\cos \frac{\pi}{4}}\right)^{4,078}$

onde $\varepsilon$ representa a fração de vazio do recheio, We o número de Weber, $F r$ o número de Froude, $\rho_{t}$ as densidades dos fluidos e $\mu$ as viscosidades dos fluidos

Os números adimensionais: Reynolds, Schmidt, Weber e Froude, para a fase líquida são apresentados nas equações (3D), (4D), (5D) e (6D), respectivamente, e para a fase gasosa são apresentados os números de Reynolds e de Schmidt nas equações (7D) e (8D), respectivamente.

$$
R e_{L}=\frac{d_{h} \rho_{t}^{L} u_{s}^{L}}{\mu^{L}}
$$

$$
S c_{L, i, k}=\frac{\mu^{L}}{\rho_{t}^{L} D_{i, k}^{L}}
$$

$$
W e_{L}=\frac{d_{h} \rho_{t}^{L}\left(u_{s}^{L}\right)^{2}}{\sigma}
$$

$$
F r_{L}=\frac{\left(u_{s}^{L}\right)^{2}}{g d_{h}}
$$


$R e_{G}=\frac{d_{h} \rho_{t}^{G} u_{s}^{G}}{\mu^{G}}$

$S c_{G, i, k}=\frac{\mu^{G}}{\rho_{t}^{G} D_{i, k}^{G}}$

onde $u_{s}$ representa as velocidades superficiais dos fluidos, $\sigma$ a tensão superficial do líquido e $g$ a constante gravitacional.

As velocidades superficiais do líquido e do gás são calculadas segundo as equações (9D) e (10D), respectivamente.

$$
\begin{aligned}
& u_{s}^{L}=\frac{L}{\bar{\rho}^{L} A_{t}} \\
& u_{s}^{G}=\frac{G}{\bar{\rho}^{G} A_{t}}
\end{aligned}
$$


ANEXO E - Detalhamento do método de Chilton e Colburn 
Nesta seção será apresentado o detalhamento matemático fornecido em Aspen Technology (2013j) para o método de Chilton e Colburn utilizado para o cálculo dos coeficientes de transferência de calor apresentados nas equações (21A) e (22A).

$\mathrm{O}$ coeficiente de transferência de massa médio é calculado para a fase líquida segundo a equação (1E) e para a fase vapor de acordo com a equação (2E).

$\bar{k}_{j}^{L}=\frac{\sum_{i=1}^{n c=1} \sum_{k=i+1}^{n c}\left(x_{i, j}+\psi\right)\left(x_{k, j}+\psi\right) k_{i, k, j}^{L}}{\sum_{i=1}^{n c=1} \sum_{k=i+1}^{n c}\left(x_{i, j}+\psi\right)\left(x_{k, j}+\psi\right)}$

$\bar{k}_{j}^{G}=\frac{\sum_{i=1}^{n c=1} \sum_{k=i+1}^{n c}\left(y_{i, j}+\psi\right)\left(y_{k, j}+\psi\right) k_{i, k, j}^{G}}{\sum_{i=1}^{n c=1} \sum_{k=i+1}^{n c}\left(y_{i, j}+\psi\right)\left(y_{k, j}+\psi\right)}$

onde $n c$ indica o número de componentes e $\psi$ é o parâmetro médio de Chilton-Colburn, definido como $10^{-4}$.

A difusividade média é calculada para a fase líquida segundo a equação (3E) e para a fase vapor de acordo com a equação (4E).

$$
\begin{aligned}
& \bar{D}_{j}^{L}=\frac{\sum_{i=1}^{n c=1} \sum_{k=i+1}^{n c}\left(x_{i, j}+\psi\right)\left(x_{k, j}+\psi\right) D_{i, k, j}^{L}}{\sum_{i=1}^{n c=1} \sum_{k=i+1}^{n c}\left(x_{i, j}+\psi\right)\left(x_{k, j}+\psi\right)} \\
& \bar{D}_{j}^{G}=\frac{\sum_{i=1}^{n c=1} \sum_{k=i+1}^{n c}\left(y_{i, j}+\psi\right)\left(y_{k, j}+\psi\right) D_{i, k, j}^{G}}{\sum_{i=1}^{n c=1} \sum_{k=i+1}^{n c}\left(y_{i, j}+\psi\right)\left(y_{k, j}+\psi\right)}
\end{aligned}
$$

